University of Tennessee Health Science Center

UTHSC Digital Commons

\title{
Examining the Roles of GABAA Receptor Subtypes in Anxiety and Anxiolysis: Focusing on the Basolateral Amygdala
}

\section{Yudong Gao}

University of Tennessee Health Science Center

Follow this and additional works at: https://dc.uthsc.edu/dissertations

Part of the Neurosciences Commons

\section{Recommended Citation}

Gao, Yudong (http://orcid.org/0000-0002-2371-4693), "Examining the Roles of GABAA Receptor Subtypes in Anxiety and Anxiolysis: Focusing on the Basolateral Amygdala" (2016). Theses and Dissertations (ETD). Paper 379. http://dx.doi.org/10.21007/etd.cghs.2016.0390. 


\title{
Examining the Roles of GABAA Receptor Subtypes in Anxiety and Anxiolysis: Focusing on the Basolateral Amygdala
}

\author{
Abstract \\ The investigation of the differential roles $G_{A B A}$ receptor $\left(G A B A_{A} R\right)$ subtypes play in mediating various \\ behaviors such as fear and anxiety was an intriguing research topic over the past decade. At present, \\ most evidence suggests that benzodiazepine (BZ)-induced anxiolysis is primarily mediated by GABA $\mathrm{A}_{\mathrm{A}}$ \\ containing the $\alpha 2$-subunit ( $\alpha 2$-subtype). However, there is conflicting evidence as to whether $\alpha 1$ - and \\ $\alpha 3$-subtypes might also be involved in BZ-induced anxiolysis. In an attempt to further discern the role \\ played by different $\alpha$-subtype GABAARs in BZ-induced anxiolysis both systemically and within the \\ basolateral amygdala (BLA), a brain region crucial for anxiety-like behaviors, we examined the anxiolytic- \\ like effects, as measured by elevated-plus maze test (EPM), of several subtype selective and non- \\ selective $G_{A B A} R$ positive allosteric modulators (PAMs) both in wild type mice and in mutant mice that \\ express BZ-insensitive GABAARs of specific $\alpha$-subtypes.
}

In our experiments, systemic injections of the $\alpha 1$-selective PAM zolpidem in WT mice produced slight anxiolytic-like effects with a narrow therapeutic window that overlapped with prominent motor-inhibiting effects. Systemic injection of the $\alpha 3$-selective PAM TP003 produced marked anxiolytic-like effects in WT mice that were accompanied by motor-stimulating effects. Systemic injection of the $\alpha 2-, \alpha 3-$, and $\alpha 5$-selective PAM L-838417 elicited significant anxiolytic-like effects in WT, and the effects were weakened in the $\alpha 3(\mathrm{H} 126 \mathrm{R})$ mice. Similarly, anxiolytic-like effects were observed when these selective PAMs were administered via microinjection into the BLA; however, these local injections did not significantly affect motor activity at the doses tested. In the experiment examining systemic injections of the non-selective BZ chlordiazepoxide (CDP), we found that CDP induced robust anxiolytic-like effects in both male and female WT mice. These effects were potentiated in female $\alpha 1(\mathrm{H} 101 \mathrm{R})$ mice, and were reduced in $\alpha 2(\mathrm{H} 101 \mathrm{R})$ mice of both sexes, as well as male $\alpha 3(\mathrm{H} 126 \mathrm{R})$ mice. Interestingly, intra-BLA microinjection of CDP produced few effects in WT, $\alpha 1(\mathrm{H} 101 \mathrm{R})$, or $\alpha 2(\mathrm{H} 101 \mathrm{R})$ mice, but showed some anxiolytic-like effects in $\alpha 3(\mathrm{H} 126 \mathrm{R})$ mice.

Taken together, our results suggests (i) all three ( $\alpha 1-, \alpha 2-$, and $\alpha 3-) \mathrm{GABA}_{A} \mathrm{R}$ subtypes are involved in BZinduced anxiolysis, but subtle differences do exist; (ii) augmentation of the $\alpha 1$-subtype GABAARs exerts anxiolytic-like effects; however, the therapeutic window is narrow; (iii) augmentation of the $\alpha 2-, \alpha 3-$, (and $\alpha 5-)$ subtype $G_{A B A} R$ R exerts anxiolytic-like effects and motor-stimulating effects, and these effects are weakened in $\alpha 3(\mathrm{H} 126 \mathrm{R})$ mice at doses tested, (iv) augmentation of the $\alpha 3$-subtype GABA $A$ Rs exerts anxiolytic-like effects, accompanied by motor-stimulating effects; (v) BLA is an important brain region that is sufficient to mediate the anxiolytic-like effects, but not the motor-stimulating or inhibiting effects of subtype selective GABA $A$ R PAMs; and (vi) intra-BLA microinjection of CDP yielded an inconclusive behavioral outcome, possibly due to the complex GABAergic intra-amygdaloidal microcircuitries which might antagonize each other when multiple subtypes of $\mathrm{GABA}_{A} R$ s are simultaneously modulated by BZs. Taken together, our results provide novel evidence that may benefit the current development of subtype selective drugs for treating clinical anxiety disorders.

\section{Document Type}

Dissertation

\section{Degree Name}

Doctor of Philosophy (PhD) 


\section{Program}

Biomedical Sciences

Research Advisor

Scott A. Heldt, Ph.D.

\section{Keywords}

Amygdala, Anxiety, GABA

\section{Subject Categories}

Medicine and Health Sciences | Neurosciences 
Examining the Roles of GABAA Receptor Subtypes in Anxiety and Anxiolysis:

Focusing on the Basolateral Amygdala

\author{
A Dissertation \\ Presented for \\ The Graduate Studies Council \\ The University of Tennessee \\ Health Science Center
}

In Partial Fulfillment

Of the Requirements for the Degree

Doctor of Philosophy

From The University of Tennessee

By

Yudong Gao

May 2016 
Copyright (C) 2016 by Yudong Gao. All rights reserved. 


\section{DEDICATION}

To my parents, With love. 


\section{ACKNOWLEDGEMENTS}

This work would not be possible without the support and devoted mentoring from my advisor Dr. Scott A. Heldt. I am grateful for the invaluable suggestions and critiques from my thesis committee (Drs. Joseph C. Callaway, Matthew Ennis, Robert C. Foehring, Kristin Hamre, and Kristen O'Connell). Genetically engineered mouse strains, including $\alpha 1(H 101 \mathrm{R}), \alpha 2(\mathrm{H} 101 \mathrm{R}), \alpha 3(\mathrm{H} 126 \mathrm{R})$ mice, were a generous gift from Dr. Uwe Rudolph at McLean Hospital. I am also grateful for the help from my colleagues Britany Wright, Jessica Baker and Chelsea Casaccia during my work in Dr. Scott A. Heldt's laboratory. 


\begin{abstract}
The investigation of the differential roles $\mathrm{GABA}_{\mathrm{A}}$ receptor $\left(\mathrm{GABA}_{\mathrm{A}} \mathrm{R}\right)$ subtypes play in mediating various behaviors such as fear and anxiety was an intriguing research topic over the past decade. At present, most evidence suggests that benzodiazepine (BZ)induced anxiolysis is primarily mediated by GABA $\mathrm{A}_{\mathrm{Rs}}$ containing the $\alpha 2$-subunit ( $\alpha 2$ subtype). However, there is conflicting evidence as to whether $\alpha 1$ - and $\alpha 3$-subtypes might also be involved in BZ-induced anxiolysis. In an attempt to further discern the role played by different $\alpha$-subtype GABA $\mathrm{A}_{\mathrm{A}} \mathrm{R}$ in BZ-induced anxiolysis both systemically and within the basolateral amygdala (BLA), a brain region crucial for anxiety-like behaviors, we examined the anxiolytic-like effects, as measured by elevated-plus maze test (EPM), of several subtype selective and non-selective $\mathrm{GABA}_{\mathrm{A}} \mathrm{R}$ positive allosteric modulators (PAMs) both in wild type mice and in mutant mice that express BZ-insensitive $\mathrm{GABA}_{\mathrm{A}} \mathrm{Rs}$ of specific $\alpha$-subtypes.
\end{abstract}

In our experiments, systemic injections of the $\alpha 1$-selective PAM zolpidem in WT mice produced slight anxiolytic-like effects with a narrow therapeutic window that overlapped with prominent motor-inhibiting effects. Systemic injection of the $\alpha 3$ selective PAM TP003 produced marked anxiolytic-like effects in WT mice that were accompanied by motor-stimulating effects. Systemic injection of the $\alpha 2-, \alpha 3-$, and $\alpha 5-$ selective PAM L-838417 elicited significant anxiolytic-like effects in WT, and the effects were weakened in the $\alpha 3(\mathrm{H} 126 \mathrm{R})$ mice. Similarly, anxiolytic-like effects were observed when these selective PAMs were administered via microinjection into the BLA; however, these local injections did not significantly affect motor activity at the doses tested. In the experiment examining systemic injections of the non-selective BZ chlordiazepoxide (CDP), we found that CDP induced robust anxiolytic-like effects in both male and female WT mice. These effects were potentiated in female $\alpha 1(\mathrm{H} 101 \mathrm{R})$ mice, and were reduced in $\alpha 2(\mathrm{H} 101 \mathrm{R})$ mice of both sexes, as well as male $\alpha 3(\mathrm{H} 126 \mathrm{R})$ mice. Interestingly, intraBLA microinjection of CDP produced few effects in WT, $\alpha 1(\mathrm{H} 101 \mathrm{R})$, or $\alpha 2(\mathrm{H} 101 \mathrm{R})$ mice, but showed some anxiolytic-like effects in $\alpha 3(\mathrm{H} 126 \mathrm{R})$ mice.

Taken together, our results suggests (i) all three ( $\alpha 1-, \alpha 2-$, and $\alpha 3-)$ GABA $\mathrm{R}$ subtypes are involved in BZ-induced anxiolysis, but subtle differences do exist; (ii) augmentation of the $\alpha 1$-subtype $\mathrm{GABA}_{\mathrm{A}} \mathrm{Rs}$ exerts anxiolytic-like effects; however, the therapeutic window is narrow; (iii) augmentation of the $\alpha 2-, \alpha 3-$, (and $\alpha 5-$ ) subtype $\mathrm{GABA}_{\mathrm{A}}$ Rs exerts anxiolytic-like effects and motor-stimulating effects, and these effects are weakened in $\alpha 3(\mathrm{H} 126 \mathrm{R})$ mice at doses tested, (iv) augmentation of the $\alpha 3$-subtype $\mathrm{GABA}_{\mathrm{A}}$ Rs exerts anxiolytic-like effects, accompanied by motor-stimulating effects; (v) BLA is an important brain region that is sufficient to mediate the anxiolytic-like effects, but not the motor-stimulating or inhibiting effects of subtype selective GABA $\mathrm{R}$ PAMs; and (vi) intra-BLA microinjection of CDP yielded an inconclusive behavioral outcome, possibly due to the complex GABAergic intra-amygdaloidal microcircuitries which might antagonize each other when multiple subtypes of GABA $A_{A}$ Rs are simultaneously modulated by BZs. Taken together, our results provide novel evidence that may benefit the current development of subtype selective drugs for treating clinical anxiety disorders. 


\section{TABLE OF CONTENTS}

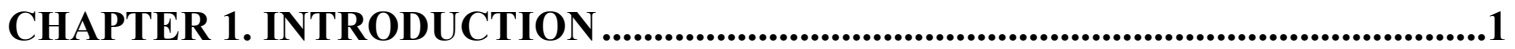

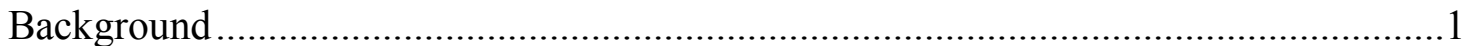

Clinical Significance .........................................................................................

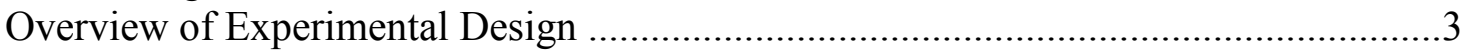

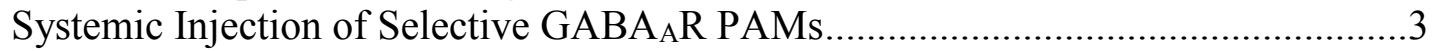

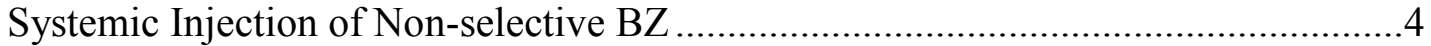

Intra-BLA Microinjection of Selective GABA ${ }_{A}$ R PAMs ........................................4

Intra-BLA Microinjection of Non-selective BZ ..................................................4

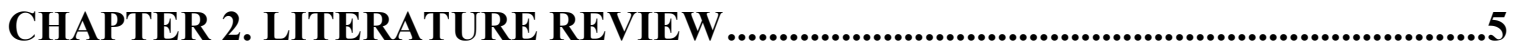

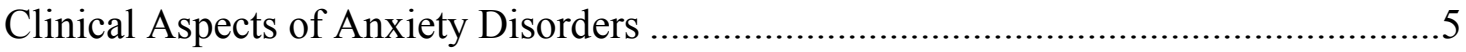

Animal Models for Assessing Fear and Anxiety-like Behaviors ................................5

Brain Areas and Neurotransmitters Involved in Fear and Anxiety ..............................6

Amygdala .................................................................................................... 7

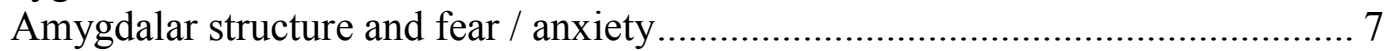

Amygdalar GABAergic signaling and fear / anxiety ....................................... 8

Other amygdalar neurotransmitters and fear / anxiety ..................................... 9

Bed Nucleus of the Stria Terminalis ................................................................... 10

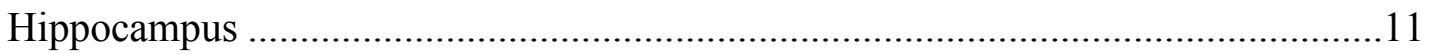

The Differential Functional Roles of GABA ${ }_{A}$ R Subtypes ....................................... 12

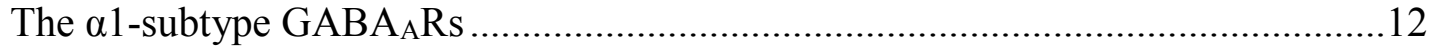

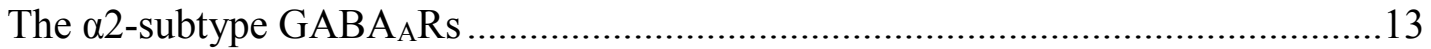

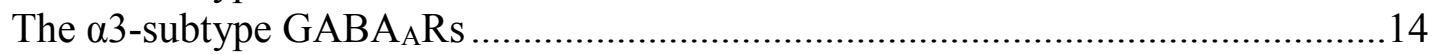

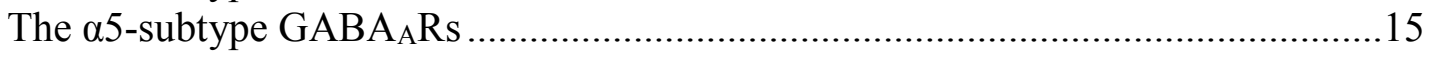

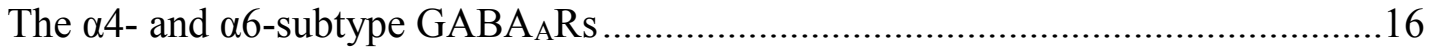

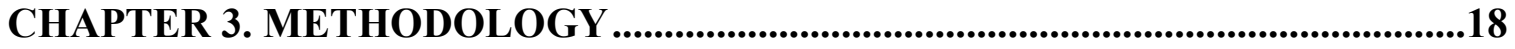

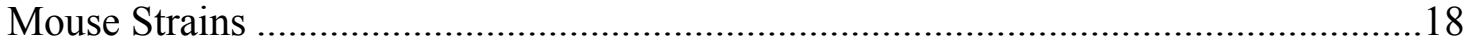

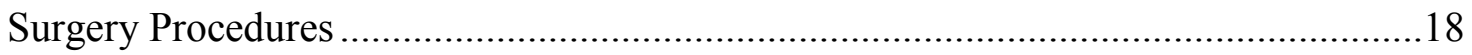

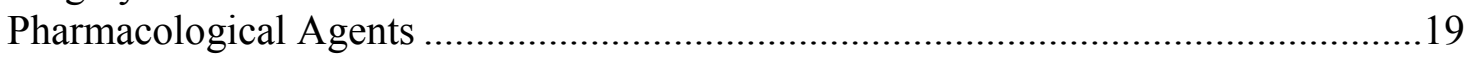

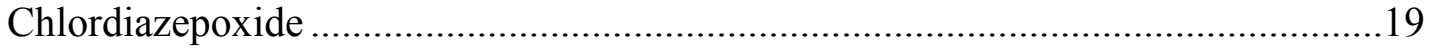

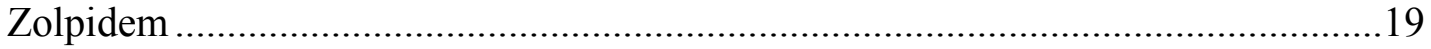

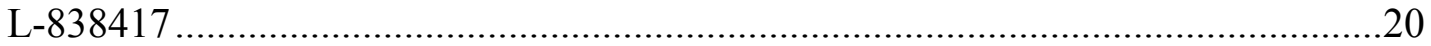

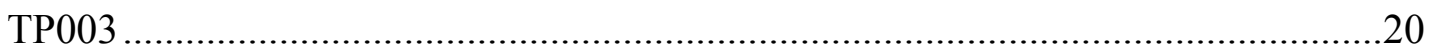

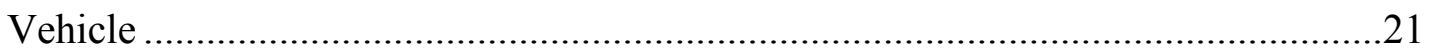

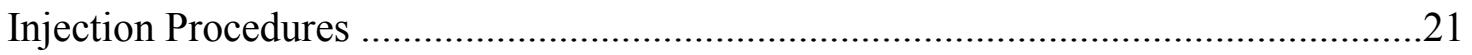

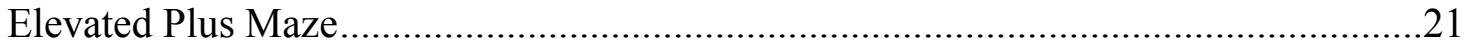

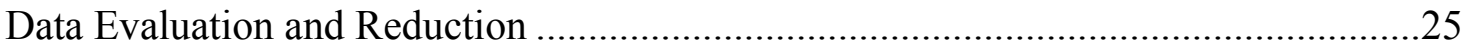

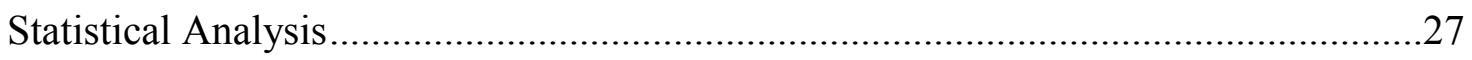

CHAPTER 4. RESULTS ......................................................................................28

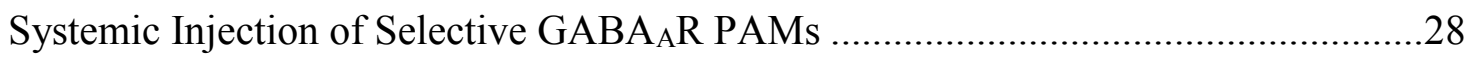


Systemic Injection of Zolpidem in WT C57BL/6J Mice ......................................28

Systemic Injection of L-838417 in WT C57BL/6J Mice.....................................28

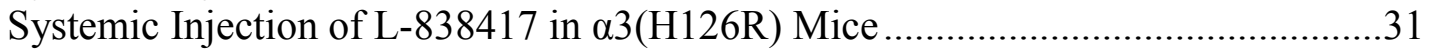

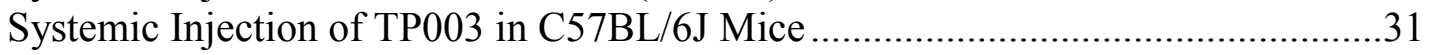

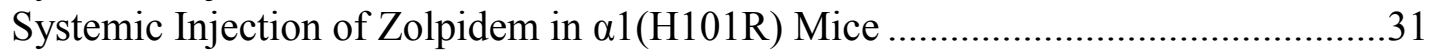

Systemic Injection of TP003 in $\alpha 2(\mathrm{H} 101 \mathrm{R})$ and $\alpha 3(\mathrm{H} 126 \mathrm{R})$ Mice ............................35

Systemic Injection of Selective GABA ${ }_{A}$ R PAMs - Other Parameters.......................35

Systemic Injection of Non-Selective CDP in Point Mutant Mice .................................35

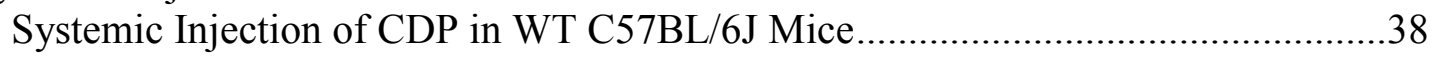

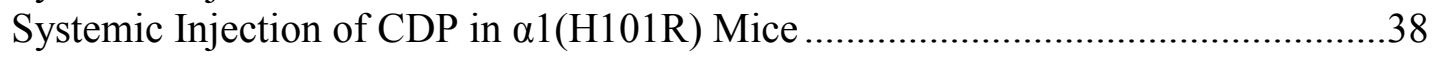

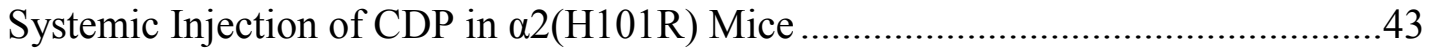

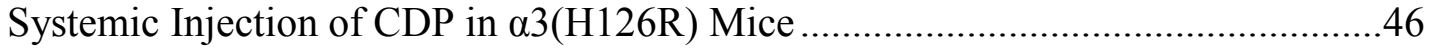

Systemic Injection of Non-Selective CDP - Other Parameters ................................46

Intra-BLA Microinjection of Selective GABA ${ }_{A}$ R PAMs...........................................46

Intra-BLA Microinjection of Zolpidem in WT C57BL/6J Mice ..............................46

Intra-BLA Microinjection of L-838417 in $\alpha 3(\mathrm{H} 126 \mathrm{R})$ Mice ..................................50

Intra-BLA Microinjection of TP003 in WT C57BL/6J Mice ..................................50

Intra-BLA Microinjection of Subtype Selective GABA $\mathrm{A}_{\mathrm{R}}$ PAMs - Other

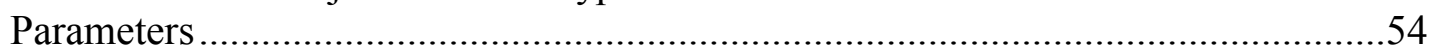

Intra-BLA Microinjection of Non-Selective CDP in Point Mutant Mice .....................54

Intra-BLA Microinjection of CDP in WT C57BL/6J Mice ...................................54

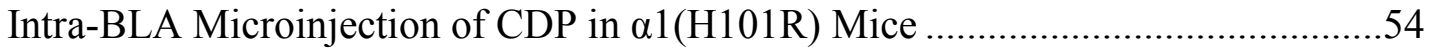

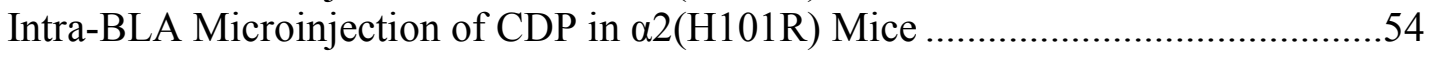

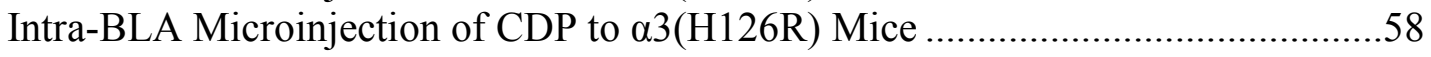

Intra-BLA Microinjection of Non-Selective CDP - Other Parameters ......................58

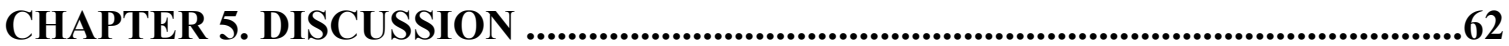

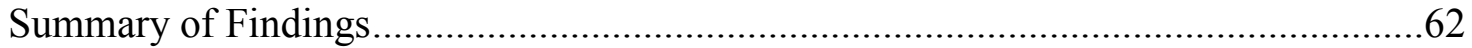

The Effects of Systemic Injection of Selective GABA ${ }_{A}$ R PAMs.............................62

The Effects of Systemic Injection of the Non-Selective CDP ..................................63

The Effects of Intra-BLA Microinjection of Selective GABA ${ }_{A}$ R PAMs ..................64

The Effects of Intra-BLA Microinjection of Non-Selective CDP ..........................64

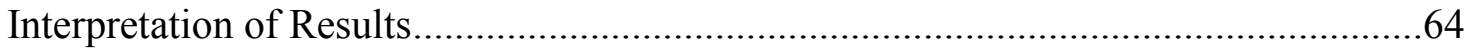

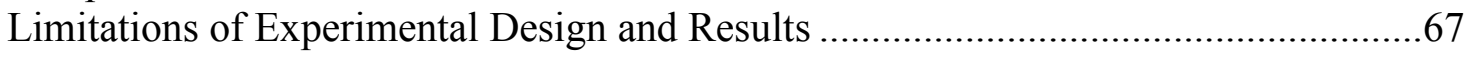

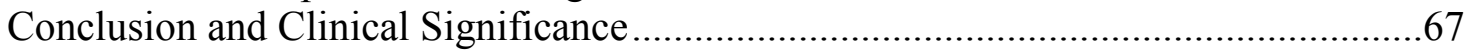

LIST OF REFERENCES ............................................................................................69

VITA 


\section{LIST OF TABLES}

Table 4-1. Systemic Injection of Selective GABAAR PAMs - Descriptive Statistics of Other Parameters .................................................................................... 37

Table 4-2. Systemic Injection of Non-Selective CDP - Descriptive Statistics of Other Parameters

Table 4-3. Intra-BLA Microinjection of Subtype Selective GABAAR PAMs Descriptive Statistics of Other Parameters ................................................55

Table 4-4. Intra-BLA Microinjection of Non-Selective CDP - Descriptive Statistics

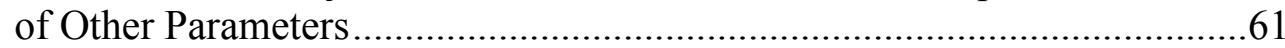




\section{LIST OF FIGURES}

Figure 3-1. Illustration of the Dimension of EPM Apparatus Used in This Study. .......22

Figure 3-2. Illustration of the Effects of BZ on Animals Behavior on the EPM............24

Figure 3-3. Illustration of Bilateral Dye Injection Showing the Injection Sites .............26

Figure 4-1. Systemic Injection of Zolpidem in WT C57BL/6J Mice............................29

Figure 4-2. Systemic Injection of L-838417 in WT C57BL/6J Mice............................30

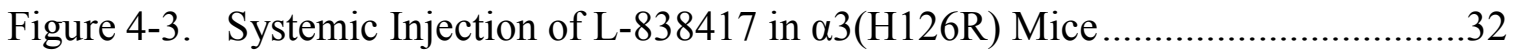

Figure 4-4. Systemic Injection of TP003 in WT C57BL/6J Mice.................................33

Figure 4-5. Systemic Injection of Zolpidem in $\alpha 1(\mathrm{H} 101 \mathrm{R})$ Mice ................................34

Figure 4-6. Systemic Injection of TP003 in $\alpha 2(\mathrm{H} 101 \mathrm{R})$ and $\alpha 3(\mathrm{H} 126 \mathrm{R})$ Mice..............36

Figure 4-7. Systemic Injection of CDP in Male WT C57BL/6J Mice ..........................39

Figure 4-8. Systemic Injection of CDP in Female WT C57BL/6J Mice........................40

Figure 4-9. Systemic Injection of CDP in Male $\alpha 1(\mathrm{H} 101 \mathrm{R})$ Mice................................41

Figure 4-10. Systemic Injection of CDP in Female $\alpha 1(\mathrm{H} 101 \mathrm{R})$ Mice ...........................42

Figure 4-11. Systemic Injection of CDP in Male $\alpha 2(\mathrm{H} 101 \mathrm{R})$ Mice...............................44

Figure 4-12. Systemic Injection of CDP in Female $\alpha 2(\mathrm{H} 101 \mathrm{R})$ Mice...........................45

Figure 4-13. Systemic Injection of CDP in Male $\alpha 3(H 126 \mathrm{R})$ Mice...............................47

Figure 4-14. Systemic Injection of CDP in Female $\alpha 3(H 126 \mathrm{R})$ Mice ...........................48

Figure 4-15. Intra-BLA Microinjection of Zolpidem in WT C57BL/6J Mice................51

Figure 4-16. Intra-BLA Microinjection of L-838417 in $\alpha 3(\mathrm{H} 126 \mathrm{R})$ Mice ......................52

Figure 4-17. Intra-BLA Microinjection of TP003 in WT C57BL/6J Mice......................53

Figure 4-18. Intra-BLA Microinjection of CDP in WT C57BL/6J Mice.........................56

Figure 4-19. Intra-BLA Microinjection of CDP in $\alpha 1(\mathrm{H} 101 \mathrm{R})$ Mice ..............................57

Figure 4-20. Intra-BLA Microinjection of CDP in $\alpha 2(\mathrm{H} 101 \mathrm{R})$ Mice .............................59

Figure 4-21. Intra-BLA Microinjection of CDP in $\alpha 3(\mathrm{H} 126 \mathrm{R})$ Mice .............................60 


\section{LIST OF ABBREVIATIONS}

GABA

$\mathrm{GABA}_{\mathrm{A}} \mathrm{R}$

$\mathrm{BZ}$

CDP

EPM

PAM

BLA

CeA

DG

BNST

SSRI

SNRI

WT

O.A.

C.A.

D.O.A.

$\%$ O.A. Time

$\%$ O.A. Entry
gamma-Aminobutyric acid

gamma-Aminobutyric acid type A receptor

Benzodiazepine

Chlordiazepoxide

Elevated plus maze

Positive allosteric modulator

Basolateral amygdala

Central nucleus of amgydala

Dentate gyrus

Bed nucleus of stria terminalis

Selective serotonin reuptake inhibitor

Serotonin-norepinephrine reuptake inhibitor

Wild type

Open arm

Closed arm

Distal open arm

Percentage of time spent on the open arm

Percentage of entry to the open arm 


\section{CHAPTER 1. INTRODUCTION}

\section{Background}

The neurotransmitter gamma-aminobutyric acid (GABA), initially identified in the brain circa 1950, is an key substance in mediating inhibitory neuronal functions (Curtis, Duggan, Felix, \& Johnston, 1970; Enna, 2011; Roberts, 1974; Roberts \& Frankel, 1950). There are three subcategories of GABA receptors, namely type A (ionotropic), type $\mathrm{B}$ (metabotropic), and a third type, sometimes referred to as type $\mathrm{C}$ (ionotropic) (Barnard et al., 1998). GABA type A receptors $\left(\mathrm{GABA}_{\mathrm{A}} \mathrm{Rs}\right)$ are ligand-gated ion channels that mediate chloride (anion) currents which, under normal physiological conditions in adults, inhibits the neuron; although they might also mediate excitatory transmission especially during early development (Barnard et al., 1998; Cherubini, Gaiarsa, \& Ben-Ari, 1991). GABA ${ }_{A}$ Rs are pentameric receptors composed of unique combinations of receptor subunits, including, but limited to, $\alpha, \beta, \gamma$, or $\delta$ subunits (Olsen $\&$ Sieghart, 2009; E. Sigel \& Steinmann, 2012). Among them, $\alpha 1 \beta 2 \gamma 2, \alpha 2 \beta 3 \gamma 2$, and $\alpha 3 \beta 3 \gamma 2$ are by far the highest expressed BZ-sensitive subunit compositions in the brain (Whiting, 2003). The physiological response of $\mathrm{GABA}_{A} \mathrm{Rs}$ can be modulated by various substrates that bind to different binding sites on the receptor, such as benzodiazepines (BZs), ethanol, barbiturates, and neurosteroids (Olsen, 2015). GABA ${ }_{A} R s$ containing a $\alpha 1-$ , $\alpha 2-, \alpha 3-$, or $\alpha 5$-subunit positioned adjacent to the $\gamma$-subunit form a "BZ-site" that binds BZ-like ligands, which can modulate the activity of $\mathrm{GABA}_{\mathrm{A}}$ Rs (Möhler, Crestani, \& Rudolph, 2001; Erwin Sigel, 2002). These receptors are often referred by which $\alpha$ subunits they contain in adjacent to the $\gamma$-subunit, e.g., $\alpha 1-, \alpha 2$-, $\alpha 3$-, or $\alpha 5$-subtype $\mathrm{GABA}_{\mathrm{A}}$ Rs. Positive modulation of GABA ${ }_{A}$ Rs by BZs are known to mediate a plethora of pharmacological and behavioral effects, such as anxiolysis (reduction of anxiety), myorelaxation, sedation, amnesia, and seizure inhibition (Rudolph \& Knoflach, 2011). Among them, the anxiolytic-like effects of the positive allosteric modulators (PAMs) of the BZ-site are of high significance in both clinical treatment of anxiety disorders and in basic neuroscience research (Atack, 2010a; Kalat, 2007; T. A. Smith, 2001).

During the last two decades, considerable evidence has revealed similarities and differences in the regional distribution and physiological functions of distinct $\mathrm{GABA}_{\mathrm{A}} \mathrm{R}$ subtypes (Rudolph \& Knoflach, 2011). At present, several studies have revealed that the 22-subtype $\mathrm{GABA}_{\mathrm{A}}$ Rs play a predominant role in BZ-induced anxiolysis (Low et al., 2000; K. S. Smith, Engin, Meloni, \& Rudolph, 2012). However, past studies have also revealed conflicting results concerning the involvement of $\alpha 1$ - and $\alpha 3$-subtype $\mathrm{GABA}_{\mathrm{A}} \mathrm{Rs}$ in anxiety, and have yet to distinguish the differential contribution of these subtypes. For example, past evidence suggested that selective antagonism of the $\alpha 1$-subtype $\mathrm{GABA}_{\mathrm{A}} \mathrm{R}$ abolished the anxiolytic-like effects of systemic BZ treatment, supporting the involvement of $\alpha 1$-subtype in BZ-induced anxiolysis (Belzung, Le Guisquet, \& Griebel, 2000). Other studies using BZ-site point mutant mice that rendered them insensitive to BZs, [ $\alpha 1(\mathrm{H} 101 \mathrm{R}), \alpha 2(\mathrm{H} 101 \mathrm{R})$, and $\alpha 3(\mathrm{H} 126 \mathrm{R})]$, indicated the anxiolytic-like effects of systemic BZ treatment are largely mediated by $\alpha 2$ - rather than $\alpha 1$ - or $\alpha 3$-subtype (Low et al., 2000; K. S. Smith et al., 2012). Still, other independent studies found that systemic 
injection of the $\alpha 3$-selective PAM TP003 produced anxiolytic-like effects while systemic administration of the $\alpha 3$-selective inverse-agonist Alpha3IA caused an anxiogenic-like behavioral profile, supporting the possibility that $\alpha 3$-subtype also mediate BZ-induced anxiolysis (Atack et al., 2005; Dias et al., 2005).

BZ-sensitive $\mathrm{GABA}_{\mathrm{A}} \mathrm{Rs}$ are located in a number of brain regions known to play roles in mediating behaviors indicative of anxiety, including the hippocampus, amygdala, and bed nucleus of stria terminalis (Pirker, Schwarzer, Wieselthaler, Sieghart, \& Sperk, 2000). Among them, the basolateral amygdala (BLA) is a particularly crucial brain region involved in the control of anxiety and fear-related behaviors, and is densely populated with BZ-sensitive GABA ${ }_{\mathrm{A}}$ Rs (M. Davis, 2000; File, 2000; LeDoux, 2000; Pirker et al., 2000). It receives various sensory inputs and sends processed information to the central amygdala (CeA), which is a main output nucleus controlling the downstream brain regions that contribute to fear/anxiety responses (Janak \& Tye, 2015; Lee, Kim, Kwon, Lee, \& Kim, 2013; Sah, Faber, Lopez De Armentia, \& Power, 2003). Animal studies showed that non-selective BZs produce anxiolytic-like effects when injected directly into the BLA (McNamara \& Skeleton, 1993; Menard \& Treit, 1999; Pesold \& Treit, 1995). However, it is currently unclear whether these anxiolytic-like effects are mediated by the action of BZs on particular $\alpha 1-, \alpha 2-$ or $\alpha 3$-subtypes, or whether all subtypes act synergistically to reduce anxiety.

In this study, we utilized both the point mutant mice and the subtype selective $\mathrm{GABA}_{\mathrm{A}} \mathrm{R}$ PAMs to investigate the differential roles of $\alpha 1-, \alpha 2$ - and $\alpha 3$-subtypes in BZinduced anxiolysis after systemic injections. Further, we locally delivered the drugs to the BLA to test whether BLA is a crucial brain area mediating the anxiolytic-like effects found in global positive modulation of $\mathrm{GABA}_{\mathrm{A}} \mathrm{R}$ by systemic injection. Our overall goal is to assess and discern the differential contributions of $\alpha 1-, \alpha 2-$ and $\alpha 3$-subtypes in mediating BZ-induced anxiolysis, both systemically and within the BLA.

\section{Clinical Significance}

The acute use of classic non-selective BZs is effective in reducing anxiety in humans. However, long-term use of BZs as an anxiolytic treatment can result in the development of tolerance and dependence, among many other side effects (Stevens \& Pollack, 2005). Some evidence suggests that $\alpha 1$-subtype GABA $\mathrm{A}_{\mathrm{A}}$ mediate the undesirable addictive properties of BZs (Rudolph \& Knoflach, 2011; Tan et al., 2010). A $\alpha 1$-subtype selective $\mathrm{GABA}_{\mathrm{A}} \mathrm{R}$ PAM, zolpidem, also causes motor-impairing and amnesic side effects in animal studies (Cope et al., 2004; Zanin et al., 2013), further reviewed in (Fitzgerald, Wright, \& Heldt, 2014). Thus, developing subtype selective anxiolytics that have little affinity or efficacy to $\alpha 1$-subtype is promising (Atack, 2005).

In addition to BZs, selective serotonin reuptake inhibitors (SSRIs) that inhibit serotonin reuptake and augment synaptic serotonin levels are also effective in reducing anxiety; however, anxiolytic-like effects only develop following chronic, but not acute treatment. In fact, acute SSRI treatment actually increases fear and anxiety responses in 
both human as well as in laboratory animals (Burghardt, Sullivan, McEwen, Gorman, \& LeDoux, 2004; Grillon, Levenson, \& Pine, 2007; Pettersson, Naslund, Nilsson, Eriksson, $\&$ Hagsater, 2015). The acute anxiogenic profile makes the usage of SSRI disadvantageous in cases where anxiety symptoms need to be managed acutely (Burghardt et al., 2004). Taken together, although classic non-selective BZs are suitable for acute treatment of anxiety disorders, their tolerance properties and side effects render them far from ideal for chronic anxiety management. Conversely, although SSRIs are effective in chronic treatment settings, they are disadvantageous for situations where anxiety symptoms needs to be managed acutely. This makes the development of novel subtypes-selective $\mathrm{GABA}_{\mathrm{A}} \mathrm{R}$ PAMs that retain the efficacy in anxiolysis but with their side effects minimized a promising venue for improving the existing pharmaceutical treatment options for anxiety disorders (Rudolph \& Knoflach, 2011).

The purpose of the present study is to differentiate between the contributions of $\alpha 1-, \alpha 2$ and $\alpha 3$-subtype $\mathrm{GABA}_{\mathrm{A}}$ Rs to BZ-induced anxiolysis. Our work will clarify not only the general involvement of $\alpha$-subtypes in BZ-induced anxiolysis but also reveal whether positive modulations of different $\alpha$-subtypes in the BLA participate in the induction of anxiolysis. Our results may provide important evidence useful for the development of novel subtype selective drugs for the treatment of clinical anxiety disorders.

\section{Overview of Experimental Design}

\section{Systemic Injection of Selective GABA $A_{A}$ PAMs}

We examined the presence (or absence) of anxiolytic-like effects elicited by systemic administration of selective PAMs of $\alpha 1-, \alpha 2$ - and/or $\alpha 3$-subtype GABA ${ }_{A}$ Rs. To achieve this, we assessed the anxiety-like behaviors using the EPM after selective positive modulation of $\alpha 1-, \alpha 2-$, and/or $\alpha 3$-subtypes pharmacologically via systemic injection of the following compounds: (i) Zolpidem, a $\alpha 1$-selective $\mathrm{GABA}_{\mathrm{A}} \mathrm{R}$ PAM; (ii) TP003, a $\alpha 3$-selective GABA ${ }_{A} R$ PAM; (iii) L-838417, a partial PAM for the $\alpha 2-, \alpha 3-$, and $\alpha 5$-subtypes (McKernan et al., 2000), was administered to $\alpha 3$ (H126R) mice expressing BZ-insensitive $\alpha 3$-subtype $\mathrm{GABA}_{\mathrm{A}} \mathrm{Rs}$. The latter approach (iii) was employed as we were unable to obtain a reliable $\alpha 2$-selective $\mathrm{GABA}_{\mathrm{A}} \mathrm{R}$ PAM. Thus, a combination of selective drug and point mutant mice was used. The Ki value of L-838417 to $\alpha 5$ subtype $\mathrm{GABA}_{\mathrm{A}} \mathrm{Rs}$ was $\sim 3$ times as high as that of $\alpha 2$ - and $\alpha 3$-subtypes in a radioligand binding assay, although the efficacy of L-838417 at $\alpha 5$-subtype $\mathrm{GABA}_{\mathrm{A}} \mathrm{Rs}$ was comparable to that of $\alpha 2$ - and $\alpha 3$-subtypes (McKernan et al., 2000). Since the $\alpha 5$-subtype $\mathrm{GABA}_{\mathrm{A}} \mathrm{Rs}$ have a much lower expression profile in the whole brain when compared to $\alpha 1-, \alpha 2$, and $\alpha 3$-subtypes (Whiting, 2003), and are considered non-essential in mediating BZ-induced anxiolysis (Collinson et al., 2002), we argue that the anxiolytic-like effect seen in this experiment should be predominantly due to the selective positive modulation of $\alpha 2$-subtype $\mathrm{GABA}_{\mathrm{A}}$ Rs. 


\section{Systemic Injection of Non-selective BZ}

We examined the presence (or absence) of anxiolytic-like effects elicited by systemic administration of non-selective BZ to animals where a specific $\alpha$-subtype was rendered BZ-insensitive. We tested whether the anxiolytic-like effect of systemic BZ treatment was blunted in $\alpha 1(\mathrm{H} 101 \mathrm{R}), \alpha 2(\mathrm{H} 101 \mathrm{R})$ or $\alpha 3(\mathrm{H} 126 \mathrm{R})$ mice as measured by the EPM. A similar line of study was previously conducted (K. S. Smith et al., 2012). We extended that study by including female subjects in our experiment and examining whether the anxiolytic-like effects of systemic BZ treatment are sex-dependent.

\section{Intra-BLA Microinjection of Selective GABAAR PAMs}

Since the BLA is known to be a crucial brain region in mediating anxiety-like behaviors and anxiolytic-like effects of BZs (M. Davis, 2000; Green \& Vale, 1992; Heldt \& Ressler, 2006; Pesold \& Treit, 1995; Sanders \& Shekhar, 1995), we examined the presence (or absence) of anxiolytic-like effects elicited by administration of selective positive modulators of $\alpha 1$-, $\alpha 2$ - and/or $\alpha 3$-subtype GABA $\mathrm{A}_{\mathrm{A}}$ within the BLA. To achieve this, we assessed the anxiety-like behaviors using the EPM after administration of subtype selective pharmacological agents via intra-BLA microinjection. Mice were tested for anxiety-like behaviors after intra-BLA administration of one of the following drug treatments: (i) Zolpidem, a $\alpha 1$-selective GABA $\mathrm{A}_{\mathrm{A}} \mathrm{PAM}$; (ii) TP003, a $\alpha 3$-selective $\mathrm{GABA}_{\mathrm{A}} \mathrm{R}$ PAM; (iii) a combination of selective drug, L-838417, and point mutant mice, $\alpha 3(\mathrm{H} 126 \mathrm{R})$, was used to achieve selective positive modulation of the $\alpha 2$ - and $\alpha 5$ subtypes, as described in an earlier section. Since the expression of $\alpha 5$-subtype is low in the amygdala compared to $\alpha 1-, \alpha 2-$ and $\alpha 3$-subtypes (Fritschy \& Mohler, 1995; Mathiasen, Rodgers, \& Mirza, 2007; Pirker et al., 2000), the effects seen should be predominantly due to the positive modulation of $\alpha 2$-subtypes.

\section{Intra-BLA Microinjection of Non-selective BZ}

We also examined the presence (or absence) of anxiolytic-like effects elicited by intra-BLA administration of non-selective BZ in animals where a specific $\alpha$-subtype was rendered BZ-insensitive. To achieve this, we investigated whether the anxiolytic-like effects of intra-BLA microinjection of BZ were blunted in $\alpha 1(\mathrm{H} 101 \mathrm{R}), \alpha 2(\mathrm{H} 101 \mathrm{R})$ or $\alpha 3(\mathrm{H} 126 \mathrm{R})$ mice as measured by the EPM.

The current view that $\alpha 2$-subtype $\mathrm{GABA}_{\mathrm{A}} \mathrm{Rs}$ are necessary for mediating BZinduced anxiolysis comes from studies showing that the anxiolytic-like effects of BZ were ablated in point mutant mice with BZ-insensitive $\alpha 2$-subtype GABA $\mathrm{Rs}$, as assessed by the EPM (Low et al., 2000; K. S. Smith et al., 2012). In our experiments, we used the combination of subtype selective drugs and point mutant mice to gain further insights into the differential roles $\alpha 1-, \alpha 2$-, and $\alpha 3$-subtype $\mathrm{GABA}_{\mathrm{A}} \mathrm{Rs}$ play in anxiety and BZ-induced anxiolysis. 


\section{CHAPTER 2. LITERATURE REVIEW}

\section{Clinical Aspects of Anxiety Disorders}

Anxiety disorders are common psychiatric conditions with a $28.8 \%$ lifetime prevalence among U.S. adults and cause significant economic burden to both patients and society (Kessler et al., 2005; Kessler \& Greenberg, 2002). They are an umbrella of several specific disorders, including, but not limited to, generalized anxiety disorder, phobias, and panic attacks (American Psychiatric Association, 2000). Normal levels of anxiety and fear are essential for vigilance and adaptation towards a threat uncertainty, and dissipate quickly when signals that indicate safety arise. However, pathological anxiety and fear during the interpretation and response towards threat uncertainty are maladaptive and can cause suffering of the subject (Grupe \& Nitschke, 2013).

Anxiety disorders can be managed by both psychotherapy and pharmacotherapy in the clinic. Various modalities of psychotherapy were developed or adapted to treat anxiety disorders with promising effectiveness, such as cognitive behavioral therapy and interpersonal psychotherapy (Graham \& Milad, 2011; Markowitz, Lipsitz, \& Milrod, 2014). Several lines of pharmacotherapy options are also available, such as antidepressant (SSRIs and SNRIs), azapirones, and benzodiazepines (Chessick et al., 2006; Farach et al., 2012; Katzman et al., 2014; Reinhold \& Rickels, 2015). However, these traditional treatment options have several limitations, such as significant side effects, or prolonged delay before the onset of efficacy, see the "Clinical Significance" section in Chapter 1.

\section{Animal Models for Assessing Fear and Anxiety-like Behaviors}

The terms "fear" and "anxiety" co-occur very often in the literature and are indeed deeply intertwined with each other (Suinn, 1969). In recent years, the distinctive differences between anxiety and fear have become increasingly recognized from both behavioral and neural circuitry points of view, and the different but overlapping underlying neural circuitries are being elucidated (M. Davis, Walker, Miles, \& Grillon, 2010; Perusini \& Fanselow, 2015; Tovote, Fadok, \& Lüthi, 2015). In animals, the predatory imminence theory provides an accepted distinction between fear, and anxiety (Perusini \& Fanselow, 2015).

To study the neurological basis of anxiety and fear, researchers have long used the behaviors of animals as models of these complex human emotions. To validate an animal behavioral paradigm as a tool to study the emotion of fear and anxiety, face validity (whether the test appears to measure the emotion), construct validity (whether the parameter collected reflects the underlying emotion), as well as predictive validity (whether the test can predict other measures of the emotion) must be met, although these standards are evolving (Belzung \& Lemoine, 2011; Walf \& Frye, 2007; Willner, 1984). In animals, the anxiety-like and fear-like behaviors are usually measured by their 
responses to either (i) a potential, non-specific threat, such as exposure to an open space; (ii) a specific, but unconditioned threat, such as exposure to a predator odor; or (iii) a specific, conditioned, but non-imminent cue, such as an environmental context which is experimentally associated with a distinctive aversive stimulus, or (iv) a specific, conditioned, and imminent cue which is experimentally associated with a distinctive aversive stimulus, e.g. (Goosens \& Maren, 2001; Wilson \& Junor, 2008). Further, stressinduced behavioral alterations and social interaction tests are also commonly used (File \& Hyde, 1979; Fuchs \& Fliugge, 2006; Zethof, Van der Heyden, Tolboom, \& Olivier, 1995).

In rodents, anxiety-like behaviors are assessed by behavioral paradigms such as open field, EPM, light dark box, defensive burying test, social interaction test, and stressinduced hyperthermia test. Conversely, fear-like behaviors are typically assessed following a training session where punishing stimuli are delivered, such as Pavlovian conditioning paradigms (Adriaan Bouwknecht, Olivier, \& Paylor, 2007; Bailey \& Crawley, 2009; Blanchard, Griebel, \& Blanchard, 2003; Curzon, Rustay, \& Browman, 2009; M. Davis, 1993; File, 1980; Njung'e \& Handley, 1991; Pellow \& File, 1986).

In animals, experimental exposures to stressful or aversive stimuli, brain lesions, and genetic / pharmacological manipulations can produce excessive fear and anxiety-like behaviors which serve as models of pathological conditions in humans. It is reported that stressful events, such as immobilization, maternal separation, and social defeat might lead to heightened state of anxiety in rodents (Huang et al., 2015; Kedia \& Chattarji, 2014; Romeo et al., 2003). Recent study also reveals that mice display an elevated state of fear and anxiety following exposure to closed-head mild traumatic brain injury (Heldt et al., 2014). These models are particularly useful in mimicking various clinical conditions where pathological anxiety is induced by a known stressor.

In this study, we used the EPM test, a validated behavioral paradigm to measure anxiety in rodents (Pellow \& File, 1986; Walf \& Frye, 2007), to study the differential anxiolytic-like effects of various $\mathrm{GABA}_{\mathrm{A}} \mathrm{R}$ PAMs and the differential contributions of $\alpha 1-, \alpha 2-$, and $\alpha 3$-subtype $\mathrm{GABA}_{\mathrm{A}} \mathrm{Rs}$ to anxiety-like behaviors.

\section{Brain Areas and Neurotransmitters Involved in Fear and Anxiety}

Brain areas and their associated neurocircuitries that mediate fear and anxiety are highly conserved across a wide range of species (Adolphs, Tranel, Damasio, \& Damasio, 1995; Davies, Martinez-Garcia, Lanuza, \& Novejarque, 2002; Janak \& Tye, 2015). This is not surprising when considering the evolutionary importance of adaptive fear and anxiety in the survival of most species (Marks \& Nesse, 1994; Ohman \& Mineka, 2001; Price, 2003). While many brain regions participate in the generation and modulation of fear and anxiety behaviors, the amygdala, bed nucleus of the stria terminalis (BNST), hippocampus, hypothalamus, periaqueductal grey (PAG), and prefrontal cortex are well recognized as playing important roles in these processes (Avery, Clauss, \& Blackford, 2015; Bishop, Duncan, Brett, \& Lawrence, 2004; Graeff, 2007; Graeff, Silveira, 
Nogueira, Audi, \& Oliveira, 1993; Tovote et al., 2015). These regions are admittedly not exclusively involved in fear and anxiety processes and both past and continued research recognizes that other brain areas, such as the lateral septum, also participate in these processes (Anthony et al., 2014).

The precise balance of neurotransmitter release in these brain areas is critical for their normal functions, e.g. (Gao et al., 2014; Prager, Bergstrom, Wynn, \& Braga, 2015). Over the past few decades, a number of neurotransmitters have been identified to be involved in mediating fear and anxiety, including but not limited to, GABA, serotonin, norepinephrine, neurosteroids, and acetylcholine (Charney, Heninger, \& Breier, 1984; Feighner \& Boyer, 1989; File, Gonzalez, \& Andrews, 1998; Hoehn-Saric, 1982; Kavaliers, Wiebe, \& Galea, 1994). The roles these neurotransmitters and their receptors play in mediating anxiety and fear within the amygdala, BNST, and hippocampus are of great interest and are reviewed in the following sections.

\section{Amygdala}

The amygdala complex is often divided into three major subdivisions: the basolateral amygdala (BLA), the central nucleus (CeA), and the medial nucleus (MeA) (Butler et al., 2012). Sensory input from cortical and thalamic regions converge to the BLA. In turn, the BLA sends efferent projections to separate subdivisions of the CeA and further project to various brain regions including the hypothalamus and the PAG (Janak $\&$ Tye, 2015).

\section{Amygdalar structure and fear / anxiety}

In humans, damage to the BLA results in impairments in conditioned fear acquisition and fear recognition, as well as decreases in levels of anxiety (Adolphs et al., 2005; Dellacherie, Hasboun, Baulac, Belin, \& Samson, 2011; Klumpers, Morgan, Terburg, Stein, \& van Honk, 2015). Currently, there is limited evidence available regarding the impact of specific focal lesions of the CeA in human; although, it is reported that the impairments in fear recognition are comparable between humans with complete unilateral amygdala damage and unilateral BLA damage that spares the CeA (Dellacherie et al., 2011).

Most evidence revealing the role the amygdala plays in fear and anxiety comes from animal studies. Lesions of the CeA in adolescent rhesus monkeys resulted in the suppression of fear expressions when they were confronted with potentially threatening stimuli (Kalin, Shelton, \& Davidson, 2004), although neonatal amygdalar lesions resulted in an impaired but not abolished fear response in macaques, suggesting that although amygdala is an important structure for mediating fear response, other parallel pathways also exist during development (Kazama, Heuer, Davis, \& Bachevalier, 2012). Lesions of the BLA in rats lead to impaired conditioned avoidance, but left intact behavioral suppression response to the conditioned aversive stimulus, while CeA lesions resulted in reduced conditioned behavioral suppression, but left intact conditioned avoidance, 
suggesting a marked distinction between the contribution of BLA and CeA to fear response (Killcross, Robbins, \& Everitt, 1997). More recent studies showed that both lateral amygdala and CeA lesions, as well as disconnection between the two regions, resulted in deficits in fear processing and conditioned suppression (Campese, Gonzaga, Moscarello, \& LeDoux, 2015). Lesions of the CeA in rats resulted in reduction of stressinduced anxiety as measured by the EPM, as well as both contextual and cued-fear in a fear conditioning paradigm (Möller, Wiklund, Sommer, Thorsell, \& Heilig, 1997;

Sullivan et al., 2004; Ventura-Silva et al., 2013). Lesion of the MeA or BLA in mice also lead to reduction of anxiety (Wang, Zhao, Liu, \& Fu, 2014). These studies suggested an indispensable and complex role of amygdala in mediating fear and anxiety-like behaviors.

In addition to classic lesion studies, the use of advanced circuitry mapping approaches, such as optogenetics (Boyden, 2011; Boyden, Zhang, Bamberg, Nagel, \& Deisseroth, 2005), has added to the growing evidence supporting the key role the amygdala plays in mediating fear and anxiety. Overall, non-selective activation of BLA somata resulted in an anxiogenic outcome (Tye et al., 2011). On a projection-specific level, it is reported that optogenetic activation of the BLA to medial prefrontal cortex (mPFC) projection resulted in elevated anxiety-like behaviors while optogenetic inhibition of the pathway resulted in anxiolytic-like outcomes (Felix-Ortiz, BurgosRobles, Bhagat, Leppla, \& Tye, 2015). Similar behavioral effects of optogenetic manipulation on social interaction were also found upon stimulating or inhibiting the BLA to ventral hippocampus projection (Felix-Ortiz \& Tye, 2014). However, it is reported that optogenetic activation of the BLA to anterodorsal BNST projection, as well as the BLA to CeA projection, elicited anxiolytic-like effects (Kim et al., 2013; Tye et al., 2011). These studies suggested that although the net output of BLA projection likely produces an anxiogenic profile, the projections from BLA to different brain areas have distinct and, in some cases, opposite effects.

\section{Amygdalar GABAergic signaling and fear / anxiety}

The pivotal role amygdala plays in anxiety and fear is also supported by numerous pharmacological studies that employed local manipulation of various neurotransmitters and receptors. For example, intra-BLA microinjection of BZs elicited anxiolytic-like effects, whereas intra-BLA microinjection of GABA $\mathrm{R}$ antagonists produced an anxiogenic-like outcome (M. Davis, 2000; Green \& Vale, 1992; Heldt \& Ressler, 2006; Pesold \& Treit, 1995; Sanders \& Shekhar, 1995). Intra-CeA microinjection of midazolam elicited anxiolytic-like effects as measured by the shockprobe burying paradigm but not the EPM. Thus, the anxiolytic-like effects of BZ manipulation in the CeA appeared to be task-dependent (Pesold \& Treit, 1995). Other studies reported that microinjections of the $\mathrm{GABA}_{\mathrm{A}} \mathrm{R}$ agonist muscimol into the $\mathrm{CeA}$, rather than the BLA, produced anxiolytic-like effects as measured by the EPM (Moreira, Masson, Carvalho, \& Brandão, 2007). The results from these two studies suggested differential effects of benzodiazepines (GABA $\mathrm{R}$ positive allosteric modulators) versus muscimol (GABA ${ }_{A} R$ agonist) when microinjected to the BLA. Taken together, these studies suggested that GABAergic neurotransmission in the amygdala mainly inhibits 
fear and anxiety. However, at present, the effects of microinjection of GABAAR subtype selective compounds in the amygdala remains largely unclear due to limited supporting evidence.

A number of subpopulations of GABAergic interneurons reside in the amygdala complex. They can be divided roughly into the following three groups: a parvalbuminpositive population, a cholecystokinin-positive population, and a somatostatin-positive population (Spampanato, Polepalli, \& Sah, 2011 ; Wolff et al., 2014). It is reported that both parvalbumin and somatostatin interneurons in the BLA are implicated in fear learning via an indirect parvalbumin-somatostatin-pyramidal neuron dis-inhibitory microcircuit (Wolff et al., 2014). Increased number of parvalbumin neurons was correlated with reduced anxiety-like behaviors in a study that investigated the effects of exposure to enriched environment (Urakawa et al., 2013). Another study showed that the paraventricular nucleus of the thalamus innervated the somatostatin interneurons in the lateral $\mathrm{CeA}$ and this pathway is implicated in the control of fear processing (Penzo et al., 2015).

\section{Other amygdalar neurotransmitters and fear / anxiety}

Besides GABAergic signaling, many other neurotransmitters, such as dopamine and serotonin, are also implicated in anxiety and fear-like behaviors in the amygdala. A number of studies, reviewed by de la Mora: (de la Mora, Gallegos-Cari, ArizmendiGarcia, Marcellino, \& Fuxe, 2010), showed that microinjection of a dopamine D1 receptor agonist to the amygdala (both the BLA and the CeA) elicited anxiogenic-like effects while microinjection of a D1 receptor antagonist resulted in anxiolytic-like effects; further, microinjection of a D2-like receptor antagonist in the BLA resulted in anxiolytic-like effects while microinjection of a D2-like receptor antagonist in the CeA produced paradoxical, task-dependent anxiogenic / anxiolytic-like effects (Greba, Gifkins, \& Kokkinidis, 2001; F.A. Guarraci, Frohardt, Falls, \& Kapp, 2000; F. A. Guarraci, Frohardt, \& Kapp, 1999; Lamont \& Kokkinidis, 1998; Perez de la Mora et al., 2012). A study found that dopamine interacted with GABAergic signaling by inhibiting GABA release from parvalbumin-positive interneurons in the BLA (Chu, Ito, $\mathrm{Li}, \&$ Morozov, 2012; Pape, 2005). This finding offered a possible explanation for dopaminedriven disinhibition of the amygdala and subsequent behavioral outcomes. Another important neurotransmitter, serotonin, also plays a role in regulating the function of the amygdala. A study employing a microdialysis approach suggested that serotonin concentration in the BLA complex was elevated during a conditioned fear test (Zanoveli, Carvalho, Cunha, \& Brandao, 2009). In another study, administration of serotonin to the amygdala resulted in anxiogenic-like effects as measured by conflict test, whereas depletion of serotonin in the BLA resulted in anxiolytic-like effects as measured by a social interaction paradigm and reduced fear response in a conditioned fear test (Hodges, Green, \& Glenn, 1987; Johnson et al., 2015). Thus, both dopaminergic and serotonergic neurotransmission in the amygdala mainly promote fear and anxiety. This is in contrast with studies showing anxiolytic-like effects after chronic, systemic SSRI treatment that augmented extracellular serotonin level over a prolonged period of time (Abuhamdah, Hussain, Chazot, \& Ennaceur, 2015; Dulawa, Holick, Gundersen, \& Hen, 2004). 
However, considering the studies that showed acute systemic SSRI treatment indeed promotes fear and anxiety-like behaviors both in rodents as well as in humans (Burghardt et al., 2004; Grillon et al., 2007), it is plausible that chronic enhancement of serotonergic transmission in the amygdala might allow anxiolytic-like effects to develop.

Other neurotransmitters, such as neuropeptides and neurosteroids, are also involved in the physiological function of the amygdala that controls fear and anxiety. It is reported that microinjection of neuropeptide $\mathrm{Y}$ into the BLA, but not CeA, elicited anxiolytic-like effects as measured by a social interaction paradigm (Sajdyk, Vandergriff, \& Gehlert, 1999). Knockdown of cholecystokinin peptide by shRNA in the BLA elicited anxiolytic-like effects as measured by the EPM (Del Boca, Lutz, Le Merrer, Koebel, \& Kieffer, 2012). Microinjection of a neurosteroid, allopregnanolone, into the amygdala resulted in anxiolytic-like effects as measured by both EPM and a defensive burying task (Engin \& Treit, 2007a). These findings indicated that there is complexity due to the multitude of neurotransmitters in the amygdala and prompted further investigation of neurochemical dysregulation in the amygdala in the context of fear and anxiety.

All of the abovementioned studies, ranging from lesion studies, optogenetic studies, pharmacological studies and behavioral studies, support the major role the amygdala plays in mediating fear and anxiety. It is also worth pointing out that due to multiple effects of various projections, microcircuitries, and neurotransmitters in the amygdala, it is particularly interesting to dissect out the molecular and cellular causes of these phenomena.

\section{Bed Nucleus of the Stria Terminalis}

The bed nucleus of the stria terminalis (BNST) belongs to the extended amygdalar structure (Swanson \& Petrovich, 1998) and receives prominent inputs from the amygdala. Similar to the CeA, which also receives direct projection from the BLA, the BNST gives rise to projections that target common downstream brain areas such as the hypothalamus, and has been implicated in behaviors such as stress responses and anxiety. However, unlike the CeA, which mediates fast expression of fear and anxiety, the BNST is thought to be an important player in the orchestration of slow onset, prolonged fear and anxiety responses (Dong, Petrovich, \& Swanson, 2001; Haufler, Nagy, \& Pare, 2013; Sakanaka, Shibasaki, \& Lederis, 1986; Spencer, Buller, \& Day, 2005; Walker, Toufexis, \& Davis, 2003) .

Lesions of the BNST resulted in selective impairment of contextual fear but not cued-fear, which was in contrast to CeA lesions that impaired both functions (Sullivan et al., 2004). Inactivation of BNST blocked defensive responses towards fox odor as well as alarm pheromones in rodents (Breitfeld et al., 2015; Fendt, Endres, \& Apfelbach, 2003). These findings suggested that BNST is largely responsible for behavior responses to the environmental context. 
The role that the BNST plays in fear and anxiety is further elucidated by several optogenetics studies. Importantly, a study revealed that the two subdivisions of BNST showed opposite functions, in which activities in the oval BNST sub-nucleus increased anxiety and activities in the anterodorsal BNST sub-nucleus inhibited anxiety. Also, photostimulation of the BLA to anterodorsal BNST projection elicited anxiolytic-like effects as measured by the EPM test (Kim et al., 2013). It was reported that photostimulation of the glutamatergic BNST to ventral tegmental area (VTA) projections resulted in an anxiogenic-like outcome whereas photostimulation of the GABAergic BNST to VTA projections lead to anxiolytic-like outcome (Jennings et al., 2013). These results demonstrated how BNST is intertwined with other brain regions, such as the BLA and the VTA, to orchestrate the fine tuning of fear and anxiety-like behaviors.

GABAergic transmission is shown to be involved in mediating a number of physiological functions and behavioral outcomes in the BNST. A study reported that deletion of the $\alpha 1$-subunit of GABA $\mathrm{GR}_{\mathrm{A}}$ in the corticotropin-releasing factor-positive $(\mathrm{CRF}+)$ neurons $(\mathrm{CRF}-\alpha 1 \mathrm{KO})$ resulted in an anxiogenic outcome, which could be rescued by intra-BNST microinjection of a CRF antagonist. Same study also showed that microinjection of the $\alpha 1$-subtype selective PAM zolpidem in the BNST elicited anxiolytic-like effects in WT but not CRF- $\alpha 1$ KO mice (Gafford et al., 2012). Further, norepinephrine signaling in the ventral BNST was shown to be crucial for fear responses towards fox odor in rodents. A study reported that the noradrenaline level in the ventral BNST was significantly increased in response to trimethylthiazoline exposure, and microinjection of clonidine, a $\alpha 2$-adrenergic agonist that lowers noradrenaline level, in the ventral BNST abolished fox odor induced fear potentiation (Fendt, Siegl, \& SteinigerBrach, 2005). Further, sex hormones and neurosteroids are both implicated in modulating fear and anxiety-like behaviors in the BNST (Nagaya, Acca, \& Maren, 2015; Toufexis, 2007).

To sum up, the BNST constitutes an integral part of the extended amygdalar structure, and together with the BLA and CeA, they control a large range of emotional responses and exert interconnected and inter-balanced effects via multiple projections.

\section{Hippocampus}

Hippocampal formation (short-hand as "hippocampus" in the following text) can be roughly divided into dorsal and ventral portions, and further subdivided into several fields, including cornus ammoni (CA)1, CA2/CA3, and dentate gyrus (DG) (Amaral \& Lavenex, 2007). Studies have shown that lesions of the ventral hippocampus lead to impairment of normal expression of anxiety, and it is believed that while the dorsal hippocampus is mostly involved in memory processing, the ventral hippocampus is mostly involved in anxiety (Bannerman et al., 2003; Bannerman et al., 2004).

A recent optogenetic study revealed that the DG was differentially involved in anxiety versus fear. It was reported that the dorsal division was more involved in contextual fear encoding, whereas the ventral division was more involved in innate 
anxiety, signifying the dissociation of the differential functional roles played by the intrahippocampal subdivisions (Fournier \& Duman, 2013; Kheirbek et al., 2013). The connection from BLA to ventral hippocampus is also implicated in social anxiety (FelixOrtiz \& Tye, 2014).

Intra-hippocampal microinjection of BZ, among many other compounds, such as certain serotoninergic agonists and neurosteroids, results in anxiolytic-like effects (Engin $\&$ Treit, 2007b). A recent study utilizing intra-BLA microinjection of subtype selective $\mathrm{GABA}_{\mathrm{A}} \mathrm{R}$ ligands revealed that the anxiety-like behaviors were mediated by the $\alpha 2-$ subtype $\mathrm{GABA}_{\mathrm{A}} \mathrm{Rs}$ in the ventral hippocampus, whereas fear memory processing was mediated by the $\alpha 5$-subtype $\mathrm{GABA}_{\mathrm{A}} \mathrm{Rs}$ in the dorsal hippocampus (McEown \& Treit, 2013).

To sum up, the hippocampus is a complex structure with multiple functions. The ventral hippocampus is an important brain structure that receives input from the BLA and is implicated in anxiety-like behaviors, whereas the dorsal hippocampus is more involved in learning, memory and fear-related behaviors.

\section{The Differential Functional Roles of GABAAR Subtypes}

Most attempts to determine the contribution of the $\alpha 1-, \alpha 2-, \alpha 3-$, and $\alpha 5$-subtypes $\mathrm{GABA}_{\mathrm{A}} \mathrm{Rs}$ in mediating behaviors have come from studies examining the effects of classic BZs (such as diazepam, chlordiazepoxide, midazolam, etc.) and other BZ-like ligands (such as zolpidem, L-838417, and TP003). These compounds often differ in their affinity and efficacy for different $\alpha$-subtypes, and those that display preferential affinity and/or efficacy towards particular $\alpha$-subtypes are referred to as subtype selective drugs. In combination with the use of these $\mathrm{GABA}_{\mathrm{A}} \mathrm{R}$ ligands and genetically modified mice (KO, point-mutants), past studies have elucidated various functional differences among different $\alpha$-subtype GABA ${ }_{A}$ Rs.

\section{The $\alpha 1-s u b t y p e ~ G A B A_{A} R s$}

Currently, the role that $\alpha 1$-subtype $\mathrm{GABA}_{\mathrm{A}} \mathrm{Rs}$ play in fear and anxiety is unclear. In mice, systemic injection of $\alpha 1$-subtype selective antagonists blocked BZ-induced anxiolysis as measured by the EPM, suggesting an important role of $\alpha 1$-subtype in mediating BZ-induced anxiolysis (Belzung et al., 2000). Likewise, in mice that express BZ-insensitive $\alpha 1$-subtype $\mathrm{GABA}_{\mathrm{A}}$ Rs, i.e. the $\alpha 1(\mathrm{H} 101 \mathrm{R})$ mice, BZ-induced inhibition of a conditioned fear response was abolished, suggesting that $\alpha 1$-subtype GABA $A$ Rs are necessary for the effects of BZ on fear-like behaviors (K. S. Smith et al., 2012). In contrast, the study showed that BZs retained their anxiolytic-like effects in $\alpha 1$ (H101R) mice as measured by the EPM test, suggesting that the $\alpha 1$-subtype is not essential for BZinduced anxiolysis (K. S. Smith et al., 2012). The fact that systemic injection of zolpidem produced debatable anxiolytic-like effects that were sensitive to experimental conditions 
such as illumination of the maze (Savic et al., 2004) suggested that the role $\alpha 1$-subtype $\mathrm{GABA}_{\mathrm{A}}$ Rs play in mediating anxiolysis was influenced by complex variables.

In contrast to its role in fear and anxiety-like behaviors, the role the $\alpha 1$-subtype plays in sedation, aggression, amnesia and in addiction to BZs is better understood. The sedative effects of diazepam were abolished in the $\alpha 1(\mathrm{H} 101 \mathrm{R})$ mice, suggesting the involvement of $\alpha 1$-subtype $\mathrm{GABA}_{\mathrm{A}} \mathrm{Rs}$ in sedation (McKernan et al., 2000). Similarly, the aggression-promoting effects of midazolam were abolished in $\alpha 1(\mathrm{H} 101 \mathrm{R})$ mice in a social interaction paradigm, suggesting the involvement of $\alpha 1$-subtype GABA $\mathrm{A}_{\mathrm{R}}$ in BZinduced escalation of aggression (Newman et al., 2015). Further, it is reported that systemic administration of $\beta$-CCT, a $\alpha 1$-subtype selective antagonist, reduced alcoholinduced aggressive behaviors. However, interestingly, systemic administration of zolpidem did not increase ethanol-induced aggression, which could be attributed to the sedative effects of zolpidem (de Almeida, Rowlett, Cook, Yin, \& Miczek, 2004). The amnesic effects of diazepam, as assessed by a passive-avoidance paradigm, was also abolished in $\alpha 1(\mathrm{H} 101 \mathrm{R})$ mice, suggesting the involvement of $\alpha 1$-subytpe GABA ${ }_{\mathrm{A}} \mathrm{Rs}$ in memory processing (Rudolph et al., 1999). Similarly, amnesic / motor-impairing effects were also observed following systemic administration of zolpidem (Cope et al., 2004; Zanin et al., 2013), further reviewed in (Fitzgerald et al., 2014). Other studies have implicated $\alpha 1$-subtype GABA ${ }_{A}$ Rs in drug abuse and addiction (Rowlett \& Lelas, 2007; Tan, Rudolph, \& Luscher, 2011), as well as in anxiety induced by acute BZ-withdraw (Divljakovic et al., 2013).

Several studies have begun to elucidate the specific roles played by $\alpha 1$-subtype $\mathrm{GABA}_{\mathrm{A}} \mathrm{Rs}$ in different brain areas. Deletion of $\alpha 1$-subtype $\mathrm{GABA}_{\mathrm{A}} \mathrm{Rs}_{\mathrm{s}}$ within the amygdala reportedly disrupted the anticonvulsant and sedative effects of BZ. However, the anxiolytic-like effects of BZ, as measured by the EPM, were unaffected, suggesting that the $\alpha 1$-subtype is not essential for amygdala-mediated anxiety-like behaviors (Heldt \& Ressler, 2010). Conversely, microinjection of zolpidem to the BNST resulted in anxiolytic-like effects, as measured by the open field test (Gafford et al., 2012). These results suggest that the role played by $\alpha 1$-subtype $\mathrm{GABA}_{\mathrm{A}} \mathrm{Rs}$ in fear and anxiety-like behaviors is brain region specific.

Together, current evidence suggests that the $\alpha 1$-subtype $\mathrm{GABA}_{\mathrm{A}} \mathrm{Rs}$ are involved in sedative, amnesic, and addictive effects of BZs (Rudolph \& Knoflach, 2011). On the basis of currently published studies, the relative importance of the $\alpha 1$-subtype GABA ${ }_{\mathrm{A}} \mathrm{Rs}$ in mediating BZ-induced anxiolytic-like behaviors is ambiguous, however its role may depend upon the specific brain regions, the behavioral test conditions, and the particular responses used to assess anxiety-like behaviors.

\section{The $\alpha 2$-subtype GABAARs}

The role that $\alpha 2$-subtype $\mathrm{GABA}_{\mathrm{A}}$ Rs play in BZ-induced reductions of fear and anxiety-like behaviors is well documented. The inhibitory effects of diazepam and CDP on anxiety-like behavior, as measured by the EPM, and fear-like behavior, as measured 
by fear potentiated startle test, were reduced in $\alpha 2$ (H101R) mice (Low et al., 2000; K. S. Smith et al., 2012). Genomic deletion of the $\alpha 2$-subunit also abolished the anxiolytic-like effects of diazepam (Dixon, Rosahl, \& Stephens, 2008). In contrast, a study showed that the sedative effects of diazepam were weakened in $\alpha 1(\mathrm{H} 101 \mathrm{R})$ mice that possess BZsensitive $\alpha 2$-subtype $\mathrm{GABA}_{\mathrm{A}} \mathrm{Rs}$ when compared to induced sedation in WT mice (McKernan et al., 2000). This evidence suggests that $\alpha 2$-subtypes are not overtly involved in BZ-induced sedation.

The above findings showing that lack of involvement of $\alpha 2$-subtype in sedation support the theory that $\alpha 2$-subtype selective PAMs might be good candidates for use as day-time anxiolytic drugs, as the sedative effects of classic BZs are problematic for their day-time use (Rudolph \& Knoflach, 2011). In recent years, two compounds that have preferential efficacy at both $\alpha 2$ - and $\alpha 3$-subtype GABA $\mathrm{A}_{\mathrm{R}}$, TPA023 and TPA023B, have been developed and tested in animal experiments as well as clinical trials. In both animals and humans, these compounds reduce anxiety without major sedative effects even at high dose, however, issues with toxicity complicated the continuation of a clinical trial (Atack, 2010b; Atack, Wafford, et al., 2006).

The putative $\alpha 2$-subtype selective agonist TCS-1105 (also known as "compound 1c") reportedly exerted anxiolytic-like effects as measured by the light-dark box test (Taliani et al., 2009). However, since the selectivity of this compound was tested in $\alpha 1 \beta 2 \gamma 2, \alpha 2 \beta 2 \gamma 2$, and $\alpha 5 \beta 3 \gamma 2$ recombinant $\mathrm{GABA}_{\mathrm{A}} \mathrm{Rs}$, but not $\alpha 3$-containing GABA $\mathrm{A}$ s, the selectivity of this compound in $\alpha 2$-subtype versus $\alpha 3$-subtype is unclear at present. Currently, a reliable $\alpha 2$-subtype selective compound is sought-after by the field.

The $\alpha 2$-subtype $\mathrm{GABA}_{\mathrm{A}} \mathrm{Rs}$ are also implicated in regulating depression-like behaviors (Engin, Liu, \& Rudolph, 2012; Vollenweider, Smith, Keist, \& Rudolph, 2011) and the myorelaxation effects of BZs in mice (Crestani et al., 2001). Further, recent pharmacological studies as well as human genetics revealed that $\alpha 2$-subtype $\mathrm{GABA}_{\mathrm{A}} \mathrm{Rs}$ are also involved in reward-related behaviors and addiction (Dixon et al., 2010; Engin et al., 2014). This evidence might argue against the use of $\alpha 2$-selective PAM for anxiety management as habit-forming might be a possible side-effect.

To sum up, current evidence suggests that $\alpha 2$-subtype GABA $\mathrm{ARs}_{\mathrm{A}}$ are implicated in anxiety-like, depression-like and schizophrenia-like behaviors and are a promising target for the development of novel therapeutics (Engin et al., 2012).

\section{The $\alpha 3$-subtype GABAARs}

Currently, the role that $\alpha 3$-subtype $\mathrm{GABA}_{\mathrm{A}} \mathrm{Rs}$ play in fear and anxiety is still debatable. On one hand, in an experiment using point mutant mice, it is reported that systemic injection of diazepam retained its effects in inducing anxiolysis as well as fear reduction in $\alpha 3(\mathrm{H} 126 \mathrm{R})$ mice carrying BZ-insensitive $\alpha 3$-subtype GABA $\mathrm{A}_{\mathrm{R}}$ (K. S. Smith et al., 2012). Genomic knockout of the $\alpha 3$-subunit did not affect baseline anxiety behavior or diazepam-induced anxiolysis (Yee et al., 2005). These findings suggest that 
the $\alpha 3$-subtype $\mathrm{GABA}_{\mathrm{A}} \mathrm{Rs}$ are not essential for mediating anxiety and BZ-induced anxiolysis. On the other hand, studies using the $\alpha 3$-subtype selective PAM TP003 showed that systemic injections produced anxiolytic-like effects, as measured by the EPM and stress-induced hyperthermia in rodents as well as by a conflict test paradigm in primates (Dias et al., 2005; Fischer et al., 2011). In a conditioned emotional response paradigm, the $\alpha 2-, \alpha 3-$ and $\alpha 5$-subtype selective compound, L-838417 retained its anxiolytic-like effects in $\alpha 2(\mathrm{H} 101 \mathrm{R})$ mice, suggesting that $\alpha 3$ - and/or $\alpha 5$-subtype $\mathrm{GABA}_{\mathrm{A}}$ Rs mediate L-838417-induced anxiolysis independent of $\alpha 2$-subtype GABA $\mathrm{A}$ s (Morris, Dawson, Reynolds, Atack, \& Stephens, 2006). In another study, the systemic injections of the $\alpha 3$-subtype selective BZ-site inverse agonist named Alpha3IA produced an anxiogenic-like profile as measured by the EPM in rodents (Atack et al., 2005). Together, these studies suggest that selective modulation of $\alpha 3$-subtype $\mathrm{GABA}_{\mathrm{A}} \mathrm{Rs}$ by BZ-site ligands is sufficient to alter anxiety-like behaviors. Further, it is reported that blockade of 5- $\mathrm{HT}_{1 \mathrm{~A}}$ receptors reversed the anxiolytic-like effects elicited by TP003 in a stress-induced hyperthermia paradigm. This finding suggests that $\alpha 3$-subtype $\mathrm{GABA}_{\mathrm{A}} \mathrm{Rs}$ are involved in the interaction between GABAergic and serotonergic transmission (Vinkers, van Oorschot, Korte, Olivier, \& Groenink, 2010). Together, current findings suggest that $\alpha 3$-subtype $\mathrm{GABA}_{\mathrm{A}}$ Rs play a sufficient, but not necessary role in mediating anxiety-like behaviors and BZ-induced anxiolysis.

Similar to $\alpha 2$-subtypes, it is generally accepted that $\alpha 3$-subtype GABA $A$ Rs are not overtly involved in BZ-induced sedation as diazepam failed to elicit sedative effects in $\alpha 1(\mathrm{H} 101 \mathrm{R})$ mice with intact $\alpha 3$-subtype $\mathrm{GABA}_{\mathrm{A}} \mathrm{Rs}$ at doses that would induce sedation in WT mice (McKernan et al., 2000). It is also reported that $\alpha 3$-subtype GABA ${ }_{A} R s$ appeared to be non-essential for mediating the effects of BZ on sleep EEG (Kopp, Rudolph, Keist, \& Tobler, 2003). Lack of $\alpha 3$-subtype GABA ${ }_{A}$ Rs resulted in hyperdopaminergic and schizophrenia-like behavioral phenotypes hallmarked by sensorimotor gating deficits which could be reversed by treatment of antipsychotic drug haloperidol, suggesting that $\alpha 3$-subtype GABA ${ }_{A} R s^{\prime}$ involvement in schizophrenia (Yee et al., 2005). Similar to $\alpha 2$-subtype, the $\alpha 3$-subtype $\mathrm{GABA}_{\mathrm{A}} \mathrm{Rs}$ are also involved in myorelaxation effects of BZs in rodents as well as in primates (Crestani et al., 2001; Fischer et al., 2011). Currently, little is known about whether the $\alpha 3$-subtype GABA $\mathrm{A}_{\mathrm{A}}$ are also involved in the addictive property of BZs or not.

To sum up, current evidence suggests that $\alpha 3$-subtype $\mathrm{GABA}_{\mathrm{A}} \mathrm{Rs}$ play a role in mediating anxiolytic-like and myorelaxative, but not sedative effects of BZs. The $\alpha 3-$ subtype $\mathrm{GABA}_{\mathrm{A}}$ Rs are also implicated in schizophrenia-like behaviors in rodents.

\section{The a5-subtype GABAARs}

The $\alpha 5$-subtype GABA $\mathrm{A}_{\mathrm{R}}$ differed from $\alpha 1-, \alpha 2-$, and $\alpha 3$-subtypes in that their expression, on the protein level, is enriched the olfactory bulb, hippocampus and spinal trigeminal nucleus, and their expression elsewhere is comparatively low (Fritschy \& Mohler, 1995; Mathiasen et al., 2007; Pirker et al., 2000). Further, their subcellular expression patterns are mainly extrasynaptic and, thus they are thought to mediate tonic 
GABAergic inhibition (Crestani et al., 2002; Farrant \& Nusser, 2005; Fritschy, Johnson, Mohler, \& Rudolph, 1998; Groen et al., 2014). Due to the recognized involvement of the hippocampus in learning and memory processes, the prominent enrichment of $\alpha 5$-subtype $\mathrm{GABA}_{\mathrm{A}} \mathrm{Rs}$ in the hippocampus was postulated to play specific roles in mediating learning and memory. The $\alpha 5$-subunit knockout mice performed better in a spatial learning task (Collinson et al., 2002), and inverse agonism of the $\alpha 5$-subtype by a compound named L655,708 resulted in cognitive improvement both under normal physiological conditions, and after general isoflurane-induced anesthesia where short-term memory was markedly impaired (Atack, Bayley, et al., 2006; Zurek, Bridgwater, \& Orser, 2012).

Currently, the evidence for the involvement of $\alpha 5$-subtype $\mathrm{GABA}_{\mathrm{A}} \mathrm{Rs}$ in anxiety is limited and contradictory. Mice with genetic deletion of the $\alpha 5$-subunit ( $\alpha 5$-subunit $\mathrm{KO}$ ) performed similarly to WT mice on the EPM test and in response to BZ (Collinson et al., 2002). Administration of a $\alpha 5$-subtype selective inverse agonist, $\alpha 5$ IA, also did not significantly alter anxiety-like behaviors in rodents (Dawson et al., 2006). However, a study indicated that administration of another $\alpha 5$-subtype selective inverse agonist, L655,708 , resulted in anxiogenic-like effects in the EPM paradigm (Navarro, Burón, \& Martín-López, 2002), although questions were raised as to whether these effects were indeed mediated exclusively by the $\alpha 5$-subtype GABA ${ }_{A}$ Rs (Atack, Bayley, et al., 2006). Together, currently the majority evidence suggests that the $\alpha 5$-subtype $\mathrm{GABA}_{\mathrm{A}} \mathrm{Rs}$ appear unnecessary for mediating anxiety-like behaviors.

\section{The $\alpha 4$ - and $\alpha 6$-subtype GABA $A_{A}$ s}

The $\alpha 4$ - and $\alpha 6$-subtype GABA ${ }_{A}$ Rs differ from the abovementioned receptor subtypes, in that they are insensitive to BZs due to the lack of (i) a crucial histidine residue required for the formation of functional BZ-site, and (ii) their preferential association with the $\delta$-subunit (Caruncho \& Costa, 1994; Sur et al., 1999; Wafford et al., 1996; Wieland, Lüddens, \& Seeburg, 1992). They are known to mediate extrasynaptic tonic GABAergic inhibition (Belelli et al., 2009; Brickley \& Mody, 2012; Farrant \& Nusser, 2005; Hamann, Rossi, \& Attwell, 2002).

One feature of $\alpha 4$-subtype $\mathrm{GABA}_{\mathrm{A}} \mathrm{Rs}$ is their sensitivity towards neurosteroid and hormonal modulation. This sensitivity was postulated to be involved in mediating many sex-differences in anxiety states, such as premenstrual, post-partum as well as peripuberty anxiety (Gulinello, Gong, Li, \& Smith, 2001; Gulinello, Orman, \& Smith, 2003; Shen et al., 2007; S. S. Smith et al., 1998). The $\alpha 4$-subtype $\mathrm{GABA}_{\mathrm{A}} \mathrm{Rs}$ are also regulated by stress hormones and steroids, such as corticotrophin releasing hormone and $3 \alpha, 5 \alpha[\beta]$ THP, and are thought to be a key player in mediating stress and anxiety responses in a sex dependent manner (Mody \& Maguire, 2011; Shen, Mohammad, Ramroop, \& Smith, 2013; S. S. Smith, 2013; S. S. Smith, Shen, Gong, \& Zhou, 2007).

Limited evidence indicates that $\alpha 6$-subtype $\mathrm{GABA}_{\mathrm{A}} \mathrm{Rs}$ are involved in regulating fear and anxiety, amongst other behaviors and physiological functions. One report showed that midazolam-induced anxiolysis is attenuated in human subjects carrying the 
Pro385Ser mutation in the $\alpha 6$-subunit (Hoffman, Balyasnikova, Mahay, Danilov, \& Baughman, 2002). Some evidence also suggested that genetic variation within the $\alpha 6-$ subunits is associated with epilepsy in human (Hernandez, Gurba, $\mathrm{Hu}, \&$ Macdonald, 2011; Hirose, 2014). Also, a reduction of $\alpha 6$-subunit protein expression was reported in the superior frontal cortex of autistic subjects (Fatemi et al., 2014). Further, $\alpha 6$-subtype $\mathrm{GABA}_{\mathrm{A}}$ Rs are also implicated in alcohol dependency (Loh \& Ball, 2000).

In summary, the $\alpha 4$ - and $\alpha 6$-subtype $\mathrm{GABA}_{\mathrm{A}} \mathrm{Rs}$ exhibit distinct physiological, pharmacological, and functional profiles that set them apart from the other BZ-sensitive $\mathrm{GABA}_{\mathrm{A}} \mathrm{R}$ subtypes. In this study, we will mostly focus on the $\mathrm{GABA}_{\mathrm{A}} \mathrm{R}$ subtypes that are both BZ-sensitive and abundantly expressed in the amygdala, i.e., the $\alpha 1-, \alpha 2-, \alpha 3-$ subtypes. 


\section{CHAPTER 3. METHODOLOGY}

\section{Mouse Strains}

C57BL/6J mice (Jackson Laboratory, Bar Harbor, Maine) were used in this study as WT controls to test the anxiolytic profile of various selective and non-selective $\mathrm{GABA}_{\mathrm{A}} \mathrm{R}$ PAMs in both systemic and intra-BLA microinjection experiments. This strain of mice are widely used in behavioral studies and their characteristic patterns of anxiety and fear-like behaviors are well understood. For example, C57BL/6J showed lower baseline anxiety level and higher sensitivity to BZ when compared to BALB/c mice (Lepicard, Joubert, Hagneau, Perez-Diaz, \& Chapouthier, 2000), and they also showed slower fear extinction when compared to DBA/2J mice (Waddell, Dunnett, \& Falls, 2004).

In experiments that examined the functional silencing of selective $\mathrm{GABA}_{\mathrm{A}} \mathrm{R}$ subtypes towards the modulatory effects of $B Z s, G A B A_{A} R$ point mutant mice, generously gifted by Dr. Uwe Rudolph from McLean Hospital, were used. These strains of mice were created in the last decade and have become of great value in the investigation of the selective function of different subunits (Rudolph \& Mohler, 2004). Three lines of point mutant mice were used in our experiment: $\alpha 1(\mathrm{H} 101 \mathrm{R}), \alpha 2(\mathrm{H} 101 \mathrm{R})$, and $\alpha 3(\mathrm{H} 126 \mathrm{R})$. As previously described (Low et al., 2000; Rudolph et al., 1999; K. S. Smith et al., 2012), these mice have a mutated residue (histidine to arginine) in the BZ binding site of a particular $\alpha$-subunit, rendering the receptor insensitive to the modulatory effects of BZs. These mutant mice were maintained on C57BL/6J genetic background and bred as homozygotes.

All animals were housed in micro-isolation cages with ad libitum access to food and water, $12 \mathrm{~h}$ light-dark cycle and controlled temperature / humidity. All animals used in this study were adult mice (between 2-6 months of age). For most experiments, male subjects were used, except for the systemic CDP injection experiment, where mice of both sexes were used. All testing procedures were conducted in the light-phase of the day and were approved by the Animal Care and Use Committee of the University of Tennessee Health Science Center.

\section{Surgery Procedures}

Stereotaxic surgeries were performed using procedures previously described in detail (Heldt \& Ressler, 2006). Adult mice were anesthetized with an intraperitoneal (i.p.) injection of a cocktail of ketamine $(80 \mathrm{mg} / \mathrm{kg})$ and xylazine $(10 \mathrm{mg} / \mathrm{kg})$. Upon confirmation of anesthesia, their heads were shaved, swabbed with betadine, and mounted in a stereotaxic surgical frame (David Kopf Instruments, Tujunga, CA) with metal ear bars inserted and secured. Ophthalmic ointment was applied to prevent the eyes from drying out. An incision along the midline of the skull was made, and the surrounding skin was retracted to expose the surgical site. Two anchoring screws were then implanted. Holes were drilled in the skull over the intended cannula implantation 
sites and bilateral 26 gauge guide cannulae (PlasticOne, Roanoke, VA) were planted stereotaxically at the following coordinates in reference to Bregma : AP:-1.5, ML: \pm 3.3 or \pm 3.4 , DV: -5.0 or -5.1 according to a reference stereotaxic atlas (Paxinos \& Franklin, 2001). The cannula fixture was secured with dental cement and the surgical incision was closed with adhesives. After surgery, animals were placed on a heating pad for recovery and a dose of post-operation analgesics (Buprenorphine $0.1 \mathrm{mg} / \mathrm{kg}$ or Carprofen 5.0 $\mathrm{mg} / \mathrm{kg}$ ) was administered. Animals were then allowed to fully recover from surgery for at least 4 days, during this period they were closely monitored for signs of pain and distress. They were also handled with gloved hand daily to allow acclimation to the gentle restraint required for the microinjection procedure, and to minimize the stress induced by the injection procedure preceding the behavioral test.

\section{Pharmacological Agents}

Many BZ-site ligands are known to exert positive allosteric modulatory effects on GABA $_{A}$ Rs. Non-selective classic BZs (e.g., CDP) are promiscuous to $\alpha 1-, \alpha 2-, \alpha 3-$, and $\alpha 5$-subtype $\mathrm{GABA}_{\mathrm{A}} \mathrm{Rs}$, on the other hand, subtype selective BZ-site ligands are defined as having either preferential affinity (e.g. zolpidem) and/or preferential efficacy (e.g. L838417 and TP003) towards a particular subset of BZ-sensitive $\alpha$-subtypes (Rudolph $\&$ Knoflach, 2011).

\section{Chlordiazepoxide}

Chlordiazepoxide (CDP, Sigma Aldrich, St Louis, MO), a classic BZ and nonselective GABA $\mathrm{A}_{\mathrm{A}}$ PAM, was used to augment the $\alpha 1-, \alpha 2-, \alpha 3-$, and $\alpha 5$-subtype $\mathrm{GABA}_{\mathrm{A}} \mathrm{Rs}$ in systemic and intra-BLA microinjection experiments. CDP absorbs well after i.p. injection and a $5 \mathrm{mg} / \mathrm{kg}$ i.p. injection in rats results in $25 \%$ receptor occupancy in the brain (Dias et al., 2005). For CDP systemic injection experiments, we used $10 \mathrm{mg} / \mathrm{kg}$ as the high dose. The dose was chosen based on a previous systemic injection study that used the same dose as the high dose for mice (K. S. Smith et al., 2012). For CDP microinjection experiments, we used $20 \mu \mathrm{g} / \mu \mathrm{L}$ as the high dose working concentration and $0.3 \mu \mathrm{L}$ injection volume was delivered. This was based on a previous microinjection study that used the same concentration of CDP $(20 \mu \mathrm{g} / \mu \mathrm{L})$ with $0.5 \mu \mathrm{L}$ injection volume as the high dose for rats (Stackman \& Walsh, 1995).

\section{Zolpidem}

Zolpidem (Toronto Research Chemicals, North York, ON, Canada), a selective BZ-site PAM of $\alpha 1$-subtype GABA $\mathrm{A}_{\mathrm{R}}$ with $\sim 5$-fold selectivity over other subtypes (Petroski et al., 2006), was used to selectively augment $\alpha 1$-subtype GABA $\mathrm{A}_{\mathrm{R}}$ in both systemic injection experiments and intra-BLA microinjection experiments. The binding affinity of zolpidem is drastically reduced in $\alpha 1$ (H101R) mice (McKernan et al., 2000). Zolpidem absorbs well after i.p. injection. In mice, an i.p. dose of $1.8 \mathrm{mg} / \mathrm{kg}$ results in 
approximately 50\% receptor occupancy in the brain (Hopkins, Brian Nofsinger, Allen, Koch, \& Varney, 2009). Ranges of drug dosages used in this study were carefully chosen based on previously published studies. For the zolpidem systemic injection experiment, we used $2 \mathrm{mg} / \mathrm{kg}$ as the high dose. The dose was chosen based on a previous systemic injection study that used $3 \mathrm{mg} / \mathrm{kg}$ as the high dose for mice and reported sedative effects at this dose (Mathiasen, Mirza, \& Rodgers, 2008). We also observed pronounced motor impairment even at $2 \mathrm{mg} / \mathrm{kg}$ dose that rendered the mice unable to reliably perform in the EPM test, thus we used $2 \mathrm{mg} / \mathrm{kg}$ as the high dose for our experiment. For the zolpidem microinjection experiment, we used $0.5 \mu \mathrm{g} / \mu \mathrm{L}$ as the high dose working concentration and $0.3 \mu \mathrm{L}$ injection volume was delivered. This was based on a previous microinjection study that used $0.25 \mu \mathrm{g} / \mu \mathrm{L}$ concentration and $0.5 \mu \mathrm{L}$ injection volume as the working dose for mice (Gafford et al., 2012).

\section{L-838417}

L-838417 (Tocris, Bristol, UK) is a selective BZ-site PAM that binds to $\alpha 1-, \alpha 2-$, $\alpha 3$-, and $\alpha 5$-subtype $\mathrm{GABA}_{\mathrm{A}} \mathrm{Rs}$, but only exerts positive modulatory effects on the $\alpha 2-$, $\alpha 3-$, and $\alpha 5$-subtypes in recombinant receptors. The binding affinity of L-838417 is lower in $\alpha 5$-subtype when compared to $\alpha 1-, \alpha 2-, \alpha 3$-subtypes. Further, although no direct evidence is available about the binding affinity of L-838417 for $\alpha 3(\mathrm{H} 126 \mathrm{R})$ receptors, it is known that the binding affinity of L-838417 is drastically reduced in $\alpha 1(\mathrm{H} 101 \mathrm{R})$ receptors (McKernan et al., 2000). Since both the $\alpha 1$ - and $\alpha 3$-subtypes share similar BZsite structure that requires the histidine residue, we deduce that the binding affinity of L838417 should also be lost in $\alpha 3$ (H126R) receptors. L-838417 absorbs well after i.p. injection. In mice, a dose of $1 \mathrm{mg} / \mathrm{kg}$ or $3 \mathrm{mg} / \mathrm{kg}$ i.p. injection results in 30-40\% receptor occupancy in the brain (Scott-Stevens, Atack, Sohal, \& Worboys, 2005), although a more recent study reports that the $\mathrm{OC}_{50}$ is around $1.3 \mathrm{mg} / \mathrm{kg}$ (Hopkins et al., 2009). For the L838417 systemic injection experiment, we used $2 \mathrm{mg} / \mathrm{kg}$ as the high dose. This dose was chosen based on a previous systemic injection study that found anxiolytic-like effects at $3 \mathrm{mg} / \mathrm{kg}$ dose in a Vogel conflict test for mice and in a conditioned emotional response test for rat (Mathiasen et al., 2008; Mathiasen et al., 2007). In an initial experiment, we found robust anxiolytic-like effects at $2 \mathrm{mg} / \mathrm{kg}$ and even with a $0.5 \mathrm{mg} / \mathrm{kg}$ dose in WT mice. Thus, we used $2 \mathrm{mg} / \mathrm{kg}$ as the high dose in our experiment. For the L-838417 microinjection experiment, we used $0.5 \mu \mathrm{g} / \mu \mathrm{L}$ as the high dose working concentration and $0.3 \mu \mathrm{L}$ injection volume was delivered. This was based on a previous microinjection study that used $0.4 \mu \mathrm{g} / \mu \mathrm{L}$ concentration and $1 \mu \mathrm{L}$ injection volume as the working dose for rats (Mathiasen et al., 2007).

\section{TP003}

TP003 (Tocris, Bristol, UK) is a 23 -subtyp.e selective BZ-site PAM (Dias et al., 2005; Marowsky, Rudolph, Fritschy, \& Arand, 2012). In vitro, TP003 binds to $\alpha 1-, \alpha 2-$, $\alpha 3$-, and $\alpha 5$-subtype $\mathrm{GABA}_{\mathrm{A}} \mathrm{Rs}$ with high affinity, but only exerts positive modulatory effects on the $\alpha 3$-subtype in recombinant $\mathrm{GABA}_{\mathrm{A}} \mathrm{Rs}$. The binding affinity of TP003 is 
drastically reduced in $\alpha 2$ (H101R) receptors (Dias et al., 2005). TP003 absorbs well after i.p. injection. In rat, a $0.3 \mathrm{mg} / \mathrm{kg}$ i.p. injection resulted in $75 \%$ receptor occupancy in the brain (Dias et al., 2005). For TP003 systemic injection experiment, we used $2 \mathrm{mg} / \mathrm{kg}$ as the high dose. This dose was chosen based on a previous systemic injection study that found anxiolytic-like effects at $3 \mathrm{mg} / \mathrm{kg}$ dose for mice (Dias et al., 2005). In an initial experiment, we found robust anxiolytic-like effects at $2 \mathrm{mg} / \mathrm{kg}$ and even a $0.5 \mathrm{mg} / \mathrm{kg}$ dose in WT mice, thus we used $2 \mathrm{mg} / \mathrm{kg}$ as the high dose in our experiment. Presently, to the best of our knowledge, no studies have attempted microinjection of TP003 in the brain. For this reason, we chose to use a range of concentrations, which were comparable to that of zolpidem and L-838417 microinjections, for TP003 microinjection. This was based on our initial findings showing that TP003 had comparable dose response relationships to zolpidem and L-838417 at similar concentrations in systemic injection experiments as measured by the EPM.

\section{Vehicle}

Due to the poor solubility of many drugs used in this study in aqueous solutions, several vehicles were used to accommodate the doses required for particular experiments. For systemic injection and intra-BLA microinjection of selective drugs, the compounds were dissolved in a vehicle consisting of $10 \%$ DMSO and $20 \%$ cyclodextrin in $0.85 \%$ saline. For systemic injection of CDP, the drug was dissolved in $0.85 \%$ saline. For intraBLA microinjection of CDP, most groups received drugs dissolved in a vehicle consisting of $10 \%$ DMSO in $0.85 \%$ saline, except for the $\alpha 2$ (H101R) mice groups, where half of the mice (balanced numbers across treatment groups) received drugs dissolved in a vehicle consisting of $10 \%$ DMSO and $20 \%$ cyclodextrin in $0.85 \%$ saline during a transition period.

\section{Injection Procedures}

For the systemic injection experiments, drug solutions were delivered via i.p. injection $30 \mathrm{~min}$ before the EPM test (described below). For microinjection experiments, $0.3 \mu \mathrm{L}$ of drug solution was delivered gradually over the course of 30 seconds using a $5 \mu \mathrm{L}$ Hamilton syringe connected to a 33 gauge microinjector (PlasticOne, Roanoke, VA) manually. The injector was left in the cannula for $1 \mathrm{~min}$ after each injection to reduce backflow of injected solution. After completing bilateral microinjection, the animal was returned to a holding cage for 5-8 min before being tested on the EPM.

\section{Elevated Plus Maze}

The EPM is a widely used test apparatus for measuring anxiety-related behaviors in rodents (Pellow \& File, 1986). The apparatus used in this study had transparent plexiglass for the walls and opaque plexiglass for the floor. The dimensions of the maze are illustrated in Figure 3-1. The maze was located in a dedicated behavioral testing 


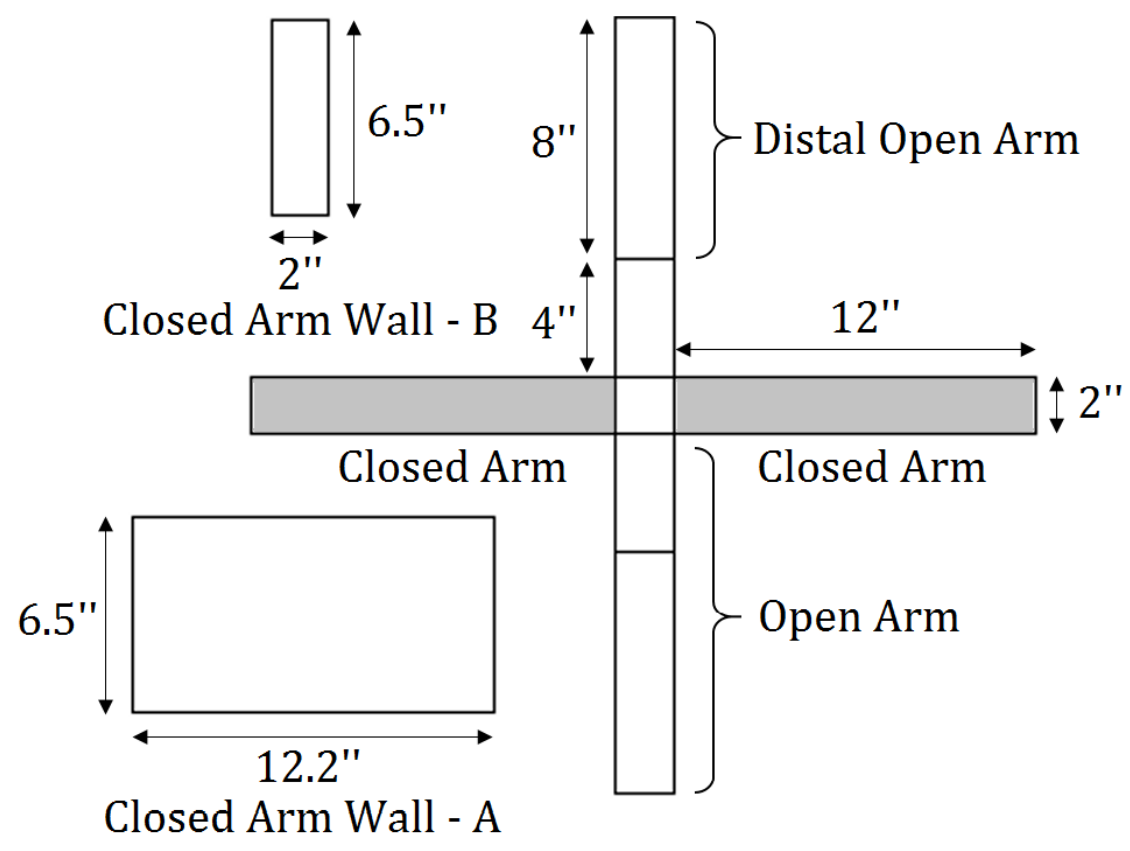

Figure 3-1. Illustration of the Dimension of EPM Apparatus Used in This Study.

Schematic drawing of the dimensions of the elevated plus maze (EPM) apparatus. The closed arm walls were constructed using transparent plexiglass, and the floor of the maze was constructed using opaque material 
room and was illuminated with dim ambient light from the ceiling. The experimenter was located behind a curtain and was invisible to the mice during the test. Video was recorded during the test ( 5 min duration) with an overhead camera and the movement of the subject was tracked by ANY-Maze software (Stoelting, Wood Dale, IL).

Rodents generally have a native aversion to the open and elevated spaces where they are exposed to the surrounding open environment, and thigmotaxis (in this case, the tendency to remain in close proximity to the walls of the closed arm) is typically observed (Filgueiras, Carvalho-Netto, \& Estanislau, 2014). Anxiety-like behavior is traditionally measured by preference for the closed arm over the open arm. Classic anxiolytic drugs, such as BZs, reportedly reduce an animal's aversion to the open arm, e.g. (K. S. Smith et al., 2012). On the other hand, traumatic events, such as exposure to immobilization stress, typically enhance the aversion to the open arm (Viswanatha, Shylaja, Sandeep Rao, Santhosh Kumar, \& Jagadeesh, 2012).

We measured the commonly reported EPM parameters including the percentage of time in the open arm, the percentage of open arm entry, and the distance traveled during the test. We also recorded several parameters that are not often reported in the EPM tests. First, we observed a subtle difference in the animal's behavior in the proximal open arm (where they could quickly flee and hide in the closed arm) as opposed to the distal open arm (where they were far away from their "safe zone" and were highly exposed to the surrounding open environment), we collected the time the animal spent in and the entry to the distal open arm as more sensitive measurements of anxiety-like behaviors. Second, as we consistently observed the animals' risk-assessing behavior characterized by extending their head outside the edge of the open arm to investigate the surrounding environment, we counted the number of such investigatory behaviors (head dips) as an index of risk assessment by the subject. Of note, the parameter "head dips" was operationally defined here as the incidences where the animal extended its head over the edge of the open arm, rather than as downward movements of the head. Our pilot data showed a clear increase of this behavior in BZ-treated mice. Together, the EPM test gave us both the traditional measurements of anxiety in addition to some potentially more sensitive measurements of the animal's subtle behaviors on the maze, and allowed us to reliably quantify the effects of drug treatment on anxiety-like behaviors.

To score the activities in the open or closed arm, the software tracked the animal's entire body area to effectively reducing the spurious counts of entry/exit when the animal hesitantly moved its body around the boundary of the center zone. To count an entry, $80 \%$ of the animals' body must enter an open or closed arm. To count an exit, the animal must fail to retain $70 \%$ of its body in an open or closed arm. For activities in the distal open arm, the software tracked the center of the animal's body. For counting head dips, the software tracked the head of the animal. An example of the animal's behavior on the EPM with or without BZ treatment is illustrated in Figure 3-2 as an occupancy plot heatmap.

Based on an initial assessment, we found that many of the parameters collected during the EPM task were correlated with each other. For the clarity of the data 


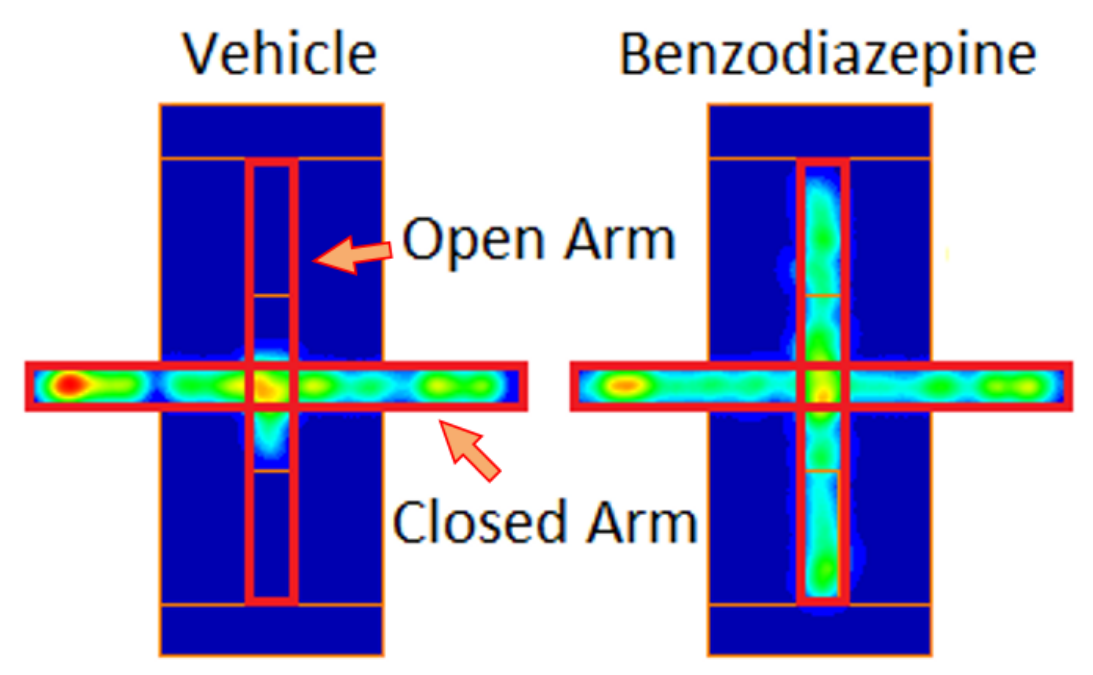

Figure 3-2. Illustration of the Effects of BZ on Animals Behavior on the EPM

Typical occupancy plot heat-maps of animals' behavior on the elevated plus maze (EPM) with or without benzodiazepine (BZ) treatment. BZ treatment increased the animals' activity on the open arm (O.A.). 
presentation we reported the following parameters as the main indicators of the animal's behavior on the EPM: percentage of time in the open arm (\% O.A. Time), percentage of open arm entry (\% O.A. Entry), number of head dips (Head Dips), and overall distance travelled on the EPM (Distance). The first three measurements are indicators of the anxiety level and the investigatory behaviors of the subject. The fourth measurement is an indicator of the motor activity of the subject. Descriptive statistics of other dependent measures such as distal open arm (D.O.A) Time and number of D.O.A. Entry were presented in tables.

\section{Data Evaluation and Reduction}

After behavioral testing, animals were euthanized and 1\% Evan's blue dye solution $(0.3 \mu \mathrm{L})$ was microinjected via the guide cannula. Brains were rapidly collected, frozen over dry ice, and coronally sectioned on a cryostat to verify cannula placement. A typical spread of dye is illustrated in Figure 3-3. The whole brain images were taken with a Olympus BX50 microscope (Olympus, Center Valley, PA), stitched together using the Stitching plugin, and background subtracted using Fiji (Preibisch, Saalfeld, \& Tomancak, 2009; Schindelin et al., 2012; Schneider, Rasband, \& Eliceiri, 2012).

Subjects with misplaced cannula, as identified by the spread of the dye and the imprint left by the cannula, were subsequently excluded prior to data analysis (13 out of 204 mice in the intra-BLA microinjection experiments). In most cases, excluded animals had off-target injection sites that showed significant dye diffusion or cannula tract imprint in the CeA, cortex, or ventricle.

The EPM is a locomotion-dependent task (Reynolds, McKernan, \& Dawson, 2001), and the accurate measurement of anxiety-like indexes, especially the \% O.A. Entry, depends on adequate locomotion of the animal on the maze for reliable calculation. The average distance traveled during the 5 minutes test period across all subjects was $9.4 \pm 0.2$ meters (mean \pm SEM). Subjects who traveled less than 2 meters during the $5 \mathrm{~min}$ test period, which occurred rarely (2\%), were excluded from statistical analysis. In most cases, these animals traveled a short distance after placement in the EPM, and remained immobile for the remainder of the test session. An exception to this rule was allowed for the experiments with zolpidem, in which we also planned to examine the anticipated relationship between anxiety and sedation prior to the experiment. In addition, animals that fell off the maze during the test were excluded from the study. Finally, a few animals were excluded from analysis due to malfunction of the video tracking software. In total, 9 out of 204 mice in intra-BLA microinjection experiment and 6 out of 345 mice in systemic injection experiment were excluded because of either immobility, displacement from the maze, or tracking problems. 


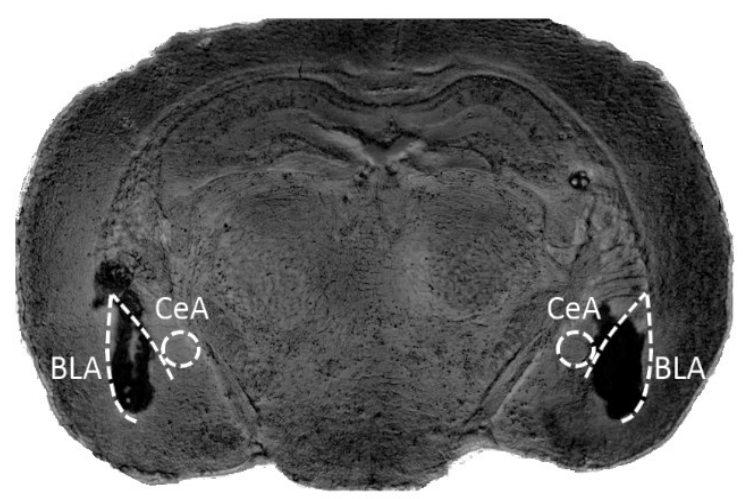

Figure 3-3. Illustration of Bilateral Dye Injection Showing the Injection Sites

A typical dye injection result showing successful bilateral microinjections targeting the basolateral amygdala (BLA), while sparing the central nucleus (CeA). 


\section{Statistical Analysis}

For all experiments, a one-way analysis of variance (one-way ANOVA) with \% O.A. Time, \% O.A. Entry, Head Dips, and Distance as dependent variables and dose of the drug as the independent variable were performed to assess the overall differences among groups. Dunnett's post hoc multiple comparison test (Dunnett, 1955, 1964) was used to compare drug injected groups against the vehicle injected group to assess the effects of drug treatment at a particular dose. For the systemic injection of CDP experiment, because both males and females were used, two-way analysis of variance (two-way ANOVA) with \% O.A. Time, \% O.A. Entry, Head Dips, and Distance as dependent variables and dose and sex as independent variables was performed to assess the overall effects of sex and drug treatment. One-way ANOVA and Dunnett's post hoc test, as described above, were subsequently performed within each sex group. The $\alpha-$ value of significance was set at 0.05 for both ANOVA and Dunnett's test. In all of the figures, data were reported as means \pm SEM. Asterisks represent significant differences between the vehicle injected control group and the drug injected experimental groups as assessed by post hoc Dunnett's comparisons, unless stated otherwise. ${ }^{*} p<0.05$; ${ }^{*} p<$ $0.01 ; * * * p<0.001$. 


\section{CHAPTER 4. RESULTS}

\section{Systemic Injection of Selective GABAAR PAMs}

To assess the differential roles of each $\mathrm{GABA}_{\mathrm{A}} \mathrm{R}$ subtype in mediating BZinduced anxiolysis on the systemic level, subtype selective $\mathrm{GABA}_{\mathrm{A}} \mathrm{R}$ PAMs were acutely administered to both adult male C57BL/6J mice and several strains of point mutant mice via systemic (i.p.) injection. The effects of the drugs on anxiety-like behaviors and motor activities were assessed by the EPM test.

\section{Systemic Injection of Zolpidem in WT C57BL/6J Mice}

To assess the role $\alpha 1$-subtype GABA ${ }_{A}$ Rs play in mediating anxiolysis, WT C57BL/6J mice were given an i.p injection of the $\alpha 1$-subtype selective PAM, zolpidem, at one of the following doses: $0.25 \mathrm{mg} / \mathrm{kg}, 0.5 \mathrm{mg} / \mathrm{kg}, 1 \mathrm{mg} / \mathrm{kg}$, or $2 \mathrm{mg} / \mathrm{kg}$. Mice were tested on the EPM 30 min post-injection. The results are shown in Figure 4-1. One-way ANOVA with dose as the independent variable revealed significant effects of zolpidem on the dependent variables of \% O.A. Entry, Head Dips, and Distance traveled on the EPM, $F \mathrm{~s}(4,35)>4.15, p \mathrm{~s}<0.01$. No significant effect of zolpidem was found on the $\%$ O.A. Time, $F(4,35)=2.39, p=0.07$. Dunnett's comparisons revealed zolpidem exerted anxiolytic-like effects as measured by significantly increased $\%$ O.A. Entry at $0.5 \mathrm{mg} / \mathrm{kg}$ and $1 \mathrm{mg} / \mathrm{kg}$ doses $(p \mathrm{~s}<0.05)$. Zolpidem also exerted significant motor-inhibiting effects as measured by significantly reduced distance traveled on the EPM at $1 \mathrm{mg} / \mathrm{kg}$ and $2 \mathrm{mg} / \mathrm{kg}$ doses $(p \mathrm{~s}<0.05)$. Further, zolpidem significantly reduced the Head Dips at $2 \mathrm{mg} / \mathrm{kg}$ dose $(p<0.05)$, which was likely an effect correlated with motor inhibition. A total of 40 mice were included in this experiment $(V e h, n=12 ; 0.25 \mathrm{mg} / \mathrm{kg}, \mathrm{n}=8 ; 0.5 \mathrm{mg} / \mathrm{kg}$, $\mathrm{n}=7 ; 1 \mathrm{mg} / \mathrm{kg}, \mathrm{n}=7$; and $2 \mathrm{mg} / \mathrm{kg}, \mathrm{n}=6$ ).

\section{Systemic Injection of L-838417 in WT C57BL/6J Mice}

To assess the that role $\alpha 2-, \alpha 3-$, (and $\alpha 5-$ ) subtype $\mathrm{GABA}_{\mathrm{A}} \mathrm{Rs}$ play in mediating anxiolysis, WT C57BL/6J mice were given an i.p. injection of the $\alpha 2-$-, $\alpha 3-$, (and $\alpha 5-$ ) subtype selective PAM, L-838417, at one of the following doses: $0.5 \mathrm{mg} / \mathrm{kg}$, or $2 \mathrm{mg} / \mathrm{kg}$. Mice were tested on the EPM 30 min post-injection. The results are shown in Figure 4-2. One-way ANOVA with dose as the independent variable revealed significant effects of L-838417 on the dependent variables of \% O.A. Time, \% O.A. Entry, Head Dips, and Distance traveled on the EPM, $F \mathrm{~s}(2,24)>11.81, p \mathrm{~s}<0.001$. Dunnett's comparisons revealed L-838417 exerted anxiolytic-like effects as measured by significantly increased $\%$ O.A. Time and \% O.A. Entry at $0.5 \mathrm{mg} / \mathrm{kg}$ and $2 \mathrm{mg} / \mathrm{kg}$ doses $(p \mathrm{~s}<0.001)$. L- 838417 significantly increased the Head Dips at $0.5 \mathrm{mg} / \mathrm{kg}$ and $2 \mathrm{mg} / \mathrm{kg}$ doses $(p<0.001)$. Further, L-838417 exerted significant motor-stimulating effects as measured by significantly increased distance traveled on the EPM at $0.5 \mathrm{mg} / \mathrm{kg}$ and $2 \mathrm{mg} / \mathrm{kg}$ doses $(p \mathrm{~s}<0.01)$. A 


\section{A}

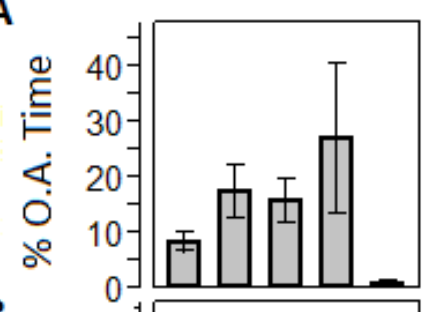

B

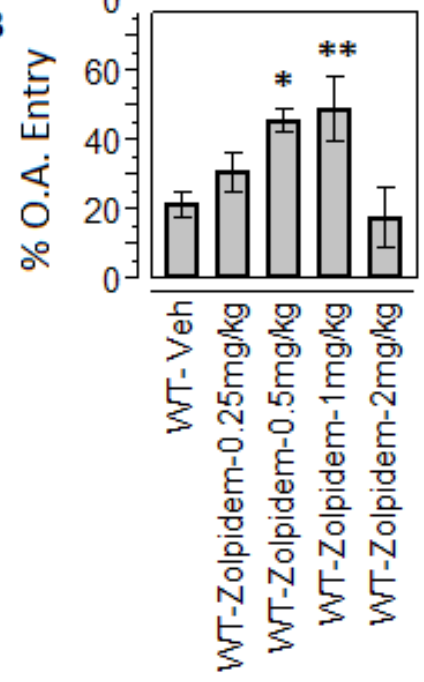

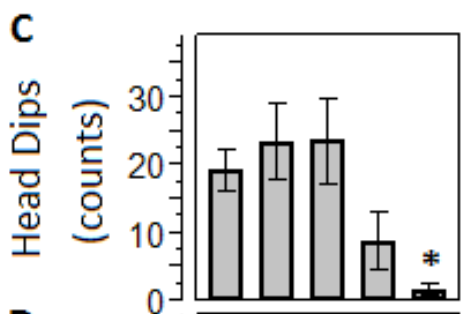

D

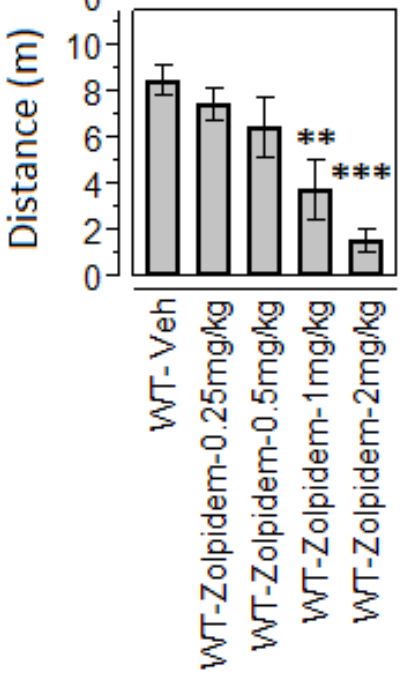

Figure 4-1. Systemic Injection of Zolpidem in WT C57BL/6J Mice

Anxiety-like and locomotor behaviors following drug treatment as assessed by elevated plus maze (EPM) test. (A): percentage of time spent on the open arm (\% O.A. Time). (B): percentage of entry to the open arm (\% O.A. Entry). (C): counts of incidences where the animal extended its head over the edge of the open arm (Head Dips). (D): total distance traveled on the EPM. Asterisks represent significant differences between the vehicle injected control group and the drug injected experimental groups as assessed by ANOVA followed by post hoc Dunnett's comparisons against vehicle (Veh) injected group. ${ }^{*} p<$ $0.05 ; * *<0.01 ; * * * p<0.001$. 
A

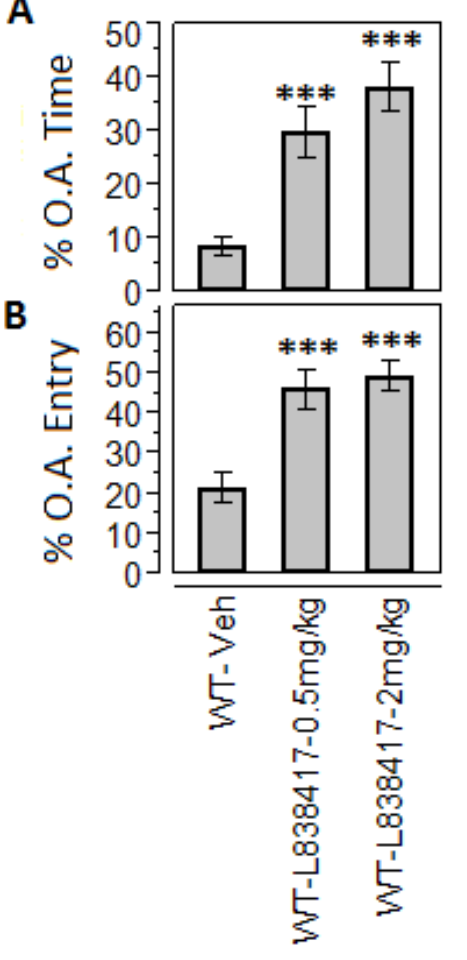

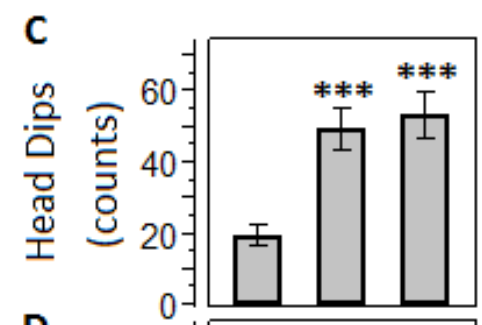

D

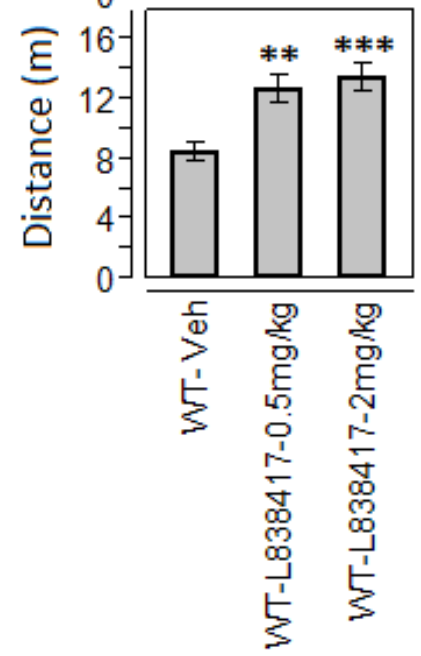

\section{Figure 4-2. Systemic Injection of L-838417 in WT C57BL/6J Mice}

Anxiety-like and locomotor behaviors following drug treatment as assessed by elevated plus maze (EPM) test. (A): percentage of time spent on the open arm (\% O.A. Time). (B): percentage of entry to the open arm (\% O.A. Entry). (C): counts of incidences where the animal extended its head over the edge of the open arm (Head Dips). (D): total distance traveled on the EPM. Asterisks represent significant differences between the vehicle injected control group and the drug injected experimental groups as assessed by ANOVA followed by post hoc Dunnett's comparisons against vehicle (Veh) injected group. ${ }^{*} p<$ $0.01 ; * * * p<0.001$. 
total of 27 mice were included in this experiment (Veh, $\mathrm{n}=12 ; 0.5 \mathrm{mg} / \mathrm{kg}, \mathrm{n}=7$; and $2 \mathrm{mg} / \mathrm{kg}, \mathrm{n}=8)$.

\section{Systemic Injection of L-838417 in $\alpha 3(\mathrm{H126R})$ Mice}

To assess the role $\alpha 2-$ (and $\alpha 5-$ ) subtype $\mathrm{GABA}_{\mathrm{A}} \mathrm{Rs}$ play in mediating anxiolysis, $\alpha 3(\mathrm{H} 126 \mathrm{R})$ mice were given an i.p. injection of L-838417 at one of the following doses: $0.5 \mathrm{mg} / \mathrm{kg}, 2 \mathrm{mg} / \mathrm{kg}$. Mice were tested on the EPM $30 \mathrm{~min}$ post-injection. The results are shown in Figure 4-3. One-way ANOVA with dose as the independent variable revealed no significant effect on the dependent variables of \% O.A. Time, \% O.A. Entry, Head Dips, or Distance traveled, $F \mathrm{~s}(2,22)<3.28, p>0.05$. No post hoc Dunnett's test was performed. A total of 25 mice were included in this experiment (Veh, $\mathrm{n}=11 ; 0.5 \mathrm{mg} / \mathrm{kg}$, $\mathrm{n}=7$; and $2 \mathrm{mg} / \mathrm{kg}, \mathrm{n}=7$ ).

\section{Systemic Injection of TP003 in C57BL/6J Mice}

To assess the role the $\alpha 3$-subtype GABA $\mathrm{A}_{\mathrm{R}}$ s play in mediating anxiolysis, C57BL/6J mice were given an i.p. injection of the $\alpha 3$-subtype selective PAM, TP003, at one of the following doses: $0.5 \mathrm{mg} / \mathrm{kg}$, or $2 \mathrm{mg} / \mathrm{kg}$. Mice were tested on the EPM $30 \mathrm{~min}$ post-injection. The results are shown in Figure 4-4. One-way ANOVA with dose as independent variable revealed significant effects of TP003 on the dependent variables of $\%$ O.A. Time, \% O.A. Entry, Head Dips, and Distance traveled on the EPM, $F_{\mathrm{s}}(2,23)>$ $5.54, p \mathrm{~s}<0.05$. Dunnett's comparisons revealed TP003 exerted anxiolytic-like effects as measured by significantly increased \% O.A. Time and \% O.A. Entry at $0.5 \mathrm{mg} / \mathrm{kg}$ and $2 \mathrm{mg} / \mathrm{kg}$ doses $(p \mathrm{~s}<0.001)$. TP003 significantly increased the Head Dips at $0.5 \mathrm{mg} / \mathrm{kg}$ and $2 \mathrm{mg} / \mathrm{kg}$ doses $(p s<0.05)$. TP003 also exerted motor-stimulating effects as measured by significantly increased distance traveled on the EPM at $0.5 \mathrm{mg} / \mathrm{kg}$ dose $(p<0.01)$. A total of 26 mice were included in this experiment (Veh, $\mathrm{n}=12 ; 0.5 \mathrm{mg} / \mathrm{kg}, \mathrm{n}=7$; and $2 \mathrm{mg} / \mathrm{kg}$, $\mathrm{n}=7$ ).

\section{Systemic Injection of Zolpidem in $\alpha 1($ H101R) Mice}

To assess the selectivity of zolpidem towards $\alpha 1$-subtype $\mathrm{GABA}_{\mathrm{A}} \mathrm{Rs}, \alpha 1(\mathrm{H} 101 \mathrm{R})$ mice were given an i.p. injection of zolpidem at one of the following doses: $1 \mathrm{mg} / \mathrm{kg}$, or $2 \mathrm{mg} / \mathrm{kg}$. As demonstrated previously, the dose $1 \mathrm{mg} / \mathrm{kg}$ elicited anxiolytic-like effects in $\mathrm{C} 57 \mathrm{BL} / 6 \mathrm{~J}$ mice, while the dose $2 \mathrm{mg} / \mathrm{kg}$ elicited motor-inhibiting effects. Mice were tested on the EPM 30 min post-injection. The results are shown in Figure 4-5. One-way ANOVA with dose as the independent variable revealed no significant effects of zolpidem on the dependent variables of \% O.A. Time, \% O.A. Entry, Head Dips, and Distance traveled on the EPM, $F \mathrm{~s}(2,19)<2.07, p \mathrm{~s}>0.1$. This indicated that the zolpidem lost its effects in $\alpha 1(\mathrm{H} 101 \mathrm{R})$ mice, and supported the hypothesis that the effects of zolpidem seen in WT mice were indeed mediated by the $\alpha 1$-subtype GABAARs. A 
A

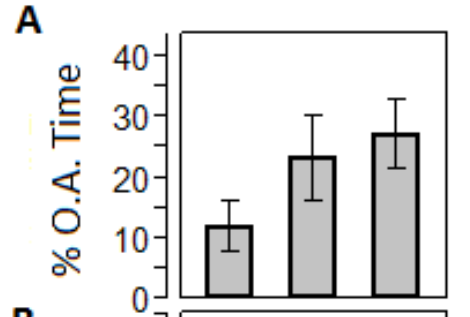

B

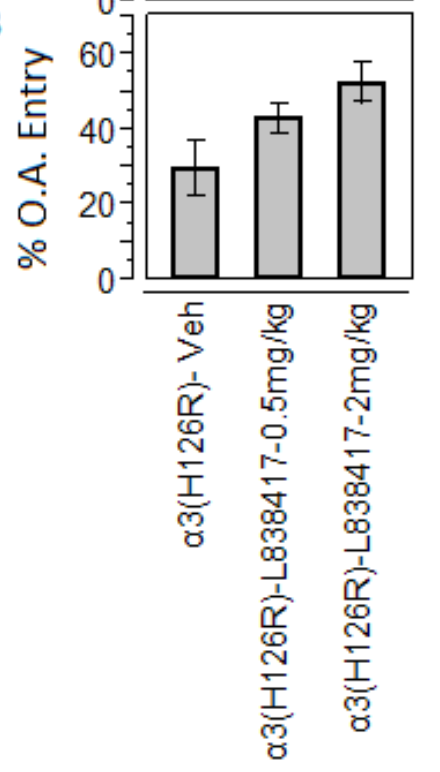

C

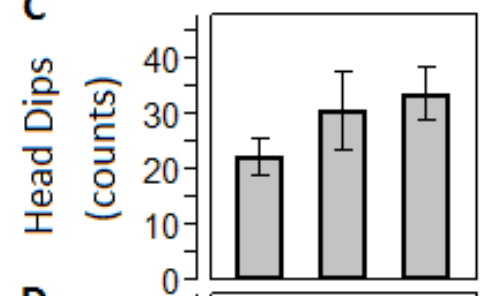

D

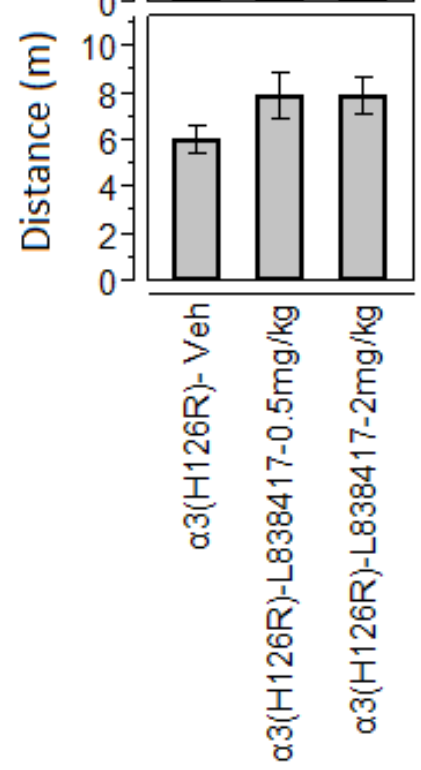

Figure 4-3. Systemic Injection of L-838417 in $\alpha 3(H 126 R)$ Mice

Anxiety-like and locomotor behaviors following drug treatment as assessed by elevated plus maze (EPM) test. (A): percentage of time spent on the open arm (\% O.A. Time). (B): percentage of entry to the open arm (\% O.A. Entry). (C): counts of incidences where the animal extended its head over the edge of the open arm (Head Dips). (D): total distance traveled on the EPM. 


\section{A}

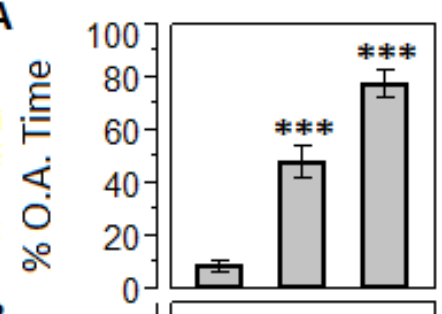

B

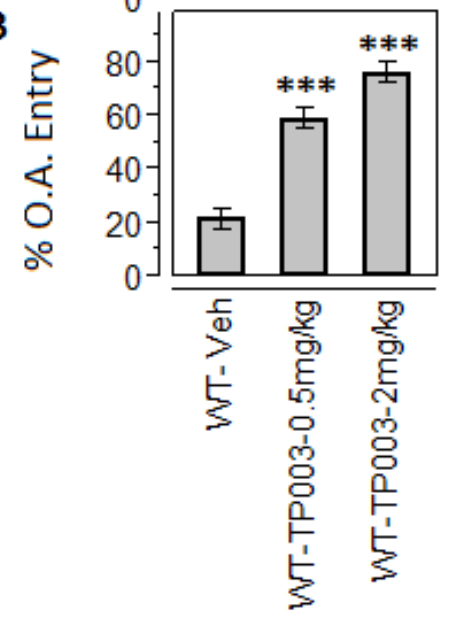

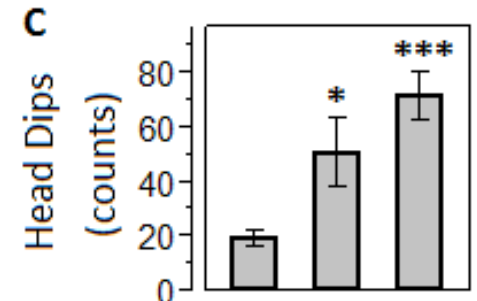

D

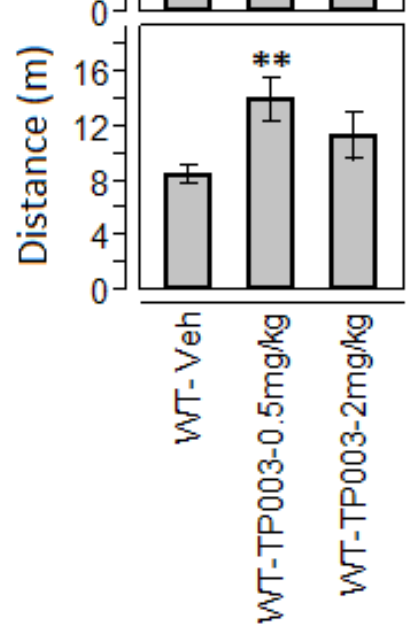

Figure 4-4. Systemic Injection of TP003 in WT C57BL/6J Mice

Anxiety-like and locomotor behaviors following drug treatment as assessed by elevated plus maze (EPM) test. (A): percentage of time spent on the open arm (\% O.A. Time). (B): percentage of entry to the open arm (\% O.A. Entry). (C): counts of incidences where the animal extended its head over the edge of the open arm (Head Dips). (D): total distance traveled on the EPM. Asterisks represent significant differences between the vehicle injected control group and the drug injected experimental groups as assessed by ANOVA followed by post hoc Dunnett's comparisons against vehicle (Veh) injected group. ${ }^{*} p<$ $0.05 ; * *<0.01 ; * * * p<0.001$. 
A

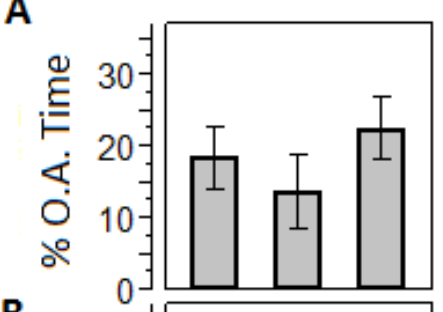

B

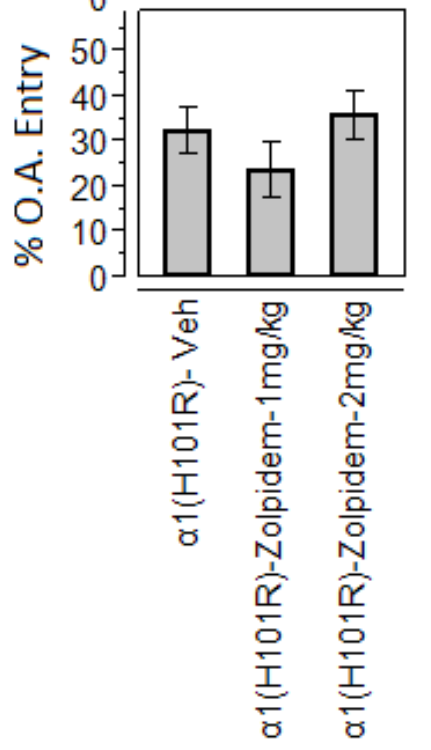

C

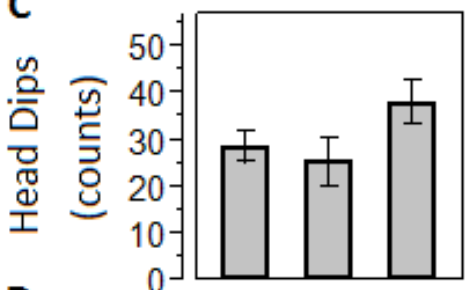

D

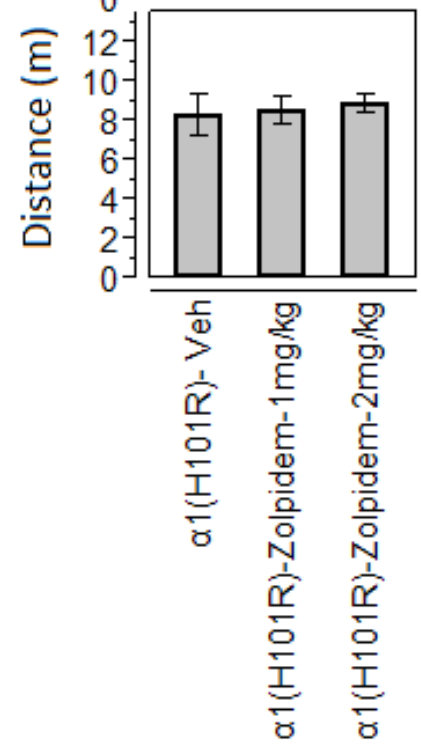

\section{Figure 4-5. Systemic Injection of Zolpidem in a1(H101R) Mice}

Anxiety-like and locomotor behaviors following drug treatment as assessed by elevated plus maze (EPM) test. (A): percentage of time spent on the open arm (\% O.A. Time). (B): percentage of entry to the open arm (\% O.A. Entry). (C): counts of incidences where the animal extended its head over the edge of the open arm (Head Dips). (D): total distance traveled on the EPM. 
total of 22 mice were included in this experiment (Veh, $\mathrm{n}=7 ; 1 \mathrm{mg} / \mathrm{kg}, \mathrm{n}=8$; and $2 \mathrm{mg} / \mathrm{kg}$, $\mathrm{n}=7)$.

\section{Systemic Injection of TP003 in $\alpha 2(\mathrm{H} 101 \mathrm{R})$ and $\alpha 3(\mathrm{H} 126 \mathrm{R})$ Mice}

To assess the selectivity of TP003 towards $\alpha 3$-subtype GABA ${ }_{A} R s, \alpha 2(\mathrm{H} 101 \mathrm{R})$ and $\alpha 3$ (H126R) mice were given an i.p. injection of TP003 at $2 \mathrm{mg} / \mathrm{kg}$ dosage. As demonstrated previously, this dose elicited prominent anxiolytic-like effects in WT C57BL/6J mice. Mice were tested on the EPM 30 min post-injection. The results are shown in Figure 4-6. Two-tailed $t$-test comparisons revealed significant effects of TP003 treatment on the dependent variables of \% O.A. Time, \% O.A. Entry, Head Dips, and Distance traveled on the EPM in $\alpha 2(\mathrm{H} 101 \mathrm{R})$ mice, $p$ s $<0.05$. No significant effect of TP003 was found on \% O.A. Time, \% O.A. Entry, or Head Dips in $\alpha 3$ (H126R) mice. However, a significant effect of TP003 on Distance traveled on the EPM was found ( $p<$ $0.05)$. Taken together, these data suggested that TP003 lost its anxiolytic-like effects in $\alpha 3(\mathrm{H} 126 \mathrm{R})$ mice but retained its anxiolytic-like effects in $\alpha 2(\mathrm{H} 101 \mathrm{R})$, and indicated that the anxiolytic-like effects were indeed mediated by $\alpha 3$-subtype $\mathrm{GABA}_{\mathrm{A}} \mathrm{Rs}$. Asterisks represented significant difference between the vehicle injected control group and the drug injected experimental group within each strain as assessed by two-tailed $t$-tests. A total of 35 mice were included in this experiment, [ $\alpha 2(\mathrm{H} 101 \mathrm{R})-\mathrm{Veh}, \mathrm{n}=8 ; \alpha 2(\mathrm{H} 101 \mathrm{R})-2 \mathrm{mg} / \mathrm{kg}$, $\mathrm{n}=8 ; \alpha 3(\mathrm{H} 126 \mathrm{R})-\mathrm{Veh}, \mathrm{n}=11$; and $\alpha 3(\mathrm{H} 126 \mathrm{R})-2 \mathrm{mg} / \mathrm{kg}, \mathrm{n}=8]$. ${ }^{*} p<0.05 ;{ }^{* *} p<0.01$; NS: non-significant.

\section{Systemic Injection of Selective GABA $\mathrm{A}$ PAMs - Other Parameters}

Besides the parameters reported in the figures, descriptive statistics were obtained for several other parameters, including the distance traveled on the open arm and closed arm, respectively (O.A. Distance, C.A. Distance), time and entry to the distal open arm (D.O.A. Time, D.O.A. Entry), as well as the time animal spent in the center zone (Center Time) during the EPM experimentation, are summarized in Table 4-1.

\section{Systemic Injection of Non-Selective CDP in Point Mutant Mice}

To assess the effects of the non-selective BZ drug, CDP, on anxiety-like behaviors, CDP was administered to both $\mathrm{C} 57 \mathrm{BL} / 6 \mathrm{~J}$ mice and three strains of point mutant mice $\alpha 1(\mathrm{H} 101 \mathrm{R}), \alpha 2(\mathrm{H} 101 \mathrm{R})$, and $\alpha 3(\mathrm{H} 126 \mathrm{R})$, via systemic (i.p.) injection. The effects of the drug on anxiety-like behaviors and motor activities were assessed by the EPM test. For this experiment, both males and females were used and were analyzed separately. 
A

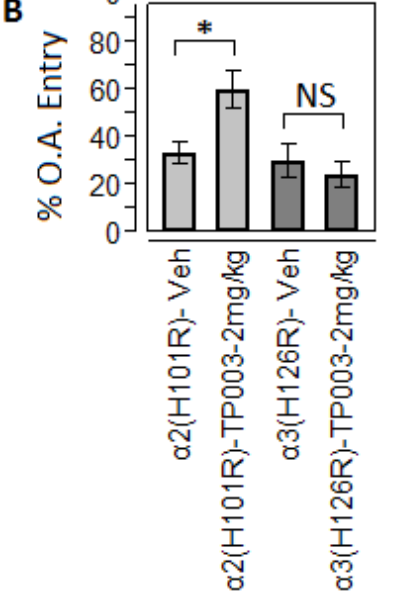

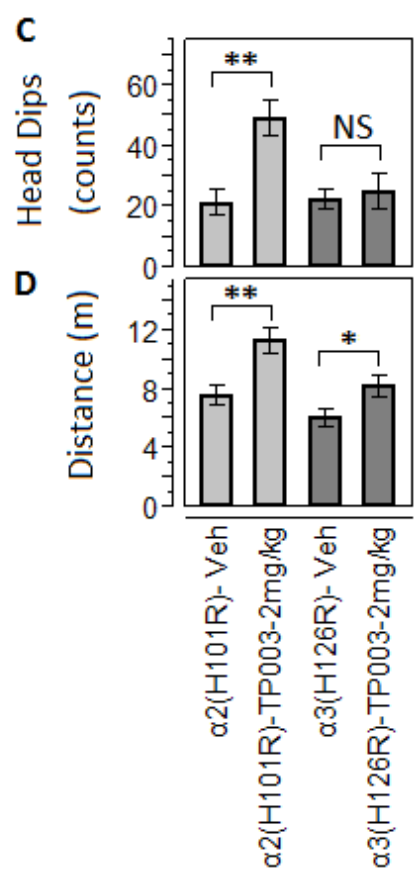

Figure 4-6. Systemic Injection of TP003 in $\alpha 2(H 101 R)$ and $\alpha 3(H 126 R)$ Mice

Anxiety-like and locomotor behaviors following drug treatment as assessed by elevated plus maze (EPM) test. (A): percentage of time spent on the open arm (\% O.A. Time). (B): percentage of entry to the open arm (\% O.A. Entry). (C): counts of incidences where the animal extended its head over the edge of the open arm (Head Dips). (D): total distance traveled on the EPM. Asterisks represented significant difference between the vehicle injected control group and the drug injected experimental group within each strain as assessed by two-tailed $t$-test. ${ }^{*} p<0.05$; $* * p 0.01$; NS: non-significant. 
Table 4-1. Systemic Injection of Selective GABAAR PAMs - Descriptive Statistics of Other Parameters

\begin{tabular}{|c|c|c|c|c|c|c|}
\hline Treatment & $\mathrm{N}$ & O.A. Distance (m) & C.A. Distance (m) & D.O.A. Time (s) & D.O.A. Entry & Center Time (s) \\
\hline WT- Veh & 12 & $0.56 \pm 0.16$ & $6.1 \pm 0.44$ & $6.6 \pm 2.61$ & $0.83 \pm 0.32$ & $45.3 \pm 6.08$ \\
\hline WT-L $838417-0.5 \mathrm{mg} / \mathrm{kg}$ & 7 & $2.69 \pm 0.66$ & $7.35 \pm 0.55$ & $29.86 \pm 8.71$ & $5.43 \pm 1.53$ & $49.79 \pm 7.44$ \\
\hline WT-L $838417-2 \mathrm{mg} / \mathrm{kg}$ & 8 & $4.14 \pm 0.71$ & $6.84 \pm 0.61$ & $54.88 \pm 8.95$ & $9.38 \pm 1.81$ & $39.08 \pm 5.59$ \\
\hline WT-TP003-0.5mg $/ \mathrm{kg}$ & 7 & $4.36 \pm 0.99$ & $6.52 \pm 0.56$ & $57.87 \pm 11.95$ & $9.43 \pm 2.1$ & $48.86 \pm 9.28$ \\
\hline WT-TP003-2mg $/ \mathrm{kg}$ & 7 & $6.1 \pm 1.2$ & $3.07 \pm 0.63$ & $126.57 \pm 20.67$ & $13 \pm 2.23$ & $21.61 \pm 3.87$ \\
\hline WT-Zolpidem- $0.25 \mathrm{mg} / \mathrm{kg}$ & 8 & $1.45 \pm 0.4$ & $4.41 \pm 0.27$ & $18.6 \pm 5.14$ & $3.38 \pm 1.03$ & $56.93 \pm 9.79$ \\
\hline WT-Zolpidem- $0.5 \mathrm{mg} / \mathrm{kg}$ & 7 & $0.96 \pm 0.3$ & $3.94 \pm 0.81$ & $14.2 \pm 5.86$ & $1.57 \pm 0.69$ & $54.41 \pm 10.95$ \\
\hline WT-Zolpidem- $1 \mathrm{mg} / \mathrm{kg}$ & 7 & $0.66 \pm 0.3$ & $2.31 \pm 0.81$ & $7.69 \pm 4.19$ & $1.14 \pm 0.59$ & $62.23 \pm 38.05$ \\
\hline WT-Zolpidem- $2 \mathrm{mg} / \mathrm{kg}$ & 6 & $0.1 \pm 0.05$ & $1.02 \pm 0.42$ & $0 \pm 0$ & $0 \pm 0$ & $60.32 \pm 46.68$ \\
\hline$\alpha 1(\mathrm{H} 101 \mathrm{R})-\mathrm{Veh}$ & 7 & $0.85 \pm 0.34$ & $5.56 \pm 0.72$ & $15 \pm 7.37$ & $1.71 \pm 0.75$ & $59.41 \pm 5.58$ \\
\hline$\alpha 1(\mathrm{H} 101 \mathrm{R})-Z$ olpidem-1mg/kg & 8 & $0.46 \pm 0.2$ & $6.44 \pm 0.69$ & $8.84 \pm 6.71$ & $1.25 \pm 0.77$ & $40.09 \pm 4.96$ \\
\hline$\alpha 1(\mathrm{H} 101 \mathrm{R})-Z$ olpidem- $2 \mathrm{mg} / \mathrm{kg}$ & 7 & $1.28 \pm 0.38$ & $5.65 \pm 0.43$ & $27.09 \pm 8.26$ & $3.14 \pm 0.63$ & $54.91 \pm 2.92$ \\
\hline$\alpha 2(\mathrm{H} 101 \mathrm{R})-\mathrm{Veh}$ & 8 & $1.06 \pm 0.28$ & $5.2 \pm 0.49$ & $14.6 \pm 4.69$ & $2 \pm 0.65$ & $42.98 \pm 5.76$ \\
\hline$\alpha 2(\mathrm{H} 101 \mathrm{R})-\mathrm{TP} 003-2 \mathrm{mg} / \mathrm{kg}$ & 8 & $4.36 \pm 0.79$ & $4.81 \pm 0.6$ & $63.13 \pm 10.35$ & $9.38 \pm 1.88$ & $36.3 \pm 2.31$ \\
\hline$\alpha 3(\mathrm{H} 126 \mathrm{R})-\mathrm{Veh}$ & 11 & $0.45 \pm 0.17$ & $4.36 \pm 0.44$ & $6.95 \pm 3.56$ & $1 \pm 0.36$ & $47.15 \pm 6.89$ \\
\hline$\alpha 3(\mathrm{H} 126 \mathrm{R})-\mathrm{L} 838417-0.5 \mathrm{mg} / \mathrm{kg}$ & 7 & $1.57 \pm 0.54$ & $4.81 \pm 0.44$ & $22.91 \pm 11.27$ & $3.29 \pm 1.36$ & $58.31 \pm 9.4$ \\
\hline$\alpha 3(\mathrm{H} 126 \mathrm{R})-\mathrm{L} 838417-2 \mathrm{mg} / \mathrm{kg}$ & 7 & $2.18 \pm 0.42$ & $4.16 \pm 0.42$ & $34.93 \pm 8.1$ & $5.86 \pm 1.01$ & $42.21 \pm 6.71$ \\
\hline$\alpha 3(\mathrm{H} 126 \mathrm{R})-\mathrm{TP} 003-2 \mathrm{mg} / \mathrm{kg}$ & 8 & $0.4 \pm 0.18$ & $6.05 \pm 0.44$ & $2.56 \pm 1.25$ & $0.88 \pm 0.44$ & $35.64 \pm 4.92$ \\
\hline
\end{tabular}




\section{Systemic Injection of CDP in WT C57BL/6J Mice}

To assess the anxiolytic-like effects of CDP, C57BL/6J mice were given an i.p injection of CDP at one of the following doses: $5 \mathrm{mg} / \mathrm{kg}$, or $10 \mathrm{mg} / \mathrm{kg}$. Mice were tested on the EPM 30 min post-injection. The results are shown in Figure 4-7 and Figure 4-8. Two-way ANOVA with dose and sex as independent variables returned significant main effects of dose on the dependent variables of \% O.A. Time, \% O.A. Entry, and Head Dip, $F \mathrm{~s}(2,43)>14.14, p \mathrm{~s}<0.001$. No significant effect of dose was detected on the dependent variable of Distance, $F(2,43)=2.806, p=0.072$. No significant effect of sex or Sex $\times$ Dose interaction was detected, $p \mathrm{~s}>0.1$.

For males, one-way ANOVA with dose as independent variable revealed significant effects of CDP on the dependent variables of \% O.A. Time, \% O.A. Entry, and Head Dips, $F \mathrm{~s}(2,18)>5.29, p \mathrm{~s}<0.05$. No significant effect of CDP was detected on Distance traveled on the EPM, $F(2,18)=1.01, p>0.05$. Dunnett's comparisons revealed CDP exerted anxiolytic-like effects as measured by significantly increased \% O.A. Time at $10 \mathrm{mg} / \mathrm{kg}$ dose $(p<0.001)$ and $\%$ O.A. Entry at $5 \mathrm{mg} / \mathrm{kg}$ and $10 \mathrm{mg} / \mathrm{kg}$ doses $(p \mathrm{~s}<0.05)$. CDP significantly increased the Head Dips at $10 \mathrm{mg} / \mathrm{kg}$ dose $(p<0.01)$. A total of 21 mice were included in this experiment (Veh, $\mathrm{n}=8 ; 5 \mathrm{mg} / \mathrm{kg}, \mathrm{n}=6$; and $10 \mathrm{mg} / \mathrm{kg}, \mathrm{n}=7$ ).

For females, one-way ANOVA with dose as independent variable revealed significant effects of CDP on the dependent variables of \% O.A. Time, \% O.A. Entry, Head Dips, and Distance traveled on the EPM, $F_{\mathrm{S}}(2,25)>4.52, p \mathrm{~s}<0.05$. Dunnett's comparisons revealed CDP exerted anxiolytic-like effects as measured by significantly increased \% O.A. Time, \% O.A. Entry and Head Dips at $10 \mathrm{mg} / \mathrm{kg}$ dose $(p \mathrm{~s}<0.001)$. CDP also exerted motor-stimulating effects as measured by significantly increased distance traveled on the EPM at $10 \mathrm{mg} / \mathrm{kg}$ dose $(p<0.05)$. A total of 28 mice were included in this experiment (Veh, $\mathrm{n}=9 ; 5 \mathrm{mg} / \mathrm{kg}, \mathrm{n}=6$; and $10 \mathrm{mg} / \mathrm{kg}, \mathrm{n}=13$ ).

\section{Systemic Injection of CDP in $\alpha 1(\mathrm{H101R})$ Mice}

To assess the anxiolytic-like effects of CDP in mice expressing the BZ-insensitive $\alpha 1$-subtype GABA ${ }_{A} R s, \alpha 1(H 101 R)$ mice were given an i.p. injection of CDP at one of the following doses: $5 \mathrm{mg} / \mathrm{kg}$, or $10 \mathrm{mg} / \mathrm{kg}$. Mice were tested on the EPM $30 \mathrm{~min}$ postinjection. The results are shown in Figure 4-9 and Figure 4-10. Two-way ANOVA with dose and sex as independent variables returned significant main effects of dose on the dependent variables of \% O.A. Time, \% O.A. Entry, Head Dip, as well as Distance, $F \mathrm{~s}(2,41)>11.29, p \mathrm{~s}<0.001$. A significant main effect of sex on the dependent variable \% O.A. Time was also detected, $F(1,41)=8.00, p<0.01$. No significant Sex $\times$ Dose interaction was detected.

For males, one-way ANOVA with dose as independent variable revealed significant effects of CDP on the dependent variables of \% O.A. Entry, Head Dips, and Distance traveled on the EPM, $F_{\mathrm{S}}(2,20)>7.36, p \mathrm{~s}<0.01$. No significant effect of CDP was detected on the $\%$ O.A. Time, $F(2,20)=3.47, p=0.0507$. Dunnett's comparisons 
A

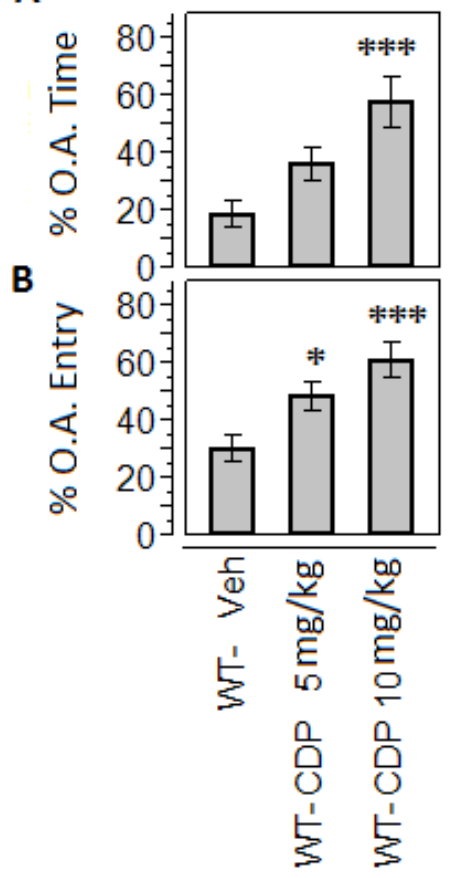

C

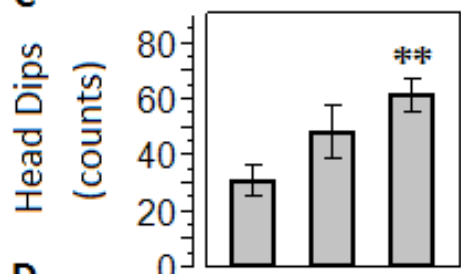

D

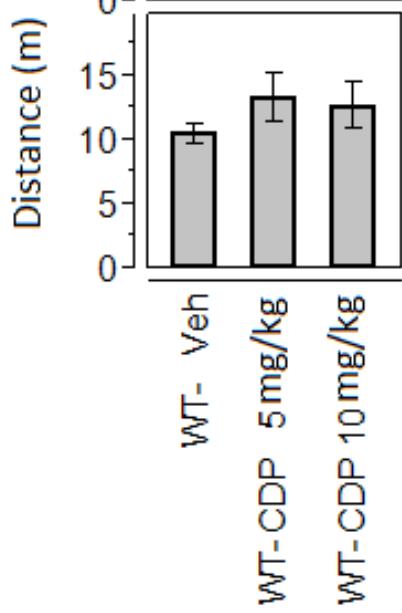

Figure 4-7. Systemic Injection of CDP in Male WT C57BL/6J Mice

Anxiety-like and locomotor behaviors following drug treatment as assessed by elevated plus maze (EPM) test. (A): percentage of time spent on the open arm (\% O.A. Time). (B): percentage of entry to the open arm (\% O.A. Entry). (C): counts of incidences where the animal extended its head over the edge of the open arm (Head Dips). (D): total distance traveled on the EPM. Asterisks represent significant differences between the vehicle injected control group and the drug injected experimental groups as assessed by ANOVA followed by post hoc Dunnett's comparisons against vehicle (Veh) injected group. ${ }^{*} p<$ 

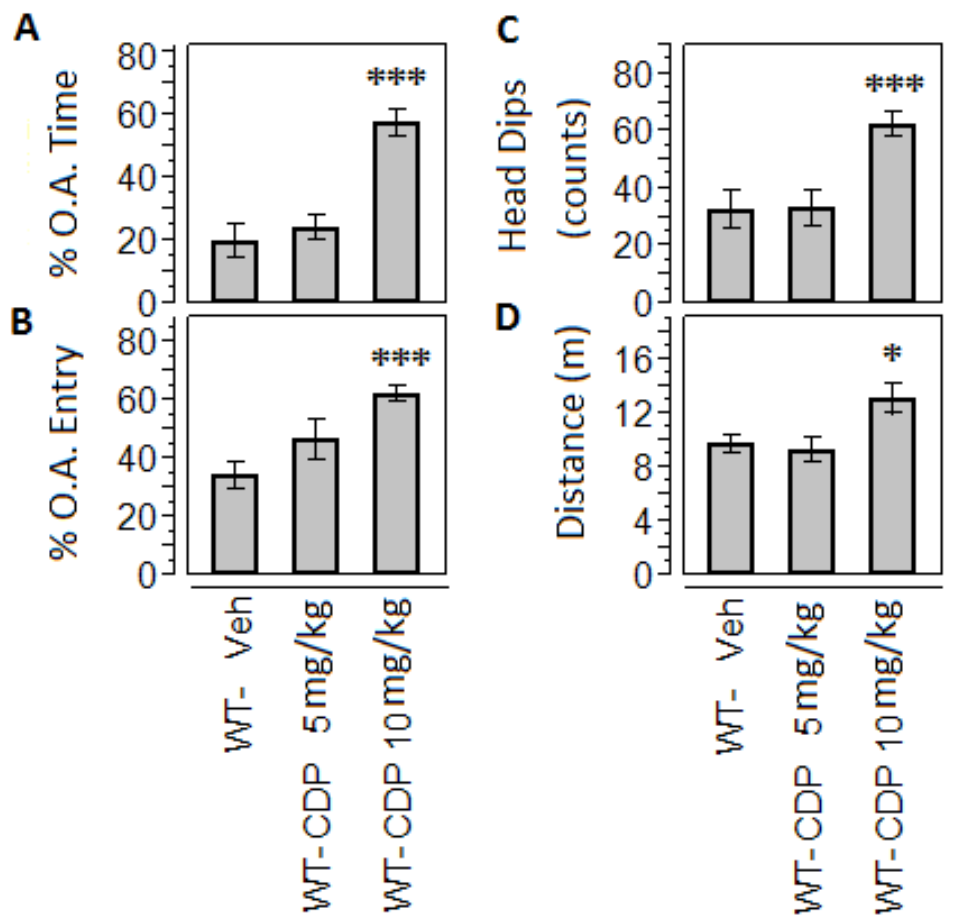

Figure 4-8. Systemic Injection of CDP in Female WT C57BL/6J Mice

Anxiety-like and locomotor behaviors following drug treatment as assessed by elevated plus maze (EPM) test. (A): percentage of time spent on the open arm (\% O.A. Time). (B): percentage of entry to the open arm (\% O.A. Entry). (C): counts of incidences where the animal extended its head over the edge of the open arm (Head Dips). (D): total distance traveled on the EPM. Asterisks represent significant differences between the vehicle injected control group and the drug injected experimental groups as assessed by ANOVA followed by post hoc Dunnett's comparisons against vehicle (Veh) injected group. ${ }^{*} p<$ $0.05 ; * * * p<0.001$. 
A

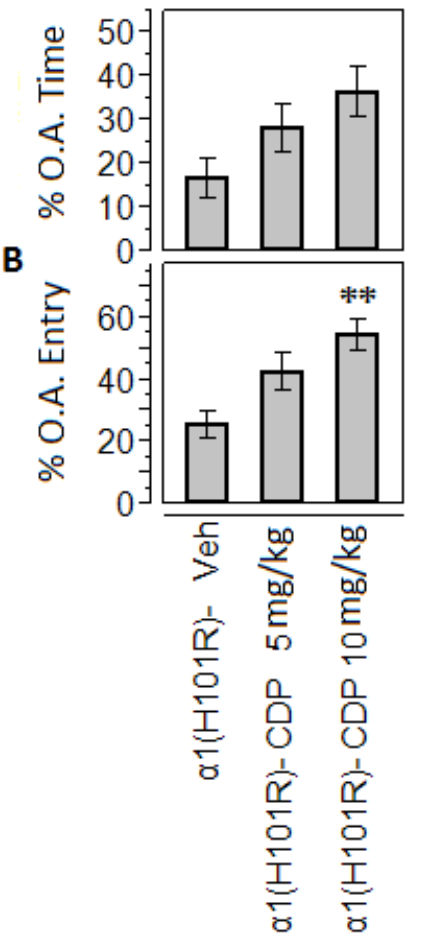

C

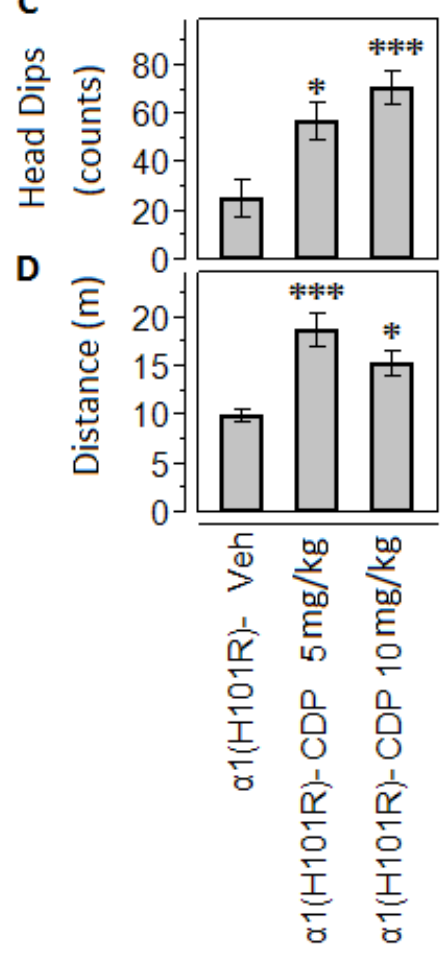

Figure 4-9. Systemic Injection of CDP in Male $\alpha 1(H 101 R)$ Mice

Anxiety-like and locomotor behaviors following drug treatment as assessed by elevated plus maze (EPM) test. (A): percentage of time spent on the open arm (\% O.A. Time). (B): percentage of entry to the open arm (\% O.A. Entry). (C): counts of incidences where the animal extended its head over the edge of the open arm (Head Dips). (D): total distance traveled on the EPM. Asterisks represent significant differences between the vehicle injected control group and the drug injected experimental groups as assessed by ANOVA followed by post hoc Dunnett's comparisons against vehicle (Veh) injected group. ${ }^{*} p<$ $0.05 ; * *<0.01 ; * * * p<0.001$. 
A

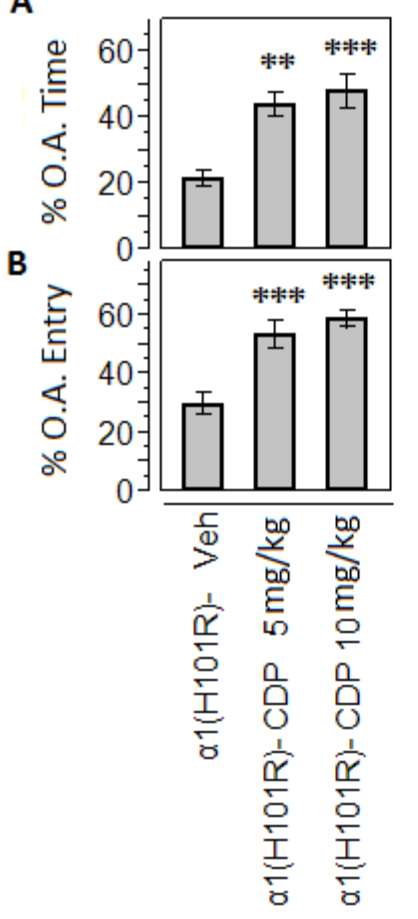

C

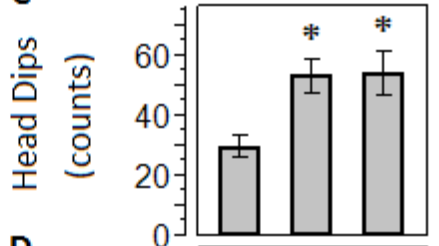

D

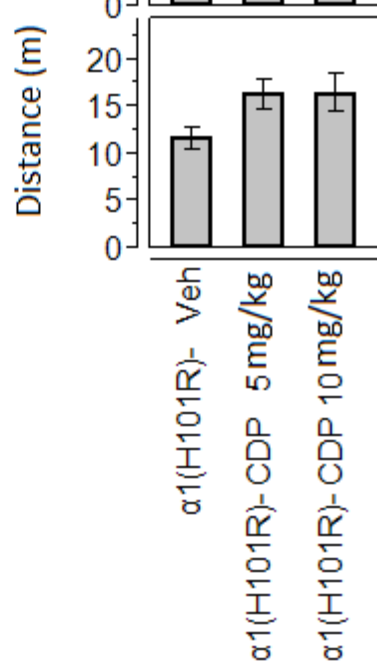

Figure 4-10. Systemic Injection of CDP in Female $\alpha 1(H 101 R)$ Mice

Anxiety-like and locomotor behaviors following drug treatment as assessed by elevated plus maze (EPM) test. (A): percentage of time spent on the open arm (\% O.A. Time). (B): percentage of entry to the open arm (\% O.A. Entry). (C): counts of incidences where the animal extended its head over the edge of the open arm (Head Dips). (D): total distance traveled on the EPM. Asterisks represent significant differences between the vehicle injected control group and the drug injected experimental groups as assessed by ANOVA followed by post hoc Dunnett's comparisons against vehicle (Veh) injected group. ${ }^{*} p<$ $0.05 ; * *<0.01 ; * * * p<0.001$. 
revealed CDP exerted anxiolytic-like effects as measured by significantly increased \% O.A. Entry at $10 \mathrm{mg} / \mathrm{kg}$ dose $(p<0.01)$. CDP also significantly increased the Head Dips at $5 \mathrm{mg} / \mathrm{kg}$ and $10 \mathrm{mg} / \mathrm{kg}$ dose $(p \mathrm{~s}<0.05)$. A significant effect of CDP on motor activities was detected at the $5 \mathrm{mg} / \mathrm{kg}$ and $10 \mathrm{mg} / \mathrm{kg}$ doses $(p \mathrm{~s}<0.05)$. A total of 23 mice were included in this experiment (Veh, $\mathrm{n}=8 ; 5 \mathrm{mg} / \mathrm{kg}, \mathrm{n}=8$; and $10 \mathrm{mg} / \mathrm{kg}, \mathrm{n}=7$ ).

For females, one-way ANOVA with dose as independent variable revealed significant effects of CDP on the dependent variables of \% O.A. Time, \% O.A. Entry, and Head Dips, $F \mathrm{~s}(2,21)>6.15, p \mathrm{~s}<0.01$. No significant effect of CDP was detected on the Distance traveled on the EPM, $F(2,21)=2.82, p>0.05$. Dunnett's comparisons revealed CDP exerted anxiolytic-like effects as measured by significantly increased \% O.A. Time and \% O.A. Entry at $5 \mathrm{mg} / \mathrm{kg}$ and $10 \mathrm{mg} / \mathrm{kg}$ doses $(p \mathrm{~s}<0.01)$. CDP also significantly increased Head Dips at both $5 \mathrm{mg} / \mathrm{kg}$ and $10 \mathrm{mg} / \mathrm{kg}$ doses $(p \mathrm{~s}<0.05)$. A total of 24 mice were included in this experiment (Veh, $\mathrm{n}=8 ; 5 \mathrm{mg} / \mathrm{kg}, \mathrm{n}=8$; and $10 \mathrm{mg} / \mathrm{kg}, \mathrm{n}=8$ ).

\section{Systemic Injection of CDP in $\alpha 2(\mathrm{H101R})$ Mice}

To assess the anxiolytic-like effects of CDP in mice with BZ-insensitive $\alpha 2$ subtype GABA $\mathrm{A}_{\mathrm{R}}, \alpha 2(\mathrm{H} 101 \mathrm{R})$ mice were given an i.p. injection of CDP at one of the following doses: $5 \mathrm{mg} / \mathrm{kg}$, or $10 \mathrm{mg} / \mathrm{kg}$. Mice were tested on the EPM $30 \mathrm{~min}$ postinjection. The results are shown in Figure 4-11 and Figure 4-12. Two-way ANOVA with dose and sex as independent variables returned significant main effects of dose on the dependent variables of \% O.A. Time, \% O.A. Entry, and Distance, $F \mathrm{~s}(2,48)>3.26, p \mathrm{~s}$ $<0.05$. Significant main effects of sex on the dependent variables of \% O.A. Entry and Head Dips were also detected, $F \mathrm{~s}(1,48)>5.04, p<0.05$. A significant Sex $\times$ Dose interaction was detected on the dependent variable of Distance, $F(2,48)=6.11, p<0.01$.

For males, one-way ANOVA with dose as independent variable revealed significant effect of CDP on the dependent variable of Distance traveled, $F(2,26)=3.69$, $p<0.05$. No significant effect was found on the dependent variables of $\%$ O.A. Time, $\%$ O.A. Entry, and Head Dips, $F_{\mathrm{s}}(2,26)<2.32, p \mathrm{~s}>0.1$. Dunnett's comparison revealed a significant difference in Distance traveled at $5 \mathrm{mg} / \mathrm{kg}$ dose when compared to the Vehicle group $(p<0.05)$. A total of 29 mice were included in this experiment (Veh, $\mathrm{n}=11$; $5 \mathrm{mg} / \mathrm{kg}, \mathrm{n}=10$; and $10 \mathrm{mg} / \mathrm{kg}, \mathrm{n}=8)$.

For females, one-way ANOVA with dose as independent variable revealed no significant effect of CDP on the dependent variables of \% O.A. Time, \% O.A. Entry and Head Dips, $F \mathrm{~s}(2,22)<3.11, p \mathrm{~s}>0.05$. A significant effect of CDP on Distance traveled on the EPM was found, $F(2,22)=4.81, p<0.05$. However, post hoc Dunnett's comparison returned no significant difference of the drug injected groups from the vehicle injected group. A total of 25 mice were included in this experiment (Veh, $n=10$; $5 \mathrm{mg} / \mathrm{kg}, \mathrm{n}=8$; and $10 \mathrm{mg} / \mathrm{kg}, \mathrm{n}=7$ ). 
A

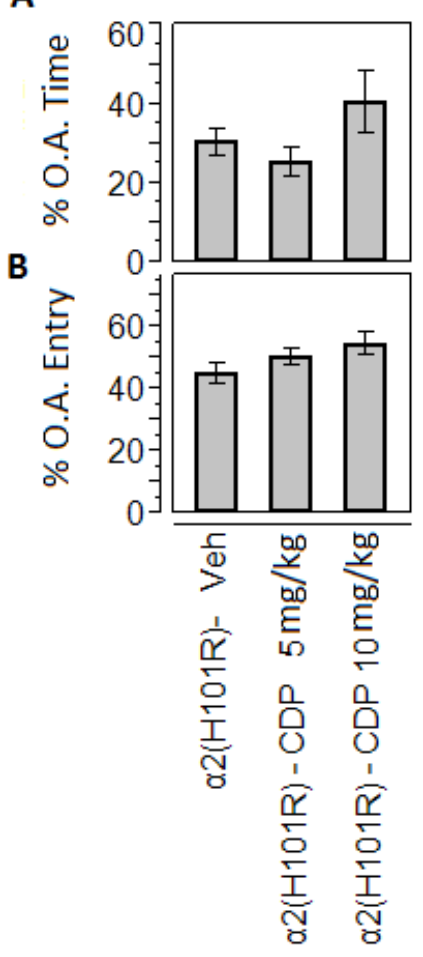

C

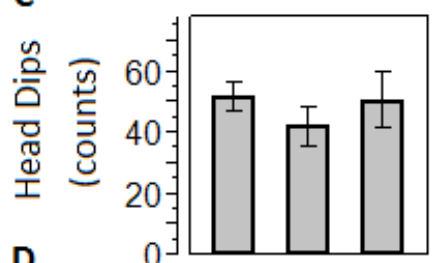

D

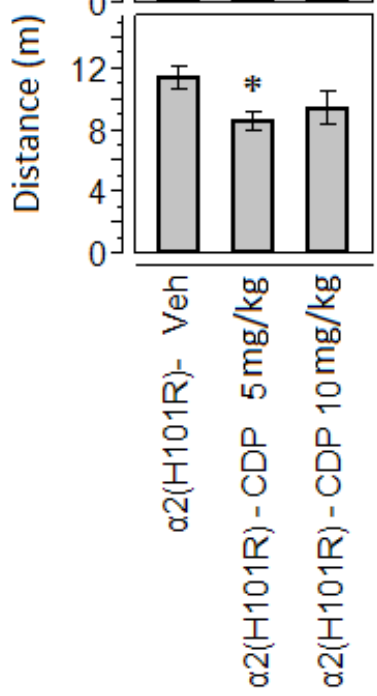

Figure 4-11. Systemic Injection of CDP in Male a2(H101R) Mice

Anxiety-like and locomotor behaviors following drug treatment as assessed by elevated plus maze (EPM) test. (A): percentage of time spent on the open arm (\% O.A. Time). (B): percentage of entry to the open arm (\% O.A. Entry). (C): counts of incidences where the animal extended its head over the edge of the open arm (Head Dips). (D): total distance traveled on the EPM. Asterisks represent significant differences between the vehicle injected control group and the drug injected experimental groups as assessed by ANOVA followed by post hoc Dunnett's comparisons against vehicle (Veh) injected group. ${ }^{*} p<$ 0.05 . 
A

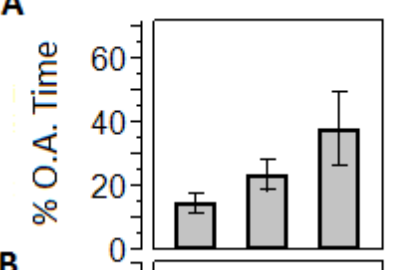

B

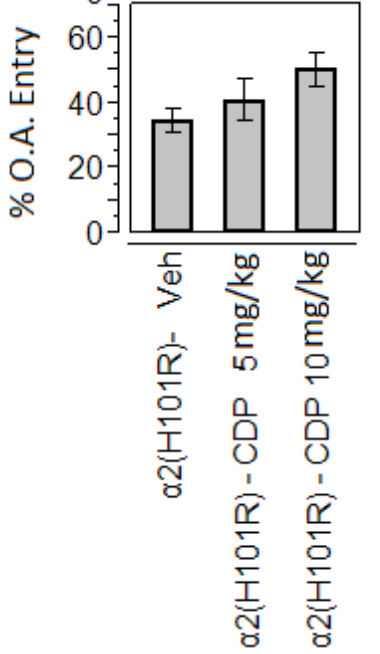

C
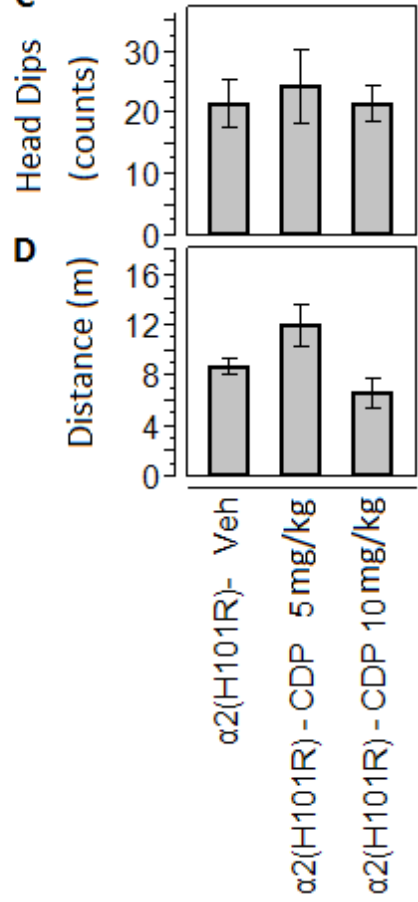

Figure 4-12. Systemic Injection of CDP in Female $\alpha 2(H 101 R)$ Mice

Anxiety-like and locomotor behaviors following drug treatment as assessed by elevated plus maze (EPM) test. (A): percentage of time spent on the open arm (\% O.A. Time). (B): percentage of entry to the open arm (\% O.A. Entry). (C): counts of incidences where the animal extended its head over the edge of the open arm (Head Dips). (D): total distance traveled on the EPM. 


\section{Systemic Injection of CDP in $\alpha 3(\mathrm{H} 126 \mathrm{R})$ Mice}

To assess the anxiolytic-like effects of CDP in mice with BZ-insensitive $\alpha 3$ subtype $\mathrm{GABA}_{\mathrm{A}} \mathrm{Rs}, \alpha 3(\mathrm{H} 126 \mathrm{R})$ mice were given an i.p. injection of CDP at one of the following doses: $5 \mathrm{mg} / \mathrm{kg}$, or $10 \mathrm{mg} / \mathrm{kg}$. Mice were tested on the EPM 30 min postinjection. The results are shown in Figure 4-13 and Figure 4-14. Two-way ANOVA with dose and sex as independent variables returned significant main effects of dose on the dependent variables of \% O.A. Time and \% O.A. Entry, $F \mathrm{~s}(2,43)>4.60, p \mathrm{~s}<0.05$. No significant effect of sex or Sex $\times$ Dose interaction was detected, $p \mathrm{~s}>0.05$.

For males, one-way ANOVA with dose as independent variable revealed no significant effect of CDP on the dependent variables of \% O.A. Time, \% O.A. Entry, Head Dips, and Distance, $F \mathrm{~s}(2,19)<3.35, p \mathrm{~s}>0.05$. A total of 22 mice were included in this experiment (Veh, $\mathrm{n}=8 ; 5 \mathrm{mg} / \mathrm{kg}, \mathrm{n}=6$; and $10 \mathrm{mg} / \mathrm{kg}, \mathrm{n}=8)$.

For females, one-way ANOVA with dose as independent variable revealed significant effects of CDP on the dependent variables of \% O.A. Time, and \% O.A. Entry, $F \mathrm{~s}(2,24)>4.51, p \mathrm{~s}<0.05$. No significant effect was detected on the Head Dips and Distance traveled on the EPM, $F \mathrm{~s}(2,24)<2.04, p \mathrm{~s}>0.01$. Dunnett's comparisons revealed CDP exerted anxiolytic-like effects as measured by significantly increased \% O.A. Time and $\%$ O.A. Entry at $10 \mathrm{mg} / \mathrm{kg}$ dose $(p \mathrm{~s}<0.05)$. A total of 27 mice were included in this experiment (Veh, $\mathrm{n}=7 ; 5 \mathrm{mg} / \mathrm{kg}, \mathrm{n}=8$; and $10 \mathrm{mg} / \mathrm{kg}, \mathrm{n}=12$ ).

\section{Systemic Injection of Non-Selective CDP - Other Parameters}

Besides the parameters reported in the figures, descriptive statistics were obtained for several other parameters, including the distance traveled on the open arm and closed arm, respectively (O.A. Distance, C.A. Distance), time and entry to the distal open arm (D.O.A. Time, D.O.A. Entry), as well as the time animal spent in the center zone (Center Time) during the EPM experimentation, are summarized in Table 4-2.

\section{Intra-BLA Microinjection of Selective GABAAR PAMs}

To assess the differential role that $\mathrm{GABA}_{\mathrm{A}} \mathrm{R}$ subtypes within the BLA play in mediating BZ-induced anxiolysis, subtype selective $\mathrm{GABA}_{\mathrm{A}} \mathrm{R}$ PAMs were administered to both adult male C57BL/6J mice and $\alpha 3(\mathrm{H} 126 \mathrm{R})$ mice via intra-BLA microinjection. The effects of the drugs on anxiety-like behaviors and motor activities were assessed by the EPM.

\section{Intra-BLA Microinjection of Zolpidem in WT C57BL/6J Mice}

To assess the role $\alpha 1$-subtype $\mathrm{GABA}_{\mathrm{A}} \mathrm{Rs}$ play in mediating anxiolysis within the BLA, C57BL/6J mice were given bilateral intra-BLA microinjections of zolpidem at one 
A

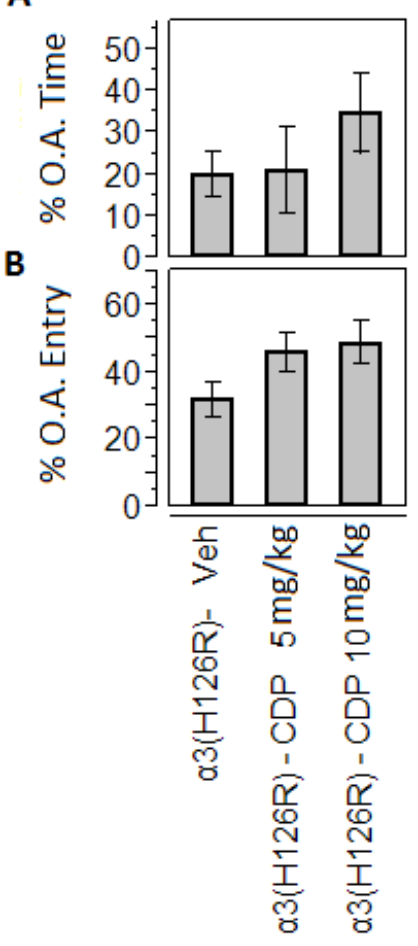

C

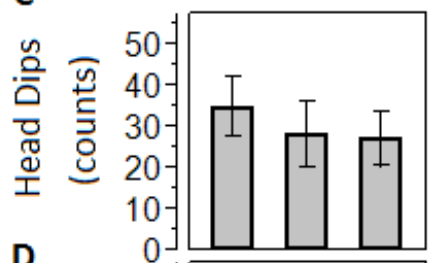

D

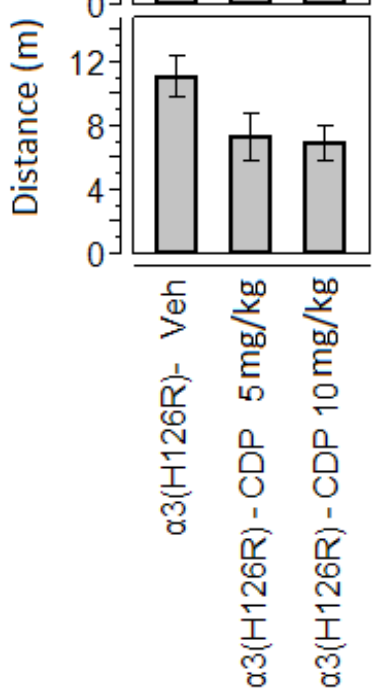

Figure 4-13. Systemic Injection of CDP in Male $\alpha 3(H 126 R)$ Mice

Anxiety-like and locomotor behaviors following drug treatment as assessed by elevated plus maze (EPM) test. (A): percentage of time spent on the open arm (\% O.A. Time). (B): percentage of entry to the open arm (\% O.A. Entry). (C): counts of incidences where the animal extended its head over the edge of the open arm (Head Dips). (D): total distance traveled on the EPM. 
A

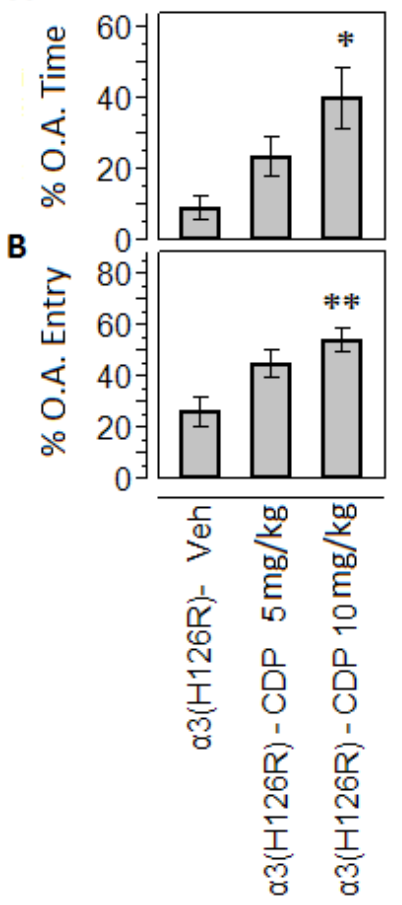

C

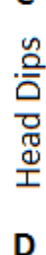

D
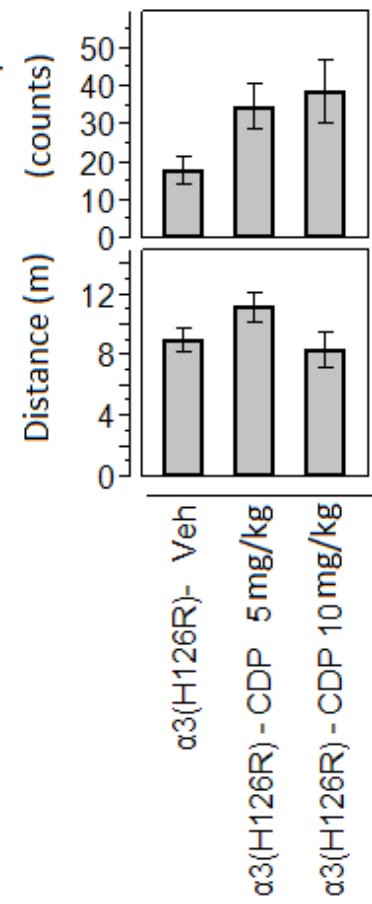

Figure 4-14. Systemic Injection of CDP in Female $\alpha 3(H 126 R)$ Mice

Anxiety-like and locomotor behaviors following drug treatment as assessed by elevated plus maze (EPM) test. (A): percentage of time spent on the open arm (\% O.A. Time). (B): percentage of entry to the open arm (\% O.A. Entry). (C): counts of incidences where the animal extended its head over the edge of the open arm (Head Dips). (D): total distance traveled on the EPM. Asterisks represent significant differences between the vehicle injected control group and the drug injected experimental groups as assessed by ANOVA followed by post hoc Dunnett's comparisons against vehicle (Veh) injected group. ${ }^{*} p<$ $0.05 ; * * p<0.01$. 


\section{Table 4-2. Systemic Injection of Non-Selective CDP - Descriptive Statistics of Other Parameters}

\begin{tabular}{|c|c|c|c|c|c|c|c|}
\hline Sex & Treatment & $\mathrm{N}$ & O.A. Distance (m) & C.A. Distance (m) & D.O.A. Time (s) & D.O.A. Entry & Center Time (s) \\
\hline Male & WT- Veh & 8 & $1.36 \pm 0.44$ & $7.03 \pm 0.46$ & $17.65 \pm 5.24$ & $3 \pm 1.05$ & $41.68 \pm 5.11$ \\
\hline Male & WT-CDP-05mg $/ \mathrm{kg}$ & 6 & $3.31 \pm 0.96$ & $7.56 \pm 1.12$ & $52.92 \pm 13.3$ & $7.83 \pm 2.21$ & $29.13 \pm 3.98$ \\
\hline Male & WT-CDP-10mg/kg & 7 & $4.8 \pm 0.86$ & $5.38 \pm 1.14$ & $103.69 \pm 26.59$ & $9 \pm 1.59$ & $24.41 \pm 2.57$ \\
\hline Male & $\alpha 1(\mathrm{H} 101 \mathrm{R})-\mathrm{Veh}$ & 8 & $1.23 \pm 0.36$ & $6.7 \pm 0.4$ & $18.85 \pm 6.57$ & $2.75 \pm 1.1$ & $50.39 \pm 6.41$ \\
\hline Male & $\alpha 1(\mathrm{H} 101 \mathrm{R})-\mathrm{CDP}-05 \mathrm{mg} / \mathrm{kg}$ & 8 & $3.7 \pm 0.98$ & $11.01 \pm 1.11$ & $30.31 \pm 9.2$ & $8.13 \pm 2.23$ & $57.7 \pm 3.75$ \\
\hline Male & $\alpha 1(\mathrm{H} 101 \mathrm{R})-\mathrm{CDP}-10 \mathrm{mg} / \mathrm{kg}$ & 7 & $4.07 \pm 1.01$ & $7.86 \pm 0.42$ & $38.53 \pm 10.47$ & $9.14 \pm 2.82$ & $49.81 \pm 6.22$ \\
\hline Male & $\alpha 2(\mathrm{H} 101 \mathrm{R})-\mathrm{Veh}$ & 11 & $2.26 \pm 0.39$ & $6.61 \pm 0.42$ & $27.98 \pm 5.72$ & $4.55 \pm 1$ & $57.45 \pm 4.68$ \\
\hline Male & $\alpha 2(\mathrm{H} 101 \mathrm{R})-\mathrm{CDP}-05 \mathrm{mg} / \mathrm{kg}$ & 10 & $1.89 \pm 0.35$ & $4.94 \pm 0.37$ & $24.52 \pm 5.55$ & $3.9 \pm 0.98$ & $48.45 \pm 5.68$ \\
\hline Male & $\alpha 2(\mathrm{H} 101 \mathrm{R})-\mathrm{CDP}-10 \mathrm{mg} / \mathrm{kg}$ & 8 & $3.16 \pm 0.64$ & $4.59 \pm 0.4$ & $63.18 \pm 15.26$ & $6.88 \pm 1.6$ & $36.76 \pm 6.66$ \\
\hline Male & $\alpha 3(\mathrm{H} 126 \mathrm{R})-\mathrm{Veh}$ & 8 & $1.97 \pm 0.63$ & $7.01 \pm 0.74$ & $26.06 \pm 7.46$ & $4 \pm 1.36$ & $44.5 \pm 5.29$ \\
\hline Male & $\alpha 3(\mathrm{H} 126 \mathrm{R})-\mathrm{CDP}-05 \mathrm{mg} / \mathrm{kg}$ & 6 & $1.44 \pm 0.47$ & $4.35 \pm 0.99$ & $15.7 \pm 6.1$ & $3.17 \pm 1.28$ & $34.93 \pm 7.13$ \\
\hline Male & $\alpha 3(\mathrm{H} 126 \mathrm{R})-\mathrm{CDP}-10 \mathrm{mg} / \mathrm{kg}$ & 8 & $2.19 \pm 0.71$ & $3.36 \pm 0.41$ & $49.33 \pm 20.44$ & $4.5 \pm 1.65$ & $24.3 \pm 5.78$ \\
\hline Female & WT- Veh & 9 & $1.18 \pm 0.37$ & $6.35 \pm 0.41$ & $15.37 \pm 6.07$ & $2 \pm 0.85$ & $50.52 \pm 2.44$ \\
\hline Female & WT-CDP-05mg $/ \mathrm{kg}$ & 6 & $1.41 \pm 0.39$ & $5.76 \pm 0.77$ & $13.67 \pm 5.41$ & $4 \pm 1.48$ & $63.37 \pm 14.94$ \\
\hline Female & WT-CDP-10mg $/ \mathrm{kg}$ & 13 & $4.65 \pm 0.57$ & $5.77 \pm 0.63$ & $81.01 \pm 10.02$ & $10.23 \pm 1.59$ & $37.53 \pm 3.21$ \\
\hline Female & $\alpha 1(\mathrm{H} 101 \mathrm{R})-\mathrm{Veh}$ & 8 & $1.58 \pm 0.26$ & $7.77 \pm 0.81$ & $23.81 \pm 3.55$ & $3.5 \pm 0.57$ & $58.03 \pm 5.38$ \\
\hline Female & $\alpha 1(\mathrm{H} 101 \mathrm{R})-\mathrm{CDP}-05 \mathrm{mg} / \mathrm{kg}$ & 8 & $4.39 \pm 0.55$ & $8.82 \pm 1.02$ & $48.18 \pm 8.37$ & $9 \pm 1.02$ & $55.2 \pm 4.19$ \\
\hline Female & $\alpha 1(\mathrm{H} 101 \mathrm{R})-\mathrm{CDP}-10 \mathrm{mg} / \mathrm{kg}$ & 8 & $5.22 \pm 1.31$ & $7.86 \pm 0.74$ & $62.88 \pm 16.7$ & $10.25 \pm 3.03$ & $48.16 \pm 5.56$ \\
\hline Female & $\alpha 2(\mathrm{H} 101 \mathrm{R})-\mathrm{Veh}$ & 10 & $1.11 \pm 0.26$ & $5.83 \pm 0.41$ & $15.12 \pm 4.41$ & $2.7 \pm 0.84$ & $39.21 \pm 3.99$ \\
\hline Female & $\alpha 2(\mathrm{H} 101 \mathrm{R})-\mathrm{CDP}-05 \mathrm{mg} / \mathrm{kg}$ & 8 & $2.49 \pm 0.63$ & $7.3 \pm 1.29$ & $30.3 \pm 6.43$ & $5.88 \pm 1.54$ & $44.9 \pm 8.68$ \\
\hline Female & $\alpha 2(\mathrm{H} 101 \mathrm{R})-\mathrm{CDP}-10 \mathrm{mg} / \mathrm{kg}$ & 7 & $1.43 \pm 0.18$ & $3.55 \pm 0.95$ & $45.89 \pm 14.22$ & $3.43 \pm 0.43$ & $61.21 \pm 21.43$ \\
\hline Female & $\alpha 3(\mathrm{H} 126 \mathrm{R})-\mathrm{Veh}$ & 7 & $0.76 \pm 0.32$ & $6.47 \pm 0.61$ & $8.46 \pm 4.42$ & $1.43 \pm 0.69$ & $44.76 \pm 5.98$ \\
\hline Female & $\alpha 3(\mathrm{H} 126 \mathrm{R})-\mathrm{CDP}-05 \mathrm{mg} / \mathrm{kg}$ & 8 & $2.64 \pm 0.73$ & $6.43 \pm 0.24$ & $32.45 \pm 8.53$ & $5.5 \pm 1.67$ & $32.78 \pm 3.84$ \\
\hline Female & $\alpha 3(\mathrm{H} 126 \mathrm{R})-\mathrm{CDP}-10 \mathrm{mg} / \mathrm{kg}$ & 12 & $2.76 \pm 0.68$ & $3.85 \pm 0.63$ & $52.52 \pm 14.44$ & $5 \pm 1.35$ & $42.48 \pm 13.41$ \\
\hline
\end{tabular}


of the following doses: $0.1 \mu \mathrm{g} / \mu \mathrm{L}, 0.25 \mu \mathrm{g} / \mu \mathrm{L}$, or $0.5 \mu \mathrm{g} / \mu \mathrm{L}$ in $0.3 \mu \mathrm{L}$ volume. Mice were tested on the EPM 5-8 min post-injection. The results are shown in Figure 4-15. Oneway ANOVA with dose as independent variable revealed significant effects of zolpidem microinjection on the dependent variables of \% O.A. Time, and \% O.A. Entry, $F_{\mathrm{S}}(3,39)$ $>3.43$, ps $<0.05$. No significant effect on Head Dips and Distance traveled was detected, $F s(3,39)<2.07, p s>0.1$. Dunnett's comparisons revealed zolpidem exerted anxiolyticlike effects as measured by significantly increased \% O.A. Time at $0.1 \mu \mathrm{g} / \mu \mathrm{L}$ dose $(p<$ 0.05). However, post hoc Dunnett's test revealed no significant difference in the \% O.A. Entry between the drug injected groups and the vehicle injected group. A total of 43 mice were included in this experiment (Veh, $\mathrm{n}=14 ; 0.1 \mu \mathrm{g} / \mu \mathrm{L}, \mathrm{n}=10 ; 0.25 \mu \mathrm{g} / \mu \mathrm{L}, \mathrm{n}=10$; and $0.5 \mu \mathrm{g} / \mu \mathrm{L}, \mathrm{n}=9)$.

\section{Intra-BLA Microinjection of L-838417 in $\alpha 3(H 126 R)$ Mice}

To assess the role the $\alpha 2-$ (and $\alpha 5-$ ) subtype $\mathrm{GABA}_{\mathrm{A}} \mathrm{Rs}$ play in mediating anxiolysis within the BLA, $\alpha 3(\mathrm{H} 126 \mathrm{R})$ mice were given bilateral intra-BLA microinjection of L-838417 at one of the following doses: $0.25 \mu \mathrm{g} / \mu \mathrm{L}$, or $0.5 \mu \mathrm{g} / \mu \mathrm{L}$ in $0.3 \mu \mathrm{L}$ volume. Mice were tested on the EPM 5-8 min post-injection. The results are shown in Figure 4-16. One-way ANOVA with dose as the independent variable revealed a significant effect of L-838417 microinjection in $\alpha 3(\mathrm{H} 126 \mathrm{R})$ mice on the dependent variables of Head Dips, $F(2,21)=3.95, p<0.05$. No significant effect was detected on $\%$ O.A. Time, \% O.A. Entry or Distance traveled, $F s(2,21)<2.96, p>0.05$. Dunnett's comparisons revealed L-838417 exerted anxiolytic-like effects as measured by significantly increased Head Dips at $0.5 \mu \mathrm{g} / \mu \mathrm{L}$ dose $(p<0.05)$. A total of 24 mice were included in this experiment (Veh, $\mathrm{n}=10 ; 0.25 \mu \mathrm{g} / \mu \mathrm{L}, \mathrm{n}=7$; and $0.5 \mu \mathrm{g} / \mu \mathrm{L}, \mathrm{n}=7$ ).

\section{Intra-BLA Microinjection of TP003 in WT C57BL/6J Mice}

To assess the role the $\alpha 3$-subtype $\mathrm{GABA}_{\mathrm{A}} \mathrm{Rs}$ play in mediating anxiolysis within the BLA, WT C57BL/6J mice were given bilateral intra-BLA microinjections of TP003 at one of the following dose: $0.1 \mu \mathrm{g} / \mu \mathrm{L}, 0.25 \mu \mathrm{g} / \mu \mathrm{L}$, or $0.5 \mu \mathrm{g} / \mu \mathrm{L}$ in $0.3 \mu \mathrm{L}$ volume. Mice were tested on the EPM 5-8 min post-injection. The results are shown in Figure 4-17. One-way ANOVA with dose as independent variable revealed significant effect of TP003 microinjection in WT mice on the dependent variable of $\%$ O.A. Time, $F(3,37)=5.11, p$ $<0.05$. No significant effect on \% O.A. Entry, Head Dips, or Distance traveled was detected, $F s(3,37)<2.34, p>0.05$. Dunnett's comparisons revealed TP003 exerted anxiolytic-like effects as measured by significantly increased \% O.A. Time at $0.25 \mu \mathrm{g} / \mu \mathrm{L}$ and $0.5 \mu \mathrm{g} / \mu \mathrm{L}$ dose $(p \mathrm{~s}<0.01)$. A total of 41 mice were included in this experiment (Veh, $\mathrm{n}=14 ; 0.1 \mu \mathrm{g} / \mu \mathrm{L}, \mathrm{n}=9 ; 0.25 \mu \mathrm{g} / \mu \mathrm{L}, \mathrm{n}=8$; and $0.5 \mu \mathrm{g} / \mu \mathrm{L}, \mathrm{n}=10)$. 


\section{A}

B
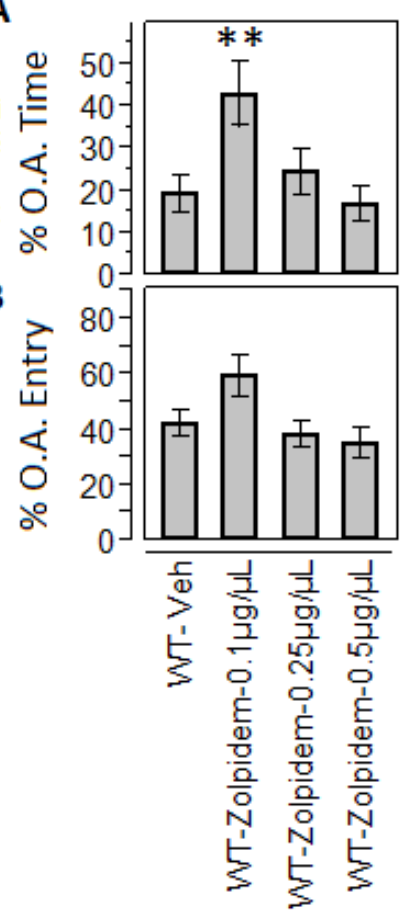

C

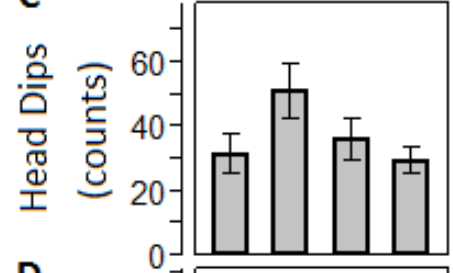

D

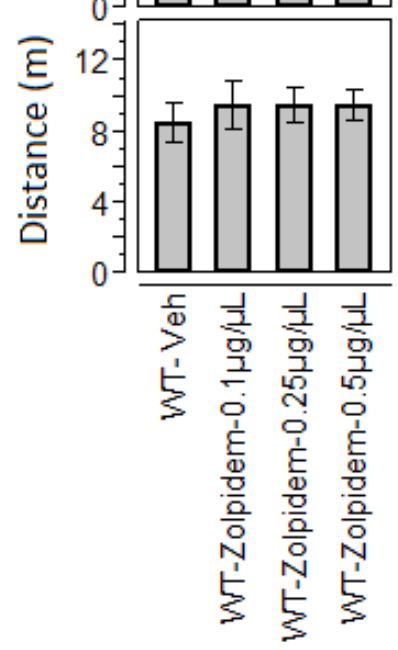

Figure 4-15. Intra-BLA Microinjection of Zolpidem in WT C57BL/6J Mice

Anxiety-like and locomotor behaviors following drug treatment as assessed by elevated plus maze (EPM) test. (A): percentage of time spent on the open arm (\% O.A. Time). (B): percentage of entry to the open arm (\% O.A. Entry). (C): counts of incidences where the animal extended its head over the edge of the open arm (Head Dips). (D): total distance traveled on the EPM. Asterisks represent significant differences between the vehicle injected control group and the drug injected experimental groups as assessed by ANOVA followed by post hoc Dunnett's comparisons against vehicle (Veh) injected group. ${ }^{*} p<$ 0.01 . 
A

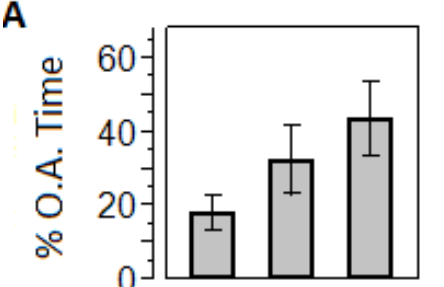

B

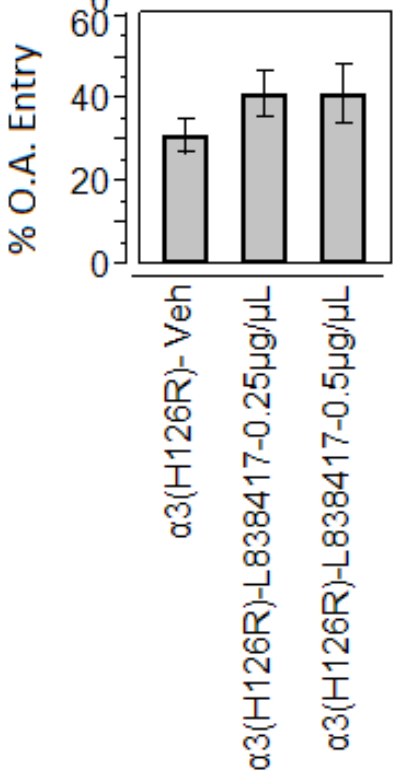

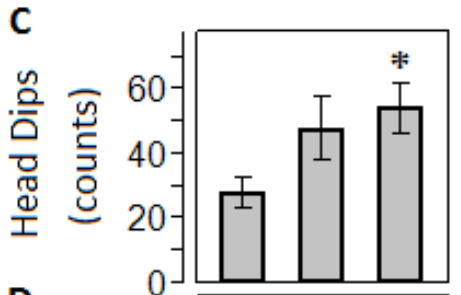

D

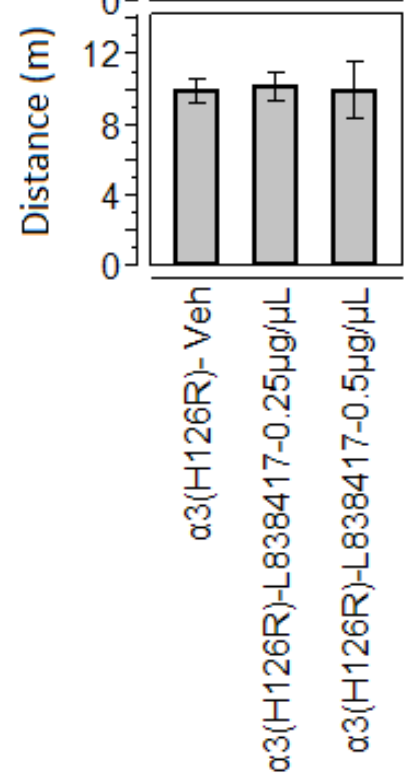

Figure 4-16. Intra-BLA Microinjection of L-838417 in $\alpha 3(H 126 R)$ Mice

Anxiety-like and locomotor behaviors following drug treatment as assessed by elevated plus maze (EPM) test. (A): percentage of time spent on the open arm (\% O.A. Time). (B): percentage of entry to the open arm (\% O.A. Entry). (C): counts of incidences where the animal extended its head over the edge of the open arm (Head Dips). (D): total distance traveled on the EPM. Asterisks represent significant differences between the vehicle injected control group and the drug injected experimental groups as assessed by ANOVA followed by post hoc Dunnett's comparisons against vehicle (Veh) injected group. ${ }^{*} p<$ 0.05 . 


\section{A}

B
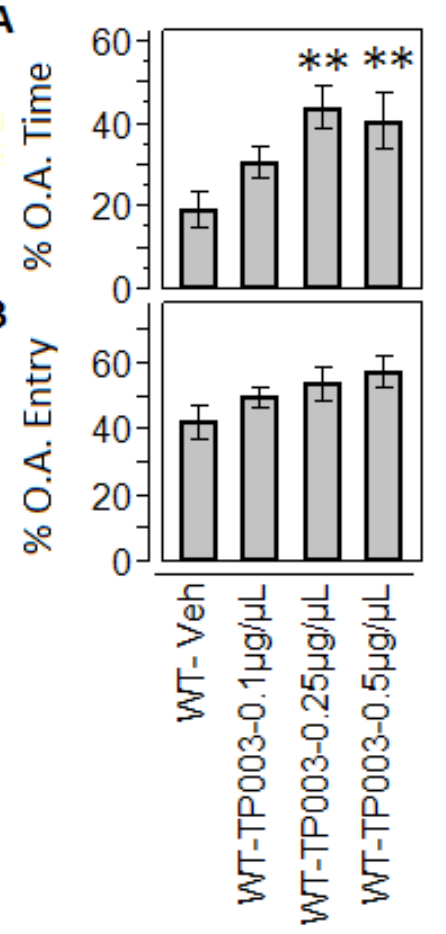

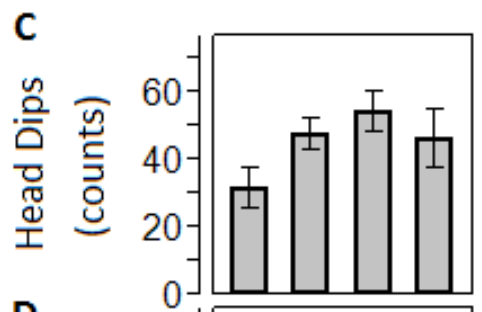

D

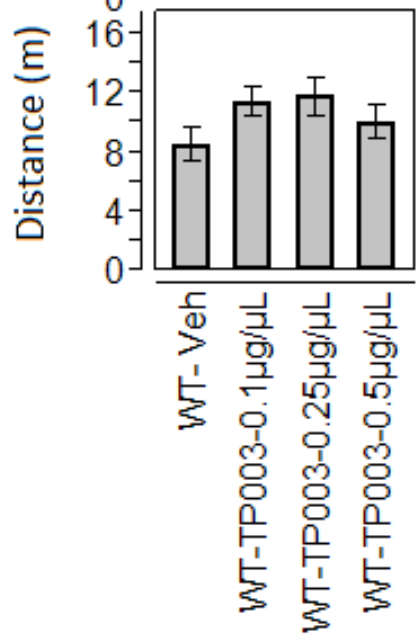

Figure 4-17. Intra-BLA Microinjection of TP003 in WT C57BL/6J Mice

Anxiety-like and locomotor behaviors following drug treatment as assessed by elevated plus maze (EPM) test. (A): percentage of time spent on the open arm (\% O.A. Time). (B): percentage of entry to the open arm (\% O.A. Entry). (C): counts of incidences where the animal extended its head over the edge of the open arm (Head Dips). (D): total distance traveled on the EPM. Asterisks represent significant differences between the vehicle injected control group and the drug injected experimental groups as assessed by ANOVA followed by post hoc Dunnett's comparisons against vehicle (Veh) injected group. ${ }^{* *} p<$ 0.01 . 


\section{Intra-BLA Microinjection of Subtype Selective GABAAR PAMs - Other Parameters}

Besides the parameters reported in the figures, descriptive statistics were obtained for several other parameters, including the distance traveled on the open arm and closed arm, respectively (O.A. Distance, C.A. Distance), time and entry to the distal open arm (D.O.A. Time, D.O.A. Entry), as well as the time animal spent in the center zone (Center Time) during the EPM experimentation, are summarized in Table 4-3.

\section{Intra-BLA Microinjection of Non-Selective CDP in Point Mutant Mice}

To assess the effects of a non-selective BZ drug, CDP, on anxiety-like behaviors within the BLA, CDP was administered to both $\mathrm{C} 57 \mathrm{BL} / 6 \mathrm{~J}$ mice and three strains of point mutant mice, $\alpha 1(\mathrm{H} 101 \mathrm{R}), \alpha 2(\mathrm{H} 101 \mathrm{R})$, and $\alpha 3(\mathrm{H} 126 \mathrm{R})$, via intra-BLA microinjection. The effects of the drugs on anxiety-like behaviors and motor activities were assessed by the EPM.

\section{Intra-BLA Microinjection of CDP in WT C57BL/6J Mice}

To assess the anxiolytic-like effects of CDP within the BLA, WT C57BL/6J mice were given bilateral intra-BLA microinjections of CDP at one of the following doses: $10 \mu \mathrm{g} / \mu \mathrm{L}$, or $20 \mu \mathrm{g} / \mu \mathrm{L}$ in $0.3 \mathrm{uL}$ volume. Mice were tested on the EPM 5-8 min postinjection. The results are shown in Figure 4-18. One-way ANOVA with dose as independent variable revealed no significant effect of CDP microinjection on the dependent variables of \% O.A. Time, \% O.A. Entry, Head Dips, or Distance traveled, $F_{S}(2,21)<1.34, p>0.1$. A total of 24 mice were included in this experiment (Veh, $\mathrm{n}=9$; $10 \mu \mathrm{g} / \mu \mathrm{L}, \mathrm{n}=6$; and $20 \mu \mathrm{g} / \mu \mathrm{L}, \mathrm{n}=9$ ).

\section{Intra-BLA Microinjection of CDP in $\alpha 1(\mathrm{H101R})$ Mice}

To assess the anxiolytic-like effects of CDP within the BLA in mice expressing the BZ-insensitive $\alpha 1$-subtype, $\alpha 1(\mathrm{H} 101 \mathrm{R})$ mice were given bilateral intra-BLA microinjections of CDP at one of the following doses: $10 \mu \mathrm{g} / \mu \mathrm{L}$, or $20 \mu \mathrm{g} / \mu \mathrm{L}$ in $0.3 \mathrm{uL}$ volume. Mice were tested on the EPM 5-8 min post-injection. The results are shown in Figure 4-19. One-way ANOVA with dose as independent variable revealed no significant effect of CDP microinjection on the dependent variables of $\%$ O.A. Time, $\%$ O.A. Entry, Head Dips, or Distance traveled, $F s(2,19)<0.74, p>0.1$. A total of 22 mice were included in this experiment (Veh, $\mathrm{n}=8 ; 10 \mu \mathrm{g} / \mu \mathrm{L}, \mathrm{n}=7 ; 20 \mu \mathrm{g} / \mu \mathrm{L}, \mathrm{n}=7$ ).

\section{Intra-BLA Microinjection of CDP in $\alpha 2(H 101 R)$ Mice}

To assess the anxiolytic-like effects of CDP within the BLA in mice expressing the BZ-insensitive $\alpha 2$-subtype, $\alpha 2$ (H101R) mice were given bilateral intra-BLA 
Table 4-3. Intra-BLA Microinjection of Subtype Selective GABAAR PAMs Descriptive Statistics of Other Parameters

\begin{tabular}{|c|c|c|c|c|c|c|}
\hline Treatment & $\mathrm{N}$ & O.A. Distance $(\mathrm{m})$ & C.A. Distance (m) & D.O.A. Time (s) & D.O.A. Entry & Center Time (s) \\
\hline WT- Veh & 14 & $1.68 \pm 0.47$ & $5.23 \pm 0.59$ & $25.81 \pm 6.61$ & $3.71 \pm 1.1$ & $27.99 \pm 3.51$ \\
\hline WT-TP003-0.1 $1 \mu \mathrm{g} / \mu \mathrm{L}$ & 9 & $2.68 \pm 0.31$ & $6.53 \pm 0.66$ & $45.08 \pm 4.91$ & $6.78 \pm 1.02$ & $30.33 \pm 2.75$ \\
\hline WT-TP003-0.25 $\mu \mathrm{g} / \mu \mathrm{L}$ & 8 & $3.29 \pm 0.68$ & $6.38 \pm 0.77$ & $73.83 \pm 15.52$ & $8.13 \pm 1.47$ & $23.05 \pm 5.41$ \\
\hline WT-TP003- $0.5 \mu \mathrm{g} / \mu \mathrm{L}$ & 10 & $3.39 \pm 0.82$ & $4.66 \pm 0.59$ & $57.82 \pm 13.7$ & $8.1 \pm 2.06$ & $30.77 \pm 6.31$ \\
\hline WT-Zolpidem- $0.1 \mu \mathrm{g} / \mu \mathrm{L}$ & 10 & $3.57 \pm 0.81$ & $4.22 \pm 0.79$ & $58.46 \pm 10.02$ & $8 \pm 1.61$ & $39.2 \pm 16.34$ \\
\hline WT-Zolpidem- $0.25 \mu \mathrm{g} / \mu \mathrm{L}$ & 10 & $1.78 \pm 0.49$ & $5.81 \pm 0.58$ & $32.67 \pm 10.49$ & $5.2 \pm 1.25$ & $31.98 \pm 4.08$ \\
\hline WT-Zolpidem- $0.5 \mu \mathrm{g} / \mu \mathrm{L}$ & 9 & $1.29 \pm 0.33$ & $6.19 \pm 0.75$ & $23.29 \pm 7.12$ & $3.11 \pm 0.82$ & $44.79 \pm 5.52$ \\
\hline$\alpha 3(\mathrm{H} 126 \mathrm{R})-\mathrm{Veh}$ & 10 & $1.42 \pm 0.39$ & $6.79 \pm 0.34$ & $25.85 \pm 9.41$ & $2.9 \pm 0.75$ & $29.6 \pm 2.58$ \\
\hline$\alpha 3(\mathrm{H} 126 \mathrm{R})-\mathrm{L} 838417-0.25 \mu \mathrm{g} / \mu \mathrm{L}$ & 7 & $2.17 \pm 0.46$ & $6.16 \pm 0.51$ & $59.89 \pm 21.96$ & $4.57 \pm 1.19$ & $26.01 \pm 1.41$ \\
\hline$\alpha 3(\mathrm{H} 126 \mathrm{R})-\mathrm{L} 838417-0.5 \mu \mathrm{g} / \mu \mathrm{L}$ & 7 & $2.57 \pm 0.57$ & $5.64 \pm 1.3$ & $77.03 \pm 26.73$ & $5.57 \pm 1.88$ & $31.46 \pm 5.11$ \\
\hline
\end{tabular}


A

B

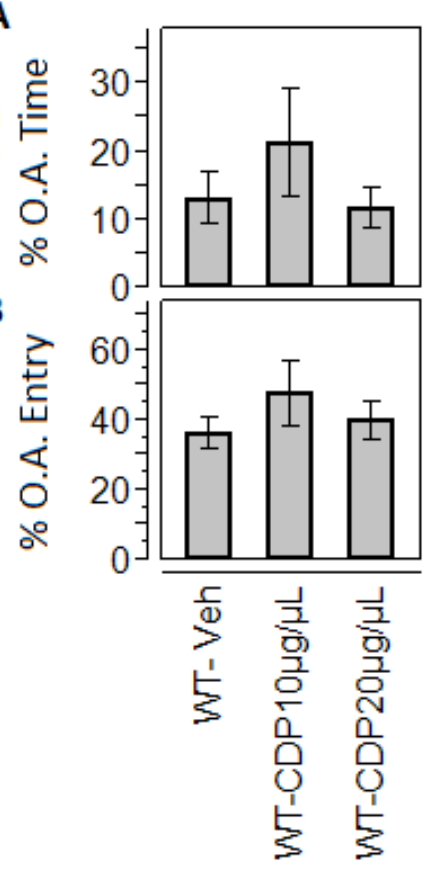

C

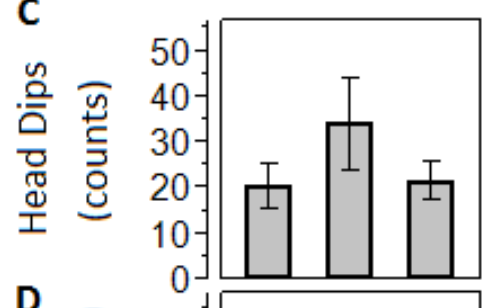

D

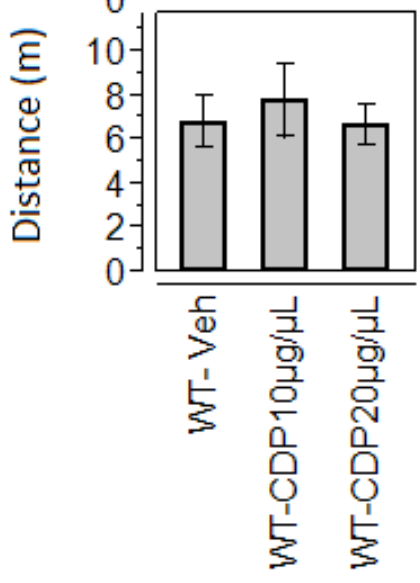

Figure 4-18. Intra-BLA Microinjection of CDP in WT C57BL/6J Mice

Anxiety-like and locomotor behaviors following drug treatment as assessed by elevated plus maze (EPM) test. (A): percentage of time spent on the open arm (\% O.A. Time). (B): percentage of entry to the open arm (\% O.A. Entry). (C): counts of incidences where the animal extended its head over the edge of the open arm (Head Dips). (D): total distance traveled on the EPM. 
A

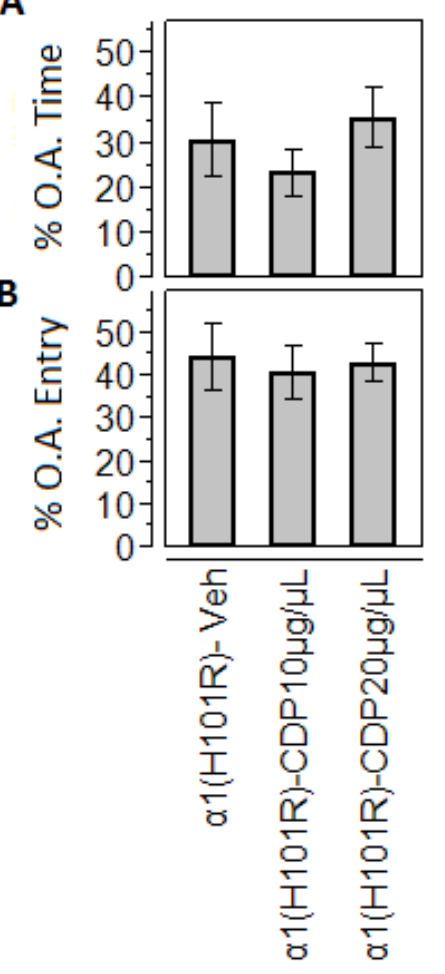

C

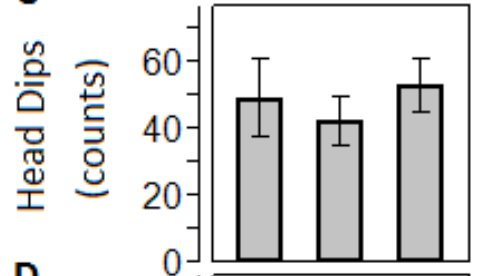

D

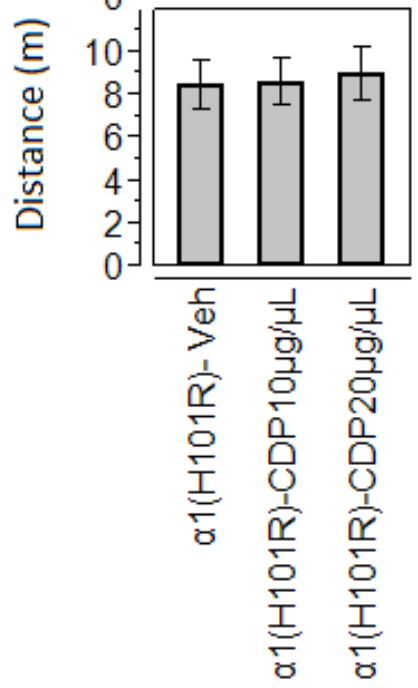

Figure 4-19. Intra-BLA Microinjection of CDP in $\alpha 1(H 101 R)$ Mice

Anxiety-like and locomotor behaviors following drug treatment as assessed by elevated plus maze (EPM) test. (A): percentage of time spent on the open arm (\% O.A. Time). (B): percentage of entry to the open arm (\% O.A. Entry). (C): counts of incidences where the animal extended its head over the edge of the open arm (Head Dips). (D): total distance traveled on the EPM. 
microinjections of CDP at one of the following doses: $10 \mu \mathrm{g} / \mu \mathrm{L}$, or $20 \mu \mathrm{g} / \mu \mathrm{L}$ in $0.3 \mathrm{uL}$ volume. Mice were tested on the EPM 5-8 min post-injection. The results are shown in Figure 4-20. One-way ANOVA with dose as independent variable revealed no significant effect of CDP microinjection on the dependent variables of \% O.A. Time, $\%$ O.A. Entry, Head Dips and Distance traveled on the EPM, $F_{s}(2,16)<1.91$, ps $>0.1$. A total of 19 mice were included in this experiment $(V e h, n=7 ; 10 \mu \mathrm{g} / \mu \mathrm{L}, \mathrm{n}=6$; and $20 \mu \mathrm{g} / \mu \mathrm{L}, \mathrm{n}=6)$.

\section{Intra-BLA Microinjection of CDP to $\alpha 3(\mathrm{H126R})$ Mice}

To assess the anxiolytic-like effects of CDP within the BLA in mice expressing the BZ-insensitive $\alpha 3$-subtype, $\alpha 3$ (H126R) mice were given bilateral intra-BLA microinjections of CDP at one of the following doses: $10 \mu \mathrm{g} / \mu \mathrm{L}$, or $20 \mu \mathrm{g} / \mu \mathrm{L}$ in $0.3 \mathrm{uL}$ volume. Mice were tested on the EPM 5-8 min post-injection. The results are shown in Figure 4-21. One-way ANOVA with dose as independent variable revealed significant effects of CDP microinjection on the dependent variables of Head Dips, and Distance traveled on the EPM, $F_{s}(2,20)>4.11$, ps $<0.05$. No significant effect was found on the dependent variables of \% O.A. Time and \% O.A. Entry. Dunnett's test revealed that CDP exerted significant anxiolytic-like and motor-stimulating effects as measured by significantly increased Head Dips and Distance traveled on the EPM at $20 \mu \mathrm{g} / \mu \mathrm{L}$ dose when compared to vehicle group $(p \mathrm{~s}<0.05)$. A total of 23 mice were included in this experiment (Veh, $\mathrm{n}=9 ; 10 \mu \mathrm{g} / \mu \mathrm{L}, \mathrm{n}=5$; and $20 \mu \mathrm{g} / \mu \mathrm{L}, \mathrm{n}=9$ ).

\section{Intra-BLA Microinjection of Non-Selective CDP - Other Parameters}

Besides the parameters reported in the figures, descriptive statistics were obtained for several other parameters, including the distance traveled on the open arm and closed arm, respectively (O.A. Distance, C.A. Distance), time and entry to the distal open arm (D.O.A. Time, D.O.A. Entry), as well as the time animal spent in the center zone (Center Time) during the EPM experimentation, are summarized in Table 4-4. 
A

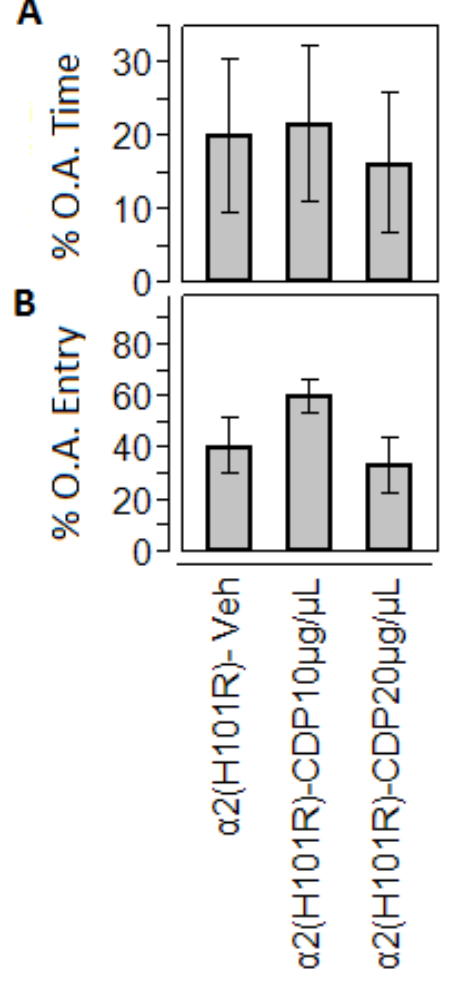

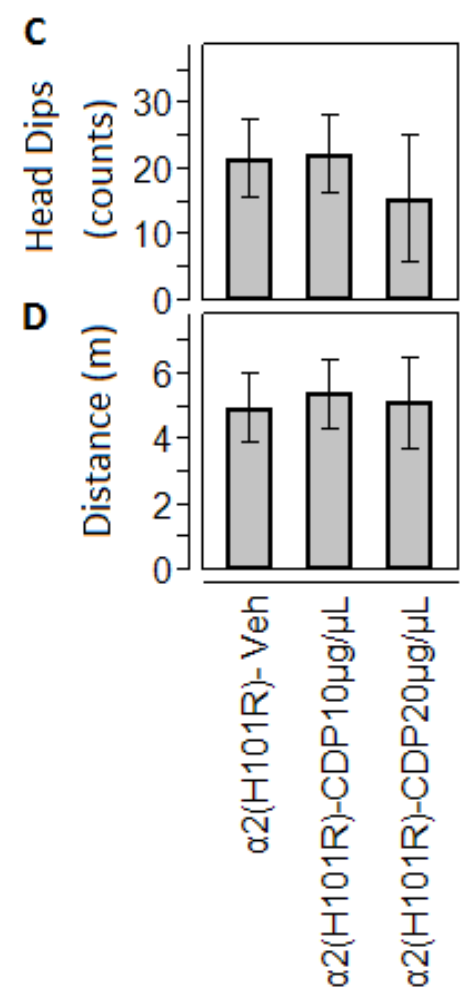

Figure 4-20. Intra-BLA Microinjection of CDP in $\alpha 2(H 101 R)$ Mice

Anxiety-like and locomotor behaviors following drug treatment as assessed by elevated plus maze (EPM) test. (A): percentage of time spent on the open arm (\% O.A. Time). (B): percentage of entry to the open arm (\% O.A. Entry). (C): counts of incidences where the animal extended its head over the edge of the open arm (Head Dips). (D): total distance traveled on the EPM. 
A

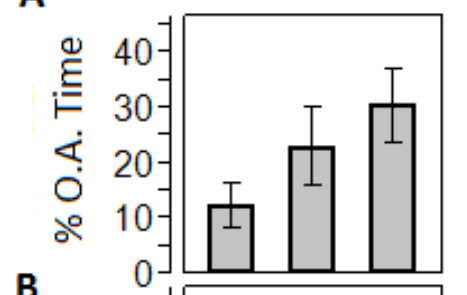

B

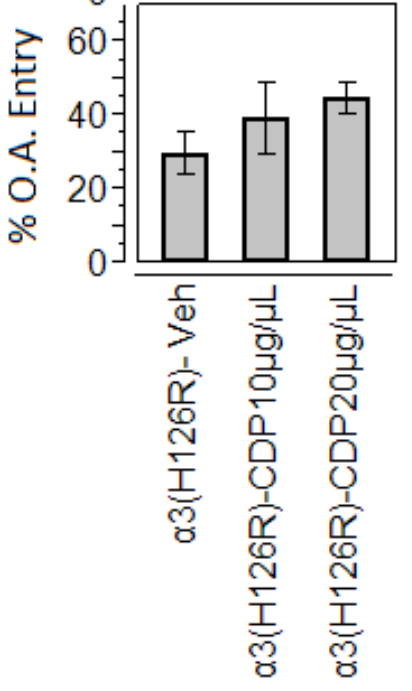

C

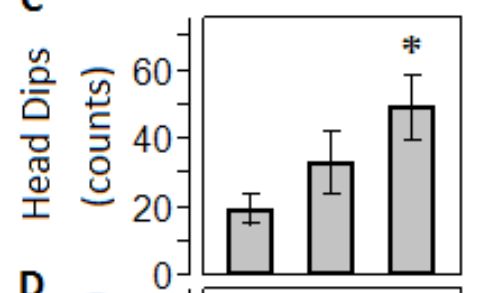

D

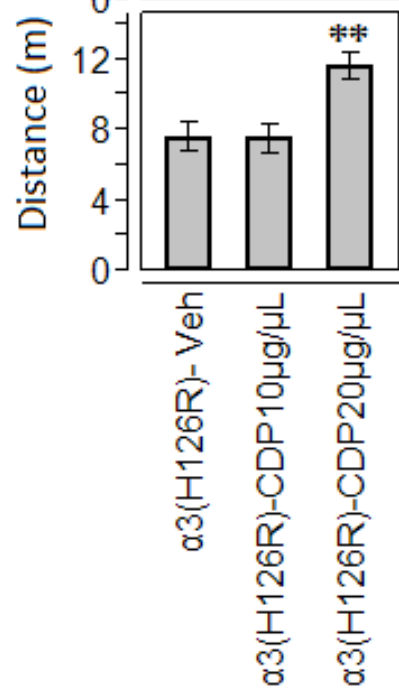

Figure 4-21. Intra-BLA Microinjection of CDP in $\alpha 3(\mathrm{H126R})$ Mice

Anxiety-like and locomotor behaviors following drug treatment as assessed by elevated plus maze (EPM) test. (A): percentage of time spent on the open arm (\% O.A. Time). (B): percentage of entry to the open arm (\% O.A. Entry). (C): counts of incidences where the animal extended its head over the edge of the open arm (Head Dips). (D): total distance traveled on the EPM. Asterisks represent significant differences between the vehicle injected control group and the drug injected experimental groups as assessed by ANOVA followed by post hoc Dunnett's comparisons against vehicle (Veh) injected group. ${ }^{*} p<$ $0.05 ; * * p 0.01$. 
Table 4-4. Intra-BLA Microinjection of Non-Selective CDP - Descriptive Statistics of Other Parameters

\begin{tabular}{lllllll}
\hline Treatment & $\mathrm{N}$ & O.A. Distance $(\mathrm{m})$ & C.A. Distance $(\mathrm{m})$ & D.O.A. Time (s) & D.O.A. Entry & Center Time (s) \\
\hline WT- Veh & 9 & $1.03 \pm 0.31$ & $4.34 \pm 0.6$ & $16.78 \pm 6.31$ & $3.11 \pm 1.06$ & $31.04 \pm 5.28$ \\
WT-CDP-10 $\mu \mathrm{g} / \mu \mathrm{L}$ & 6 & $1.77 \pm 0.85$ & $4.38 \pm 0.81$ & $20.77 \pm 10.73$ & $3.33 \pm 1.78$ & $35.78 \pm 7.1$ \\
WT-CDP-20 $\mu \mathrm{g} / \mu \mathrm{L}$ & 9 & $0.73 \pm 0.23$ & $4.52 \pm 0.6$ & $7.88 \pm 3.77$ & $1.56 \pm 0.69$ & $27.8 \pm 4.04$ \\
$\alpha 1(\mathrm{H} 101 \mathrm{R})-\mathrm{Veh}$ & 8 & $2.14 \pm 0.57$ & $4.72 \pm 0.66$ & $50.59 \pm 15.32$ & $5.63 \pm 1.51$ & $26.13 \pm 4.55$ \\
$\alpha 1(\mathrm{H} 101 \mathrm{R})-\mathrm{CDP}-10 \mu \mathrm{g} / \mu \mathrm{L}$ & 7 & $1.41 \pm 0.38$ & $5.35 \pm 0.73$ & $23.91 \pm 8.51$ & $2.86 \pm 0.8$ & $45.4 \pm 5.11$ \\
$\alpha 1(\mathrm{H} 101 \mathrm{R})-\mathrm{CDP}-20 \mu \mathrm{g} / \mu \mathrm{L}$ & 7 & $1.84 \pm 0.36$ & $5.34 \pm 0.71$ & $59.71 \pm 16.34$ & $5.43 \pm 1.38$ & $37.19 \pm 6.37$ \\
$\alpha 2(\mathrm{H} 101 \mathrm{R})-\mathrm{Veh}$ & 7 & $0.86 \pm 0.39$ & $3.1 \pm 0.81$ & $24.33 \pm 16.62$ & $2.71 \pm 1.21$ & $33.53 \pm 7.6$ \\
$\alpha 2(\mathrm{H} 101 \mathrm{R})-\mathrm{CDP}-10 \mu \mathrm{g} / \mu \mathrm{L}$ & 6 & $1.16 \pm 0.4$ & $2.91 \pm 0.69$ & $26.1 \pm 17.13$ & $2.67 \pm 1.26$ & $33.03 \pm 9.12$ \\
$\alpha 2(\mathrm{H} 101 \mathrm{R})-\mathrm{CDP}-20 \mu \mathrm{g} / \mu \mathrm{L}$ & 6 & $0.9 \pm 0.74$ & $3.12 \pm 0.67$ & $15.33 \pm 14.9$ & $1.83 \pm 1.64$ & $31.3 \pm 7.64$ \\
$\alpha 3(\mathrm{H} 126 \mathrm{R})-\mathrm{Veh}$ & 9 & $0.89 \pm 0.25$ & $5.22 \pm 0.58$ & $16.34 \pm 6.17$ & $1.56 \pm 0.41$ & $29.23 \pm 5.13$ \\
$\alpha 3(\mathrm{H} 126 \mathrm{R})-\mathrm{CDP}-10 \mu \mathrm{g} / \mu \mathrm{L}$ & 5 & $1.21 \pm 0.38$ & $4.78 \pm 0.72$ & $29.8 \pm 10.22$ & $2.4 \pm 0.68$ & $33.9 \pm 4.2$ \\
$\alpha 3(\mathrm{H} 126 \mathrm{R})-\mathrm{CDP}-20 \mu \mathrm{g} / \mu \mathrm{L}$ & 9 & $2.53 \pm 0.62$ & $6.77 \pm 0.52$ & $45.54 \pm 11.64$ & $6.11 \pm 1.69$ & $34.8 \pm 4.2$ \\
\hline
\end{tabular}




\section{CHAPTER 5. DISCUSSION}

\section{Summary of Findings}

The goal of this study was to further discern the contributions of different $\alpha$ subtype $\mathrm{GABA}_{\mathrm{A}}$ Rs to BZ-induced anxiolysis based on current existing knowledge. To accomplish this, we examined the anxiolytic-like effects of various subtype selective and non-selective $\mathrm{GABA}_{\mathrm{A}} \mathrm{R}$ PAMs given to WT C57BL/6J mice and point mutant mice that express BZ-insensitive $\alpha 1$-, $\alpha 2-$, or $\alpha 3$-subtype $\mathrm{GABA}_{\mathrm{A}} \mathrm{Rs}$. Because the BLA is known as a brain region that plays a pivotal role in mediating anxiety-like effects of BZs (M. Davis, 2000; Green \& Vale, 1992; Heldt \& Ressler, 2006; Pesold \& Treit, 1995; Sanders \& Shekhar, 1995), we also examined anxiolytic-like effects of intra-BLA microinjections of $\mathrm{GABA}_{\mathrm{A}} \mathrm{R}$ PAMs in WT mice as well as point mutant mice.

\section{The Effects of Systemic Injection of Selective GABAAR PAMs}

In the experiment using systemic injection of selective drugs, we found that selective positive modulation of $\alpha 1$-subtype $\mathrm{GABA}_{\mathrm{A}} \mathrm{Rs}$ by zolpidem produced mild anxiolytic-like effects in WT mice. The dose response relationships were in the form of inverted-U shape functions for the measurements of anxiety-like behaviors. Specifically, an increase of \% O.A. Entry could be observed at doses of $0.5 \mathrm{mg} / \mathrm{kg}$ and $1 \mathrm{mg} / \mathrm{kg}$. Systemic administration of zolpidem also produced a dose-dependent inhibition of motor activities, and resulted in pronounced motor-inhibiting effects at higher does $(1 \mathrm{mg} / \mathrm{kg}$ and $2 \mathrm{mg} / \mathrm{kg}$ ). This is in sharp contrast to the result obtained from $\alpha 1(\mathrm{H} 101 \mathrm{R})$ mice, where no effect on neither anxiety-like measurements nor motor activity was observed, suggesting the effects seen in WT mice were indeed mediated by the $\alpha 1$-subtype GABAARs.

Selective positive modulation of $\alpha 2-, \alpha 3-$, (and $\alpha 5-)$ subtype GABA $\mathrm{A}_{\mathrm{A}}$ by systemic injection of L-838417 $(0.5 \mathrm{mg} / \mathrm{kg}$ and $2 \mathrm{mg} / \mathrm{kg})$ produced profound anxiolyticlike effects in WT mice as indicated by increases in \% O.A. Time, \% O.A. Entry and Head Dips. These effects were accompanied by motor-stimulating effects at both doses tested. On the contrary, selective positive modulation of $\alpha 2-$, (and $\alpha 5-)$ subtype $\mathrm{GABA}_{\mathrm{A}}$ Rs by systemic injection of L-838417 to $\alpha 3(\mathrm{H} 126 \mathrm{R})$ mice elicited no statistically significant effects on the main measurements of anxiety-like behaviors or motor activity, suggesting that the $\alpha 3$-subtype $\mathrm{GABA}_{\mathrm{A}} \mathrm{Rs}$ are responsible for mediating a significant portion of the effects of L-838417 in the EPM paradigm. These findings were in line with a previous study showing the anxiolytic-like effects of L-838417 were left intact in $\alpha 2(\mathrm{H} 101 \mathrm{R})$ mice in a conditioned emotional response test (Morris et al., 2006), signifying the contribution of $\alpha 3$-subtype GABA $A$ Rs. However, one-way ANOVA of the measurements related to the animal's activity on the distal open arm (D.O.A.), such as D.O.A. Time and D.O.A. Entry, detected significant anxiolytic-like effects of L-838417 in $\alpha 3(\mathrm{H} 126 \mathrm{R})$ mice, $F \mathrm{~s}(2,22)>4.03, p \mathrm{~s}<0.05$. Post hoc Dunnett's tests revealed the effects were only seen at the high dose of $2 \mathrm{mg} / \mathrm{kg}, p s<0.05$. This suggested that the involvement of $\alpha 2$-subtype in mediating L-838417 induced anxiolysis should not be 
overlooked. Taken together, we conclude that both $\alpha 3$-, and to a lesser extent, $\alpha 2$-subtype $\mathrm{GABA}_{\mathrm{A}}$ Rs contribute to the anxiolytic-like effects of L-838417 at doses tested.

Selective positive modulation of $\alpha 3$-subtype $\mathrm{GABA}_{\mathrm{A}} \mathrm{Rs}$ by systemic injection of TP003 $(0.5 \mathrm{mg} / \mathrm{kg}$ and $2 \mathrm{mg} / \mathrm{kg})$ produced profound anxiolytic-like effects in WT mice at both doses tested. Motor-stimulating effects at $0.5 \mathrm{mg} / \mathrm{kg}$ dose were also observed.

Importantly, the anxiolytic-like effects of systemic TP003 injection were completely abolished in $\alpha 3(\mathrm{H} 126 \mathrm{R})$ mice. In contrast, TP003 retained its anxiolytic-like effects in $\alpha 2(\mathrm{H} 101 \mathrm{R})$ mice, suggesting the anxiolytic-like effects of TP003 were indeed mediated by $\alpha 3$-, but not $\alpha 2$-subtype GABA ${ }_{A}$ Rs. Interestingly, TP003 exerted motor-stimulating effects in $\alpha 3(\mathrm{H} 126 \mathrm{R})$ mice, suggesting that (i) the motor-stimulating effects of TP003 were not mediated entirely by the $\alpha 3$-subtype $\mathrm{GABA}_{\mathrm{A}} \mathrm{Rs}$, and (ii) the anxiolytic-like effects of TP003 in WT mice were not simply due to heightened locomotor activities.

Together, our results suggested that (i) systemic positive modulation of the $\alpha 1$ subtype $\mathrm{GABA}_{\mathrm{A}} \mathrm{Rs}$ exerted anxiolytic-like effects at certain doses, however, the "therapeutic window" was narrow and the dose for anxiolysis overlapped with the dose for motor-impairment; (ii) systemic positive modulation of the $\alpha 2-, \alpha 3-$, (and $\alpha 5-$ ) subtype $\mathrm{GABA}_{\mathrm{A}}$ Rs exerted anxiolytic-like effects and motor-stimulating effects, and such effects were weakened in $\alpha 3(\mathrm{H} 126 \mathrm{R})$ mice; and (iii) systemic positive modulation of the $\alpha 3$-subtype $\mathrm{GABA}_{\mathrm{A}} \mathrm{Rs}$ exerted anxiolytic-like effects which were accompanied by motor-stimulating effects, although the exact molecular substrates for the motorstimulating effects remained unclear.

\section{The Effects of Systemic Injection of the Non-Selective CDP}

To extend a previous study (K. S. Smith et al., 2012) that investigated the effect of CDP in male point mutant mice and to explore the potential sex differences in animals' response to BZ-induced anxiolysis, both males and females are used in this experiment. In the experiment of systemic injection of non-selective CDP, we found that although males and females generally showed little differences in terms of their response to drug treatment, some discrepancies do exist. Systemic injection of CDP elicited significant anxiolytic-like effects in both male and female WT C57BL/6J mice as well as $\alpha 1(\mathrm{H} 101 \mathrm{R})$ mice. Systemic injection of CDP produced no anxiolytic-like effects in male $\alpha 2(\mathrm{H} 101 \mathrm{R})$ mice, or in female $\alpha 2(\mathrm{H} 101 \mathrm{R})$ mice. Interestingly, in our experiment, systemic injection of CDP produced no statistically significant anxiolytic-like effects in male $\alpha 3(\mathrm{H} 126 \mathrm{R})$ mice, although in female $\alpha 3(\mathrm{H} 126 \mathrm{R})$ mice the anxiolytic-like effects were present. These results indicated that the anxiolytic-like effects of systemic CDP injection were left intact when $\alpha 1$-subtype $\mathrm{GABA}_{\mathrm{A}} \mathrm{Rs}$ were mutated, however, the anxiolytic-like effects were weakened when $\alpha 2$-, as well as $\alpha 3$-subtype $\mathrm{GABA}_{\mathrm{A}}$ Rs were mutated, suggesting that (i) the $\alpha 1$-subtype $\mathrm{GABA}_{\mathrm{A}} \mathrm{Rs}$ are dispensable for BZ-induced anxiolysis, and (ii) both the $\alpha 2$ - and $\alpha 3$-subtype $\mathrm{GABA}_{\mathrm{A}} \mathrm{Rs}$ are needed for $\mathrm{BZ}$ to exert its full effects in inducing anxiolysis. 


\section{The Effects of Intra-BLA Microinjection of Selective GABA $\mathrm{A}$ PAMs}

In the experiment with intra-BLA microinjection of selective drugs, we found that selective positive modulation of $\alpha 1$-subtype $\mathrm{GABA}_{\mathrm{A}} \mathrm{Rs}$ by zolpidem within the BLA produced an anxiolytic-like effect at $0.1 \mu \mathrm{g} / \mu \mathrm{L}$ dose, but not other doses tested. Similar to the systemic injection result, the dose response curves were in the form of inverted-U shape functions for the measurements of anxiety-like behaviors, although no motor inhibition or stimulation was observed. Selective positive modulation of $\alpha 2-$, (and $\alpha 5-)$ subtype $\mathrm{GABA}_{\mathrm{A}} \mathrm{Rs}$ via intra-BLA microinjection of L-838417 in $\alpha 3(\mathrm{H} 126 \mathrm{R})$ mice produced anxiolytic-like effects at $0.5 \mu \mathrm{g} / \mu \mathrm{L}$ dose with no significant effect on motor activity. Selective positive modulation of $\alpha 3$-subtype $\mathrm{GABA}_{\mathrm{A}} \mathrm{Rs}$ via intra-BLA microinjection of TP003 produced anxiolytic-like effects at $0.25 \mu \mathrm{g} / \mu \mathrm{L}$ and $0.5 \mu \mathrm{g} / \mu \mathrm{L}$ doses, and again, the impact on motor activity was minimal. Together, our results suggested that (i) intra-BLA microinjection of subtype selective drugs produced similar behavioral outcomes when compared to systemic injections in terms of anxiety-like behaviors; (ii) intra-BLA microinjection of subtype selective drugs generally produced little impact on motor activities; and (iii) BLA is critically involved in mediating the anxiolytic-like effects but not the locomotor effects of the subtype selective drugs.

\section{The Effects of Intra-BLA Microinjection of Non-Selective CDP}

In the experiment with intra-BLA microinjection of the non-selective CDP, our findings were unanticipated in light of previous studies that showed intra-BLA microinjection of midazolam and CDP produces anxiolytic-like effects as measured by the EPM and open field test (McNamara \& Skeleton, 1993; Menard \& Treit, 1999; Pesold \& Treit, 1995). Unexpectedly, no statistically significant anxiolytic-like effect were found when CDP was microinjected to the BLA of WT, $\alpha 1(\mathrm{H} 101 \mathrm{R})$, or $\alpha 2(\mathrm{H} 101 \mathrm{R})$ mice. Anxiolytic-like effects could be observed when CDP was microinjected to the BLA of $\alpha 3(\mathrm{H} 126 \mathrm{R})$ mice, and were accompanied by an unexpected motor-stimulating effects, suggesting that the BLA is involved in certain aspects of the anxiolytic-like and motorstimulating effects of the non-selective BZ drug CDP.

\section{Interpretation of Results}

Although the EPM is a standardized behavioral paradigm to assess anxiety-like behaviors in rodents, the actual design of the EPM apparatus and the testing conditions are far from uniform across different laboratories. Variations could arise from a number of discrepancies such as the opacity of the maze walls, the size of the testing room, and the illumination condition (Violle, Balandras, Le Roux, Desor, \& Schroeder, 2009). This inevitably makes direct comparison between results obtained from studies using different testing conditions somewhat problematic. In this study, we used the same EPM apparatus in a standard behavioral testing room with controlled lighting condition to minimize test variations, which allowed reliable comparison of test scores across different experiments. 
The results obtained in the experiments with systemic injection of selective drugs were generally in line with previous studies. Systemic positive modulation of the $\alpha 1-$ subtype $\mathrm{GABA}_{\mathrm{A}}$ Rs by zolpidem exerted mild anxiolytic-like effects at certain doses. However, the "therapeutic window" was narrow and the dose for anxiolysis overlapped with the dose for motor-inhibiting effects. This is in line with a previous study that reported similar findings in rats (Griebel, Sanger, \& Perrault, 1996), and is in keeping with another study that suggested the involvement of $\alpha 1$-subtype in anxiety (Belzung et al., 2000). However, from a pharmacological point of view, the narrow therapeutic window would severely limit the application of zolpidem as a systemic anxiolytic drug. Systemic positive modulation of the $\alpha 2$-subtype $\mathrm{GABA}_{\mathrm{A}} \mathrm{Rs}$ by injection of L-838417 in $\alpha 3$ (H126R) mice exerted minimal anxiolytic-like effects at doses tested as revealed by non-significant statistical results on the main measurements of anxiety-like behaviors, which appeared much weaker than the effects of L-838417 found in WT mice. However, parameters related to the animal's activity on the D.O.A. revealed some residue anxiolytic-like effects of L-838417 in $\alpha 3(\mathrm{H} 126 \mathrm{R})$ mice. This suggests that the $\alpha 2$-subtype $\mathrm{GABA}_{\mathrm{A}} \mathrm{Rs}$, previously thought to play a pivotal role in mediating BZ-induced anxiolysis (Low et al., 2000; K. S. Smith et al., 2012), were in fact partially involved in mediating the anxiolytic-like effects elicited by L- 838417 at doses tested. Systemic positive modulation of the $\alpha 3$-subtype GABA $\mathrm{A}_{\mathrm{A}}$ by injection of TP003 in WT mice exerted anxiolytic-like effects. This is also in keeping with the previous finding (Atack et al., 2005; Dias et al., 2005; Fischer et al., 2011) that suggested the involvement of $\alpha 3$ subtype in anxiety. Our data also revealed a motor-stimulating effects induced by systemic injection of TP003. However, systemic TP003 treatment retained its motorstimulating effects in $\alpha 3(\mathrm{H} 126 \mathrm{R})$ mice, whereas the anxiolytic-like effects were completely abolished. This suggests the motor-stimulating effect of TP003 might not be entirely mediated by the $\alpha 3$-subtype GABA ${ }_{A} R$.

In line with previous studies (K. S. Smith et al., 2012), systemic positive modulation of the $\alpha 1-, \alpha 2-, \alpha 3-$, (and $\alpha 5-$ ) subtype GABA $\mathrm{A}_{\mathrm{A}}$ s by injection of CDP in WT mice exerted anxiolytic-like effects in males. Similar effects were also observed in female WTs. The anxiolytic-like effects were preserved in both male and female $\alpha 1(\mathrm{H} 101 \mathrm{R}) \mathrm{mice}$. Of note, for female subjects, the $5 \mathrm{mg} / \mathrm{kg}$ dose elicited no significant anxiolytic-like effects in WTs, whereas the same dose elicited prominent anxiolytic-like effects in $\alpha 1(\mathrm{H} 101 \mathrm{R})$ mice, suggesting the anxiolytic-like effects of CDP was not only preserved, but also potentiated in female mice lacking BZ-sensitive $\alpha 1$-subtype $\mathrm{GABA}_{\mathrm{A}}$ Rs. Expectedly, both male and female $\alpha 2(\mathrm{H} 101 \mathrm{R})$ mice were generally insensitive towards the anxiolytic-like effects of systemic CDP injection. Surprisingly, systemic injection of CDP elicited no significant anxiolytic-like effects in male $\alpha 3(\mathrm{H} 126 \mathrm{R})$ mice, which was in contrast with a previous report (K. S. Smith et al., 2012). On the other hand, female $\alpha 3(\mathrm{H} 126 \mathrm{R})$ mice remained sensitive toward CDP induced anxiolysis. To sum up, (i) for males, the anxiolytic-like effects of BZ were unaffected in $\alpha 1(\mathrm{H} 101 \mathrm{R})$ mice, and reduced in $\alpha 2(\mathrm{H} 101 \mathrm{R})$ as well as $\alpha 3(\mathrm{H} 126 \mathrm{R})$ mice, suggesting both $\alpha 2$ - and $\alpha 3$-subtypes were crucially involved, and $\alpha 1$-subtype GABA $\mathrm{A}_{\mathrm{A}} \mathrm{R}$ were dispensable, (ii) for females, the anxiolytic-like effects of BZ were potentiated in $\alpha 1(\mathrm{H} 101 \mathrm{R})$ mice, reduced in $\alpha 2(\mathrm{H} 101 \mathrm{R})$ mice and preserved in $\alpha 3(\mathrm{H} 126 \mathrm{R})$ mice, 
suggesting that only $\alpha 2$-subtype GABA $\mathrm{A}_{\mathrm{A}}$ were crucially involved, while $\alpha 1$ - and $\alpha 3$ subtypes were dispensable.

The sex differences observed suggested that female mice were generally more resilient in terms of their sensitivity towards BZ-induced anxiolysis when a particular $\alpha$ subtype is mutated. Sex differences in GABAergic signaling were supported by various studies in human as well as in animals. For example, a previous study showed that the availability of $\mathrm{BZ}$-sensitive $\mathrm{GABA}_{\mathrm{A}} \mathrm{R}$ in women was higher when compared to men (Esterlis et al., 2013). In rodents, one study showed that the expressions of $\alpha 1$ - and $\alpha 3$ subtype $\mathrm{GABA}_{\mathrm{A}} \mathrm{Rs}$ in the anterior substantia nigra pars reticulata were higher in females than males at postnatal day 5 (Chudomel, Herman, Nair, Moshe, \& Galanopoulou, 2009). However, other studies revealed no drastic sex differences in the expression of $\alpha 1-, \alpha 2-$, or $\alpha 5$-subunit (A. M. Davis, Penschuck, Fritschy, \& McCarthy, 2000; Nett, Jorge-Rivera, Myers, Clark, \& Henderson, 1999). These findings, although ambiguous, offered a possible rationale that sex differences in $\mathrm{GABA}_{\mathrm{A}} \mathrm{R}$ expression level could explain why female mice might be more likely to retain sensitivity to BZ-induced anxiolysis when a particular $\alpha$-subtype was rendered BZ-insensitive than their male counterparts. Future experiments addressing the sex-differences of $\mathrm{GABA}_{\mathrm{A}} \mathrm{R}$ expression in the BLA and the response towards BZ-induced anxiolysis in rodents would be of great interest.

Currently, the effect of intra-BLA microinjection of selective drugs is poorly understood. Our results revealed that selective intra-BLA positive modulation of $\alpha 1-, \alpha 2-$, or $\alpha 3$-subtype $\mathrm{GABA}_{\mathrm{A}}$ Rs produced similar anxiolytic-like behavioral outcomes when compared to systemic positive modulation. This suggested that BLA is indeed a critical brain region which is sufficient to mediate the anxiolytic-like effects, but not the motorinhibiting or stimulating effects of the subtype selective GABA ${ }_{A}$ PAMs.

The result obtained from the intra-BLA microinjection of CDP experiment was somewhat difficult to interpret. CDP elicited no pronounced anxiolytic-like effects in WT, $\alpha 1(\mathrm{H} 101 \mathrm{R})$ or $\alpha 2(\mathrm{H} 101 \mathrm{R})$ mice, when administered directly to the BLA. This is in contrast to previous studies that showed intra-BLA microinjection of CDP and midazolam elicited anxiolytic-like effects in the EPM test or open field test in rodents (McNamara \& Skeleton, 1993; Menard \& Treit, 1999; Pesold \& Treit, 1995). The observed phenomena might be sensitive to the test conditions, i.e., due to the lighting condition and the particular construction of the EPM used in our experiment that had transparent plexiglass walls around the closed arm, rather than opaque or wooden ones used in many other studies. These particular factors were known to affect the animal's behavior on the EPM (Violle et al., 2009). Another possible explanation is that since $\mathrm{GABA}_{\mathrm{A}} \mathrm{Rs}$ are known to be differentially expressed on different populations of GABAergic interneurons (Baude, Bleasdale, Dalezios, Somogyi, \& Klausberger, 2007; Milenkovic et al., 2013), the augmentation effects of PAMs, including CDP, on the $\mathrm{GABA}_{\mathrm{A}} \mathrm{R}$ may not be restricted to the projection neurons. It is possible that application of CDP locally would cause inhibition of certain population of GABAergic interneurons, and subsequently result in reduced GABA release from those neurons which might further cancel out the potentiation of the inhibitory effects exerted by CDP on the projection neurons. Molecular and functional characterization of the $\mathrm{GABA}_{\mathrm{A}} \mathrm{Rs}$ 
expressed on the GABAergic interneurons within the BLA would be of great value to help better understand the properties of the GABAergic microcircuitries and their functions in the context of fear and anxiety. A third possibility is that under certain circumstances, GABA signaling might actually be excitatory rather than inhibitory. A recent study suggested that a subpopulation of parvalbumin positive interneurons could synchronize the activity of a group of pyramidal neurons via GABAergic excitation within the BLA (Spampanato, Sullivan, Perumal, \& Sah, 2016). It is thus also likely that BZ-induced augmentation of $\mathrm{GABA}_{\mathrm{A}}$ Rs might increase the synchronizing effect of the parvalbumin positive interneurons and subsequently enhance the BLA net output. Further studies that focus on addressing the alteration of intra-BLA GABAergic microcircuitries under the influence of CDP will benefit the understanding of the paradoxical effects seen here in the intra-BLA CDP microinjection experiment.

\section{Limitations of Experimental Design and Results}

As mentioned above, the EPM test is a locomotion-dependent behavioral paradigm and the measurements of anxiety should be examined with care when a motorinhibiting or stimulating effects are present (Reynolds et al., 2001). However, the use of entry ratios (\% O.A. Entry), rather than the raw numbers of O.A. entry, should help to at least reduce the bias introduced by locomotion differences amongst different groups. Future experiments employing locomotion-independent anxiety tests, such as stressinduced hyperthermia, would be beneficial for this matter.

In this study, only one brain region, i.e. the BLA, is investigated. As previously mentioned, the BNST and hippocampus are two other main brain regions known to play a role in anxiety-like behaviors (Engin \& Treit, 2007b; Gafford et al., 2012). Future studies investigating the anxiolytic-like effects of intra-BNST and intra-hippocampus microinjection of selective and non-selective GABA $\mathrm{A}_{\mathrm{R}} \mathrm{PAMs}$ in WT and point mutant mice would be of great importance in pinpointing the regional specific roles the $\mathrm{GABA}_{\mathrm{A}} \mathrm{R} \alpha$-subtypes play in mediating BZ-induced anxiolysis.

\section{Conclusion and Clinical Significance}

In an attempt to unify the current debate concerning "which $\mathrm{GABA}_{\mathrm{A}} \mathrm{R} \alpha$-subtype contributes to BZ-induced anxiolysis", this study incorporates both subtype selective $\mathrm{GABA}_{\mathrm{A}} \mathrm{R}$ PAM and $\alpha$-subunit point mutant mice to finely dissect the functional roles played by $\alpha 1-, \alpha 2-$, and $\alpha 3$-subtype $\mathrm{GABA}_{\mathrm{A}} \mathrm{Rs}$ in mediating anxiety-like behaviors and anxiolysis-like effects. In general, our findings support the conclusion that both $\alpha 1-, \alpha 2-$, and $\alpha 3$-subtype $\mathrm{GABA}_{\mathrm{A}}$ Rs are involved in mediating anxiety-like behaviors. However, subtle differences do exist. Positive modulation of $\alpha 1$-subtype GABA $A_{A}$ Rs exerts anxiolytic-like effects with a narrow therapeutic window that overlaps with the dose for motor-inhibiting effects. In contrast, positive modulation of $\alpha 2-, \alpha 3-$ (and $\alpha 5-$ ) subtype $\mathrm{GABA}_{\mathrm{A}}$ Rs exerts significant anxiolytic-like and motor-stimulating effects. These effects are weakened in the absence of BZ-sensitive $\alpha 3$-subtypes. Positive modulation of the $\alpha 3$ - 
subtype $\mathrm{GABA}_{\mathrm{A}}$ Rs exerts anxiolytic-like effects that are accompanied by significant motor-stimulating effects. Lack of either BZ-sensitive $\alpha 2$-, or $\alpha 3$-subtype $\mathrm{GABA}_{\mathrm{A}} \mathrm{Rs}$ weakened the anxiolytic-like effects of CDP in a sex-dependent manner. Together, our findings sufficiently addressed the currently debatable view of the role played by the $\alpha 3$ subtype $\mathrm{GABA}_{\mathrm{A}} \mathrm{Rs}$ in $\mathrm{BZ}$-induced anxiolysis.

We have also extended the current understanding of the differential roles played by $\alpha 1$-, $\alpha 2$-, and $\alpha 3$-subtype $\mathrm{GABA}_{\mathrm{A}} \mathrm{Rs}$ on anxiety-like behaviors from the systemic level to a specific brain area, the BLA. Our data clearly indicates that the anxiolytic-like effects of selective intra-BLA positive modulation of $\alpha 1-, \alpha 2$-, and $\alpha 3$-subtype $\mathrm{GABA}_{\mathrm{A}} \mathrm{Rs}$ are largely similar to the systemic positive modulation, in absence of the impact on motor activities. The non-selective positive modulation of $\mathrm{GABA}_{\mathrm{A}} \mathrm{Rs}$ in the BLA results in minimal, unclear effects on anxiety measures, which might be explained by a complex inhibition / disinhibition balance between the $\mathrm{GABA}_{\mathrm{A}} \mathrm{Rs}$ expressed on the projection neurons versus the $\mathrm{GABA}_{A} \mathrm{Rs}$ expressed on the inhibitory interneurons under the influence of non-selective BZs within the BLA.

Our results suggest that $\alpha 3$ - and/or $\alpha 2$-subtype selective GABA $\mathrm{R}$ PAMs, such as TP003, could be prime candidates for developing selective anxiolytic drugs. The motorstimulating effects found in systemic TP003 treatment should be further investigated to identify the exact molecular substrate mediating such effects. Our results also suggest that novel $\alpha 2$-subtype selective $\mathrm{GABA}_{\mathrm{A}} \mathrm{R}$ PAMs would be of great value for both developing anxiolytic drugs, and for advancing the investigation of the differential functional roles played by different $\mathrm{GABA}_{\mathrm{A}} \mathrm{R} \alpha$-subtypes in the brain. 


\section{LIST OF REFERENCES}

Abuhamdah, R. M., Hussain, M. D., Chazot, P. L., \& Ennaceur, A. (2015). Effects of chronic fluoxetine treatment on anxious behaviour of BALB/c mice in a 3dimensional maze. Stress, 18(6), 677-685. doi: 10.3109/10253890.2015.1083550

Adolphs, R., Gosselin, F., Buchanan, T. W., Tranel, D., Schyns, P., \& Damasio, A. R. (2005). A mechanism for impaired fear recognition after amygdala damage. Nature, 433(7021), 68-72. doi: 10.1038/nature03086

Adolphs, R., Tranel, D., Damasio, H., \& Damasio, A. R. (1995). Fear and the human amygdala. J Neurosci., 15(9), 5879-5891.

Adriaan Bouwknecht, J., Olivier, B., \& Paylor, R. E. (2007). The stress-induced hyperthermia paradigm as a physiological animal model for anxiety: a review of pharmacological and genetic studies in the mouse. Neurosci Biobehav Rev., 31(1), 41-59.

Amaral, D., \& Lavenex, P. (2007). Hippocampal Neuroanatomy. In P. Andersen, R. Morris, D. Amaral, T. Bliss \& J. O'Keefe (Eds.), The Hippocampus Book. New York, NY: Oxford University Press.

American Psychiatric Association. (2000). Diagnostic and statistical manual of mental disorders (Fourth Edition, Text Revision ed.). Washington, DC: American Psychiatric Association.

Anthony, T. E., Dee, N., Bernard, A., Lerchner, W., Heintz, N., \& Anderson, D. J. (2014). Control of stress-induced persistent anxiety by an extra-amygdala septohypothalamic circuit. Cell, 156(3), 522-536. doi: 10.1016/j.cell.2013.12.040

Atack, J. R. (2005). The benzodiazepine binding site of GABA(A) receptors as a target for the development of novel anxiolytics. Expert Opin Investig Drugs, 14(5), 601618. doi: $10.1517 / 13543784.14 .5 .601$

Atack, J. R. (2010a). Development of Subtype-Selective GABAA Receptor Compounds for the Treatment of Anxiety, Sleep Disorders and Epilepsy. In J. M. Monti, S. R. Pandi-Perumal \& H. Möhler (Eds.), GABA and Sleep, Molecular, Functional and Clinical Aspects (pp. 25-72). Basel, Switzerland: Springer Basel AG.

Atack, J. R. (2010b). GABAA receptor alpha2/alpha3 subtype-selective modulators as potential nonsedating anxiolytics. Curr Top Behav Neurosci., 2, 331-360.

Atack, J. R., Bayley, P. J., Seabrook, G. R., Wafford, K. A., McKernan, R. M., \& Dawson, G. R. (2006). L-655,708 enhances cognition in rats but is not proconvulsant at a dose selective for alpha5-containing GABAA receptors. Neuropharmacology, 51(6), 1023-1029. doi: 10.1016/j.neuropharm.2006.04.018

Atack, J. R., Hutson, P. H., Collinson, N., Marshall, G., Bentley, G., Moyes, C., . . . Dawson, G. R. (2005). Anxiogenic properties of an inverse agonist selective for alpha3 subunit-containing GABA A receptors. Br J Pharmacol, 144(3), 357-366. doi: $10.1038 /$ sj.bjp.0706056

Atack, J. R., Wafford, K. A., Tye, S. J., Cook, S. M., Sohal, B., Pike, A., .. McKernan, R. M. (2006). TPA023 [7-(1,1-dimethylethyl)-6-(2-ethyl-2H-1,2,4-triazol-3ylmethoxy)-3-(2-fluorophenyl )-1,2,4-triazolo[4,3-b]pyridazine], an agonist selective for alpha2- and alpha3-containing GABAA receptors, is a nonsedating 
anxiolytic in rodents and primates. $J$ Pharmacol Exp Ther, 316(1), 410-422. doi: 10.1124/jpet.105.089920

Avery, S. N., Clauss, J. A., \& Blackford, J. U. (2015). The Human BNST: Functional Role in Anxiety and Addiction. Neuropsychopharmacology. doi: 10.1038/npp.2015.185

Bailey, K. R., \& Crawley, J. N. (2009). Anxiety-related behaviors in mice. In J. J. Buccafusco (Ed.), Methods of Behavior Analysis in Neuroscience (Second ed.). Boca Raton, FL, USA: CRC Press/Taylor \& Francis.

Bannerman, D. M., Grubb, M., Deacon, R. M. J., Yee, B. K., Feldon, J., \& Rawlins, J. N. P. (2003). Ventral hippocampal lesions affect anxiety but not spatial learning. Behav Brain Res, 139(1-2), 197-213. doi: 10.1016/s0166-4328(02)00268-1

Bannerman, D. M., Rawlins, J. N., McHugh, S. B., Deacon, R. M., Yee, B. K., Bast, T., . .. Feldon, J. (2004). Regional dissociations within the hippocampus--memory and anxiety. Neurosci Biobehav Rev, 28(3), 273-283. doi: 10.1016/j.neubiorev.2004.03.004

Barnard, E. A., Skolnick, P., Olsen, R. W., Mohler, H., Sieghart, W., Biggio, G., . . . Langer, S. Z. (1998). International Union of Pharmacology. XV. Subtypes of gamma-aminobutyric acidA receptors: classification on the basis of subunit structure and receptor function. Pharmacol Rev, 50(2), 291-313.

Baude, A., Bleasdale, C., Dalezios, Y., Somogyi, P., \& Klausberger, T. (2007). Immunoreactivity for the GABAA receptor alpha1 subunit, somatostatin and Connexin36 distinguishes axoaxonic, basket, and bistratified interneurons of the rat hippocampus. Cereb Cortex, 17(9), 2094-2107. doi: 10.1093/cercor/bhl117

Belelli, D., Harrison, N. L., Maguire, J., Macdonald, R. L., Walker, M. C., \& Cope, D. W. (2009). Extrasynaptic GABAA receptors: form, pharmacology, and function. $J$ Neurosci, 29(41), 12757-12763. doi: 10.1523/JNEUROSCI.3340-09.2009

Belzung, C., Le Guisquet, A. M., \& Griebel, G. (2000). Beta-CCT, a selective BZomegal receptor antagonist, blocks the anti-anxiety but not the amnesic action of chlordiazepoxide in mice. Behav Pharmacol., 11(2), 125-131.

Belzung, C., \& Lemoine, M. (2011). Criteria of validity for animal models of psychiatric disorders: focus on anxiety disorders and depression. Biol Mood Anxiety Disord, 1(1), 9. doi: 10.1186/2045-5380-1-9

Bishop, S., Duncan, J., Brett, M., \& Lawrence, A. D. (2004). Prefrontal cortical function and anxiety: controlling attention to threat-related stimuli. Nat Neurosci, 7(2), 184-188. doi: 10.1038/nn1173

Blanchard, D. C., Griebel, G., \& Blanchard, R. J. (2003). The Mouse Defense Test Battery: pharmacological and behavioral assays for anxiety and panic. Eur $J$ Pharmacol, 463(1-3), 97-116.

Boyden, E. S. (2011). A history of optogenetics: the development of tools for controlling brain circuits with light. F1000 Biol Rep, 3, 11. doi: 10.3410/B3-11

Boyden, E. S., Zhang, F., Bamberg, E., Nagel, G., \& Deisseroth, K. (2005). Millisecondtimescale, genetically targeted optical control of neural activity. Nat Neurosci, 8(9), 1263-1268. doi: $10.1038 / \mathrm{nn} 1525$

Breitfeld, T., Bruning, J. E., Inagaki, H., Takeuchi, Y., Kiyokawa, Y., \& Fendt, M. (2015). Temporary inactivation of the anterior part of the bed nucleus of the stria 
terminalis blocks alarm pheromone-induced defensive behavior in rats. Front Neurosci, 9, 321. doi: 10.3389/fnins.2015.00321

Brickley, S. G., \& Mody, I. (2012). Extrasynaptic GABA(A) receptors: their function in the CNS and implications for disease. Neuron, 73(1), 23-34. doi: 10.1016/j.neuron.2011.12.012

Burghardt, N. S., Sullivan, G. M., McEwen, B. S., Gorman, J. M., \& LeDoux, J. E. (2004). The selective serotonin reuptake inhibitor citalopram increases fear after acute treatment but reduces fear with chronic treatment: a comparison with tianeptine. Biol Psychiatry, 55(12), 1171-1178. doi: 10.1016/j.biopsych.2004.02.029

Butler, R. K., White, L. C., Frederick-Duus, D., Kaigler, K. F., Fadel, J. R., \& Wilson, M. A. (2012). Comparison of the activation of somatostatin- and neuropeptide Ycontaining neuronal populations of the rat amygdala following two different anxiogenic stressors. Exp Neurol, 238(1), 52-63. doi: 10.1016/j.expneurol.2012.08.002

Campese, V. D., Gonzaga, R., Moscarello, J. M., \& LeDoux, J. E. (2015). Modulation of instrumental responding by a conditioned threat stimulus requires lateral and central amygdala. Front Behav Neurosci, 9, 293. doi: 10.3389/fnbeh.2015.00293

Caruncho, H. J., \& Costa, E. (1994). Double-immunolabelling analysis of GABAA receptor subunits in label-fracture replicas of cultured rat cerebellar granule cells. Receptors Channels, 2(2), 143-153.

Charney, D. S., Heninger, G. R., \& Breier, A. (1984). Noradrenergic function in panic anxiety. Effects of yohimbine in healthy subjects and patients with agoraphobia and panic disorder. Arch Gen Psychiatry, 41(8), 751-763.

Cherubini, E., Gaiarsa, J. L., \& Ben-Ari, Y. (1991). GABA: an excitatory transmitter in early postnatal life. Trends Neurosci, 14(12), 515-519. doi: 10.1016/01662236(91)90003-d

Chessick, C. A., Allen, M. H., Thase, M., Batista Miralha da Cunha, A. B., Kapczinski, F. F., de Lima, M. S., \& dos Santos Souza, J. J. (2006). Azapirones for generalized anxiety disorder. Cochrane Database Syst Rev(3), CD006115. doi: 10.1002/14651858.CD006115

Chu, H. Y., Ito, W., Li, J., \& Morozov, A. (2012). Target-specific suppression of GABA release from parvalbumin interneurons in the basolateral amygdala by dopamine. J Neurosci, 32(42), 14815-14820. doi: 10.1523/JNEUROSCI.2997-12.2012

Chudomel, O., Herman, H., Nair, K., Moshe, S. L., \& Galanopoulou, A. S. (2009). Ageand gender-related differences in GABAA receptor-mediated postsynaptic currents in GABAergic neurons of the substantia nigra reticulata in the rat. Neuroscience, 163(1), 155-167. doi: 10.1016/j.neuroscience.2009.06.025

Collinson, N., Kuenzi, F. M., Jarolimek, W., Maubach, K. A., Cothliff, R., Sur, C., . . . Rosahl, T. W. (2002). Enhanced Learning and Memory and Altered GABAergic Synaptic Transmission in Mice Lacking the $\alpha 5$ Subunit of the GABAAReceptor. J Neurosci., 22(13), 5572-5580.

Cope, D. W., Wulff, P., Oberto, A., Aller, M. I., Capogna, M., Ferraguti, F., . . Wisden, W. (2004). Abolition of zolpidem sensitivity in mice with a point mutation in the GABAA receptor gamma2 subunit. Neuropharmacology, 47(1), 17-34. doi: 10.1016/j.neuropharm.2004.03.007 
Crestani, F., Keist, R., Fritschy, J. M., Benke, D., Vogt, K., Prut, L., . . Rudolph, U. (2002). Trace fear conditioning involves hippocampal alpha5 GABA(A) receptors. Proc Natl Acad Sci U S A, 99(13), 8980-8985. doi: 10.1073/pnas. 142288699

Crestani, F., Low, K., Keist, R., Mandelli, M., Mohler, H., \& Rudolph, U. (2001). Molecular targets for the myorelaxant action of diazepam. Mol Pharmacol, 59(3), 442-445.

Curtis, D. R., Duggan, A. W., Felix, D., \& Johnston, G. A. (1970). GABA, Bicuculline and Central Inhibition. Nature, 226(5252), 1222-1224.

Curzon, P., Rustay, N. R., \& Browman, K. E. (2009). Cued and contextual fear conditioning for rodents. In J. J. Buccafusco (Ed.), Methods of Behavior Analysis in Neuroscience. (Second ed.). Boca Raton, FL, USA: CRC Press/Taylor \& Francis.

Davies, D. C., Martinez-Garcia, F., Lanuza, E., \& Novejarque, A. (2002). Striatoamygdaloid transition area lesions reduce the duration of tonic immobility in the lizard Podarcis hispanica. Brain Res Bull, 57(3-4), 537-541.

Davis, A. M., Penschuck, S., Fritschy, J.-M., \& McCarthy, M. M. (2000). Developmental switch in the expression of GABAA receptor subunits $\alpha 1$ and $\alpha 2$ in the hypothalamus and limbic system of the rat. Developmental Brain Research, 119(1), 127-138. doi: 10.1016/s0165-3806(99)00150-9

Davis, M. (1993). Pharmacological analysis of fear-potentiated startle. Braz J Med Biol Res., 26(3), 235-260.

Davis, M. (2000). The role of the amygdala in conditioned and unconditioned fear and anxiety. In J. P. Aggleton (Ed.), The amygdala (Second ed.). New York: Oxford University Press Inc.

Davis, M., Walker, D. L., Miles, L., \& Grillon, C. (2010). Phasic vs sustained fear in rats and humans: role of the extended amygdala in fear vs anxiety.

Neuropsychopharmacology, 35(1), 105-135. doi: 10.1038/npp.2009.109

Dawson, G. R., Maubach, K. A., Collinson, N., Cobain, M., Everitt, B. J., MacLeod, A. M., . . Atack, J. R. (2006). An inverse agonist selective for alpha5 subunitcontaining GABAA receptors enhances cognition. J Pharmacol Exp Ther, 316(3), 1335-1345. doi: 10.1124/jpet.105.092320

de Almeida, R. M., Rowlett, J. K., Cook, J. M., Yin, W., \& Miczek, K. A. (2004). GABAA/alpha1 receptor agonists and antagonists: effects on species-typical and heightened aggressive behavior after alcohol self-administration in mice.

Psychopharmacology (Berl), 172(3), 255-263. doi: 10.1007/s00213-003-1661-1

de la Mora, M. P., Gallegos-Cari, A., Arizmendi-Garcia, Y., Marcellino, D., \& Fuxe, K. (2010). Role of dopamine receptor mechanisms in the amygdaloid modulation of fear and anxiety: Structural and functional analysis. Prog Neurobiol, 90(2), 198216. doi: 10.1016/j.pneurobio.2009.10.010

Del Boca, C., Lutz, P. E., Le Merrer, J., Koebel, P., \& Kieffer, B. L. (2012). Cholecystokinin knock-down in the basolateral amygdala has anxiolytic and antidepressant-like effects in mice. Neuroscience, 218, 185-195. doi: 10.1016/j.neuroscience.2012.05.022

Dellacherie, D., Hasboun, D., Baulac, M., Belin, P., \& Samson, S. (2011). Impaired recognition of fear in voices and reduced anxiety after unilateral temporal lobe 
resection. Neuropsychologia, 49(4), 618-629. doi:

10.1016/j.neuropsychologia.2010.11.008

Dias, R., Sheppard, W. F., Fradley, R. L., Garrett, E. M., Stanley, J. L., Tye, S. J., ... Reynolds, D. S. (2005). Evidence for a significant role of alpha 3-containing GABAA receptors in mediating the anxiolytic effects of benzodiazepines. $J$ Neurosci, 25(46), 10682-10688. doi: 10.1523/JNEUROSCI.1166-05.2005

Divljakovic, J., Milic, M., Namjoshi, O. A., Tiruveedhula, V. V., Timic, T., Cook, J. M., \& Savic, M. M. (2013). betaCCT, an antagonist selective for alpha(1)GABA(A) receptors, reverses diazepam withdrawal-induced anxiety in rats. Brain Res Bull, 91, 1-7. doi: 10.1016/j.brainresbull.2012.10.011

Dixon, C. I., Morris, H. V., Breen, G., Desrivieres, S., Jugurnauth, S., Steiner, R. C., . . Stephens, D. N. (2010). Cocaine effects on mouse incentive-learning and human addiction are linked to alpha2 subunit-containing GABAA receptors. Proc Natl Acad Sci U S A, 107(5), 2289-2294. doi: 10.1073/pnas.0910117107

Dixon, C. I., Rosahl, T. W., \& Stephens, D. N. (2008). Targeted deletion of the GABRA2 gene encoding alpha2-subunits of GABA(A) receptors facilitates performance of a conditioned emotional response, and abolishes anxiolytic effects of benzodiazepines and barbiturates. Pharmacol Biochem Behav, 90(1), 1-8. doi: 10.1016/j.pbb.2008.01.015

Dong, H. W., Petrovich, G. D., \& Swanson, L. W. (2001). Topography of projections from amygdala to bed nuclei of the stria terminalis. Brain Res Brain Res Rev, 38(1-2), 192-246.

Dulawa, S. C., Holick, K. A., Gundersen, B., \& Hen, R. (2004). Effects of chronic fluoxetine in animal models of anxiety and depression. Neuropsychopharmacology, 29(7), 1321-1330. doi: 10.1038/sj.npp.1300433

Dunnett, C. W. (1955). A Multiple Comparison Procedure for Comparing Several Treatments with a Control. Journal of the American Statistical Association, 50(272), 1096. doi: 10.1080/01621459.1955.10501294

Dunnett, C. W. (1964). New Tables for Multiple Comparisons with a Control. Biometrics, 20(3), 482. doi: 10.2307/2528490

Engin, E., Bakhurin, K. I., Smith, K. S., Hines, R. M., Reynolds, L. M., Tang, W., . . . Rudolph, U. (2014). Neural basis of benzodiazepine reward: requirement for alpha2 containing GABAA receptors in the nucleus accumbens. Neuropsychopharmacology, 39(8), 1805-1815. doi: 10.1038/npp.2014.41

Engin, E., Liu, J., \& Rudolph, U. (2012). alpha2-containing GABA(A) receptors: a target for the development of novel treatment strategies for CNS disorders. Pharmacol Ther, 136(2), 142-152. doi: 10.1016/j.pharmthera.2012.08.006

Engin, E., \& Treit, D. (2007a). The anxiolytic-like effects of allopregnanolone vary as a function of intracerebral microinfusion site: the amygdala, medial prefrontal cortex, or hippocampus. Behav Pharmacol., 18(5-6), 461-470.

Engin, E., \& Treit, D. (2007b). The role of hippocampus in anxiety: intracerebral infusion studies. Behav Pharmacol, 18(5-6), 365-374. doi: 10.1097/FBP.0b013e3282de7929

Enna, S. J. (2011). A legacy of discovery: from monoamines to GABA. Neuropharmacology, 60(7-8), 1050-1057. doi: 10.1016/j.neuropharm.2010.10.005 
Esterlis, I., McKee, S. A., Kirk, K., Lee, D., Bois, F., Stiklus, S. M., . . Cosgrove, K. P. (2013). Sex-specific differences in GABA(A) -benzodiazepine receptor availability: relationship with sensitivity to pain and tobacco smoking craving. Addict Biol, 18(2), 370-378. doi: 10.1111/j.1369-1600.2011.00403.x

Farach, F. J., Pruitt, L. D., Jun, J. J., Jerud, A. B., Zoellner, L. A., \& Roy-Byrne, P. P. (2012). Pharmacological treatment of anxiety disorders: current treatments and future directions. J Anxiety Disord, 26(8), 833-843. doi: 10.1016/j.janxdis.2012.07.009

Farrant, M., \& Nusser, Z. (2005). Variations on an inhibitory theme: phasic and tonic activation of GABA(A) receptors. Nat Rev Neurosci, 6(3), 215-229. doi: $10.1038 / \mathrm{nrn} 1625$

Fatemi, S. H., Reutiman, T. J., Folsom, T. D., Rustan, O. G., Rooney, R. J., \& Thuras, P. D. (2014). Downregulation of GABAA receptor protein subunits alpha6, beta2, delta, epsilon, gamma2, theta, and rho2 in superior frontal cortex of subjects with autism. J Autism Dev Disord, 44(8), 1833-1845. doi: 10.1007/s10803-014-2078-x

Feighner, J. P., \& Boyer, W. F. (1989). Serotonin-1A anxiolytics: an overview. Psychopathology., 22(Suppl 1), 21-26.

Felix-Ortiz, A. C., Burgos-Robles, A., Bhagat, N. D., Leppla, C. A., \& Tye, K. M. (2015). Bidirectional modulation of anxiety-related and social behaviors by amygdala projections to the medial prefrontal cortex. Neuroscience. doi: 10.1016/j.neuroscience.2015.07.041

Felix-Ortiz, A. C., \& Tye, K. M. (2014). Amygdala inputs to the ventral hippocampus bidirectionally modulate social behavior. J Neurosci, 34(2), 586-595. doi: 10.1523/JNEUROSCI.4257-13.2014

Fendt, M., Endres, T., \& Apfelbach, R. (2003). Temporary Inactivation of the Bed Nucleus of the Stria Terminalis But Not of the Amygdala Blocks Freezing Induced by Trimethylthiazoline, a Component of Fox Feces. J Neurosci., 23(1), 23-28.

Fendt, M., Siegl, S., \& Steiniger-Brach, B. (2005). Noradrenaline transmission within the ventral bed nucleus of the stria terminalis is critical for fear behavior induced by trimethylthiazoline, a component of fox odor. J Neurosci, 25(25), 5998-6004. doi: 10.1523/JNEUROSCI.1028-05.2005

File, S. E. (1980). The use of social interaction as a method for detecting anxiolytic activity of chlordiazepoxide-like drugs. J Neurosci Methods., 2(3), 219-238.

File, S. E. (2000). The amygdala: anxiety and benzodiazepines. In J. P. Aggleton (Ed.), The amygdala (pp. 195-207). New York: Oxford University Press.

File, S. E., Gonzalez, L. E., \& Andrews, N. (1998). Endogenous acetylcholine in the dorsal hippocampus reduces anxiety through actions on nicotinic and muscarinic1 receptors. Behav Neurosci., 112(2), 352-359.

File, S. E., \& Hyde, J. R. (1979). A test of anxiety that distinguishes between the actions of benzodiazepines and those of other minor tranquilisers and of stimulants. Pharmacol Biochem Behav., 11(1), 65-69.

Filgueiras, G. B., Carvalho-Netto, E. F., \& Estanislau, C. (2014). Aversion in the elevated plus-maze: role of visual and tactile cues. Behav Processes, 107, 106-111. doi: 10.1016/j.beproc.2014.08.005 
Fischer, B. D., Atack, J. R., Platt, D. M., Reynolds, D. S., Dawson, G. R., \& Rowlett, J. K. (2011). Contribution of GABA(A) receptors containing alpha3 subunits to the therapeutic-related and side effects of benzodiazepine-type drugs in monkeys. Psychopharmacology (Berl), 215(2), 311-319. doi: 10.1007/s00213-010-2142-y

Fitzgerald, A. C., Wright, B. T., \& Heldt, S. A. (2014). The behavioral pharmacology of zolpidem: evidence for the functional significance of alpha1-containing GABA(A) receptors. Psychopharmacology (Berl), 231(9), 1865-1896. doi: 10.1007/s00213-014-3457-x

Fournier, N. M., \& Duman, R. S. (2013). Illuminating hippocampal control of fear memory and anxiety. Neuron, 77(5), 803-806. doi: 10.1016/j.neuron.2013.02.017

Fritschy, J. M., Johnson, D. K., Mohler, H., \& Rudolph, U. (1998). Independent assembly and subcellular targeting of GABA(A)-receptor subtypes demonstrated in mouse hippocampal and olfactory neurons in vivo. Neurosci Lett, 249(2-3), 99-102.

Fritschy, J. M., \& Mohler, H. (1995). GABAA-receptor heterogeneity in the adult rat brain: differential regional and cellular distribution of seven major subunits. $J$ Comp Neurol, 359(1), 154-194. doi: 10.1002/cne.903590111

Fuchs, E., \& Fliugge, G. (2006). Experimental animal models for the simulation of depression and anxiety. Dialogues Clin Neurosci, 8(3), 323-333.

Gafford, G. M., Guo, J. D., Flandreau, E. I., Hazra, R., Rainnie, D. G., \& Ressler, K. J. (2012). Cell-type specific deletion of GABA(A)alpha1 in corticotropin-releasing factor-containing neurons enhances anxiety and disrupts fear extinction. Proc Natl Acad Sci U S A, 109(40), 16330-16335. doi: 10.1073/pnas.1119261109

Gao, J., Wang, H., Liu, Y., Li, Y. Y., Chen, C., Liu, L. M., . . Yang, C. (2014). Glutamate and GABA imbalance promotes neuronal apoptosis in hippocampus after stress. Med Sci Monit, 20, 499-512. doi: 10.12659/MSM.890589

Goosens, K. A., \& Maren, S. (2001). Contextual and auditory fear conditioning are mediated by the lateral, basal, and central amygdaloid nuclei in rats. Learn Mem, 8(3), 148-155. doi: 10.1101/1m.37601

Graeff, F. G. (2007). [Anxiety, panic and the hypothalamic-pituitary-adrenal axis]. Rev Bras Psiquiatr, 29 Suppl 1, S3-6.

Graeff, F. G., Silveira, M. C., Nogueira, R. L., Audi, E. A., \& Oliveira, R. M. (1993). Role of the amygdala and periaqueductal gray in anxiety and panic. Behav Brain Res, 58(1-2), 123-131.

Graham, B. M., \& Milad, M. R. (2011). The study of fear extinction: implications for anxiety disorders. Am J Psychiatry, 168(12), 1255-1265. doi: 10.1176/appi.ajp.2011.11040557

Greba, Q., Gifkins, A., \& Kokkinidis, L. (2001). Inhibition of amygdaloid dopamine D2 receptors impairs emotional learning measured with fear-potentiated startle. Brain Res, 899(1-2), 218-226.

Green, S., \& Vale, A. L. (1992). Role of amygdaloid nuclei in the anxiolytic effects of benzodiazepines in rats. Behav Pharmacol, 3(3), 261-264.

Griebel, G., Sanger, D. J., \& Perrault, G. (1996). The use of the rat elevated plus-maze to discriminate between non-selective and BZ-1 (omega 1) selective, benzodiazepine receptor ligands. Psychopharmacology (Berl). 124(3), 245-254.

Grillon, C., Levenson, J., \& Pine, D. S. (2007). A single dose of the selective serotonin reuptake inhibitor citalopram exacerbates anxiety in humans: a fear-potentiated 
startle study. Neuropsychopharmacology, 32(1), 225-231. doi:

10.1038/sj.npp.1301204

Groen, M. R., Paulsen, O., Perez-Garci, E., Nevian, T., Wortel, J., Dekker, M. P., . . Meredith, R. M. (2014). Development of dendritic tonic GABAergic inhibition regulates excitability and plasticity in CA1 pyramidal neurons. $J$ Neurophysiol, 112(2), 287-299. doi: 10.1152/jn.00066.2014

Grupe, D. W., \& Nitschke, J. B. (2013). Uncertainty and anticipation in anxiety: an integrated neurobiological and psychological perspective. Nat Rev Neurosci, 14(7), 488-501. doi: 10.1038/nrn3524

Guarraci, F. A., Frohardt, R. J., Falls, W. A., \& Kapp, B. S. (2000). The effects of intraamygdaloid infusions of a D2 dopamine receptor antagonist on Pavlovian fear conditioning. Behav Neurosci., 114(3), 647-651.

Guarraci, F. A., Frohardt, R. J., \& Kapp, B. S. (1999). Amygdaloid D1 dopamine receptor involvement in Pavlovian fear conditioning. Brain Res, 827(1-2), 28-40.

Gulinello, M., Gong, Q. H., Li, X., \& Smith, S. S. (2001). Short-term exposure to a neuroactive steroid increases $\alpha 4$ GABAA receptor subunit levels in association with increased anxiety in the female rat. Brain Res., 910(1-2), 55-66.

Gulinello, M., Orman, R., \& Smith, S. S. (2003). Sex differences in anxiety, sensorimotor gating and expression of the $\alpha 4$ subunit of the GABAA receptor in the amygdala after progesterone withdrawal. Eur J Neurosci., 17(3), 641-648.

Hamann, M., Rossi, D. J., \& Attwell, D. (2002). Tonic and spillover inhibition of granule cells control information flow through cerebellar cortex. Neuron., 33(4), 625-633.

Haufler, D., Nagy, F. Z., \& Pare, D. (2013). Neuronal correlates of fear conditioning in the bed nucleus of the stria terminalis. Learn Mem, 20(11), 633-641. doi: 10.1101/lm.031799.113

Heldt, S. A., Elberger, A. J., Deng, Y., Guley, N. H., Del Mar, N., Rogers, J., . . Reiner, A. (2014). A novel closed-head model of mild traumatic brain injury caused by primary overpressure blast to the cranium produces sustained emotional deficits in mice. Front Neurol, 5, 2. doi: 10.3389/fneur.2014.00002

Heldt, S. A., \& Ressler, K. J. (2006). Localized injections of midazolam into the amygdala and hippocampus induce differential changes in anxiolytic-like motor activity in mice. Behav Pharmacol, 17(4), 349-356. doi: 10.1097/01.fbp.0000224386.86615.e0

Heldt, S. A., \& Ressler, K. J. (2010). Amygdala-specific reduction of alpha1-GABAA receptors disrupts the anticonvulsant, locomotor, and sedative, but not anxiolytic, effects of benzodiazepines in mice. J Neurosci, 30(21), 7139-7151. doi: 10.1523/JNEUROSCI.0693-10.2010

Hernandez, C. C., Gurba, K. N., Hu, N., \& Macdonald, R. L. (2011). The GABRA6 mutation, R46W, associated with childhood absence epilepsy, alters 6beta22 and 6beta2 GABA(A) receptor channel gating and expression. J Physiol, 589(Pt 23), 5857-5878. doi: 10.1113/jphysiol.2011.218883

Hirose, S. (2014). Mutant GABA(A) receptor subunits in genetic (idiopathic) epilepsy. Prog Brain Res, 213, 55-85. doi: 10.1016/B978-0-444-63326-2.00003-X

Hodges, H., Green, S., \& Glenn, B. (1987). Evidence that the amygdala is involved in benzodiazepine and serotonergic effects on punished responding but not on discrimination. Psychopharmacology (Berl). 92(4), 491-504. 
Hoehn-Saric, R. (1982). Neurotransmitters in anxiety. Arch Gen Psychiatry., 39(6), 735742.

Hoffman, W. E., Balyasnikova, I. V., Mahay, H., Danilov, S. M., \& Baughman, V. L. (2002). GABA $\alpha 6$ receptors mediate midazolam-induced anxiolysis. Journal of Clinical Anesthesia, 14(3), 206-209. doi: 10.1016/s0952-8180(02)00343-4

Hopkins, S. C., Brian Nofsinger, J., Allen, M. S., Koch, P., \& Varney, M. A. (2009). In vivo saturation binding of GABA-A receptor ligands to estimate receptor occupancy using liquid chromatography/tandem mass spectrometry. Biopharm Drug Dispos, 30(1), 9-20. doi: 10.1002/bdd.641

Huang, G. B., Zhao, T., Gao, X. L., Zhang, H. X., Xu, Y. M., Li, H., \& Lv, L. X. (2015). Effect of chronic social defeat stress on behaviors and dopamine receptor in adult mice. Prog Neuropsychopharmacol Biol Psychiatry, 66, 73-79. doi: 10.1016/j.pnpbp.2015.12.002

Janak, P. H., \& Tye, K. M. (2015). From circuits to behaviour in the amygdala. Nature., 517(7534), 284-292.

Jennings, J. H., Sparta, D. R., Stamatakis, A. M., Ung, R. L., Pleil, K. E., Kash, T. L., \& Stuber, G. D. (2013). Distinct extended amygdala circuits for divergent motivational states. Nature, 496(7444), 224-228. doi: 10.1038/nature12041

Johnson, P. L., Molosh, A., Fitz, S. D., Arendt, D., Deehan, G. A., Federici, L. M., . . Shekhar, A. (2015). Pharmacological depletion of serotonin in the basolateral amygdala complex reduces anxiety and disrupts fear conditioning. Pharmacol Biochem Behav, 138, 174-179. doi: 10.1016/j.pbb.2015.09.021

Kalat, J. W. (2007). Biological Psychology (Ninth Edition ed.). Belmont, CA: Thomson Wadsworth.

Kalin, N. H., Shelton, S. E., \& Davidson, R. J. (2004). The role of the central nucleus of the amygdala in mediating fear and anxiety in the primate. J Neurosci, 24(24), 5506-5515. doi: 10.1523/JNEUROSCI.0292-04.2004

Katzman, M. A., Bleau, P., Blier, P., Chokka, P., Kjernisted, K., Van Ameringen, M., . . . Walker, J. R. (2014). Canadian clinical practice guidelines for the management of anxiety, posttraumatic stress and obsessive-compulsive disorders. BMC

Psychiatry, 14 Suppl 1, S1. doi: 10.1186/1471-244X-14-S1-S1

Kavaliers, M., Wiebe, J. P., \& Galea, L. A. (1994). Reduction of predator odor-induced anxiety in mice by the neurosteroid 3 alpha-hydroxy-4-pregnen-20-one (3 alpha HP). Brain Res, 645(1-2), 325-329.

Kazama, A. M., Heuer, E., Davis, M., \& Bachevalier, J. (2012). Effects of neonatal amygdala lesions on fear learning, conditioned inhibition, and extinction in adult macaques. Behav Neurosci, 126(3), 392-403. doi: 10.1037/a0028241

Kedia, S., \& Chattarji, S. (2014). Marble burying as a test of the delayed anxiogenic effects of acute immobilisation stress in mice. J Neurosci Methods, 233, 150-154. doi: 10.1016/j.jneumeth.2014.06.012

Kessler, R. C., Berglund, P., Demler, O., Jin, R., Merikangas, K. R., \& Walters, E. E. (2005). Lifetime prevalence and age-of-onset distributions of DSM-IV disorders in the National Comorbidity Survey Replication. Arch Gen Psychiatry, 62(6), 593-602. doi: 10.1001/archpsyc.62.6.593

Kessler, R. C., \& Greenberg, P. E. (2002). The economic burden of anxiety and stress disorders. In K. L. Davis, D. Charney, J. T. Coyle \& C. Nemeroff (Eds.), 
Neuropsychopharmacology - 5th generation of progress (pp. 981-992).

Philadelphia, Pennsylvania, USA: Lippincott, Williams, \& Wilkins.

Kheirbek, M. A., Drew, L. J., Burghardt, N. S., Costantini, D. O., Tannenholz, L., Ahmari, S. E., ... Hen, R. (2013). Differential control of learning and anxiety along the dorsoventral axis of the dentate gyrus. Neuron, 77(5), 955-968. doi: 10.1016/j.neuron.2012.12.038

Killcross, S., Robbins, T. W., \& Everitt, B. J. (1997). Different types of fear-conditioned behaviour mediated by separate nuclei within amygdala. Nature., 388(6640), $377-$ 380.

Kim, S. Y., Adhikari, A., Lee, S. Y., Marshel, J. H., Kim, C. K., Mallory, C. S., . . Deisseroth, K. (2013). Diverging neural pathways assemble a behavioural state from separable features in anxiety. Nature, 496(7444), 219-223. doi: 10.1038 /nature 12018

Klumpers, F., Morgan, B., Terburg, D., Stein, D. J., \& van Honk, J. (2015). Impaired acquisition of classically conditioned fear-potentiated startle reflexes in humans with focal bilateral basolateral amygdala damage. Soc Cogn Affect Neurosci, 10(9), 1161-1168. doi: 10.1093/scan/nsu164

Kopp, C., Rudolph, U., Keist, R., \& Tobler, I. (2003). Diazepam-induced changes on sleep and the EEG spectrum in mice: role of the alpha3-GABAA receptor subtype. European Journal of Neuroscience, 17(10), 2226-2230. doi: 10.1046/j.1460-9568.2003.02651.x

Lamont, E. W., \& Kokkinidis, L. (1998). Infusion of the dopamine D1 receptor antagonist SCH 23390 into the amygdala blocks fear expression in a potentiated startle paradigm. Brain Res., 795(1-2), 128-136.

LeDoux, J. E. (2000). The amygdala and emotion: a view through fear. In J. P. Aggleton (Ed.), The amygdala (pp. 290-302). New York: Oxford University Press.

Lee, S., Kim, S. J., Kwon, O. B., Lee, J. H., \& Kim, J. H. (2013). Inhibitory networks of the amygdala for emotional memory. Front Neural Circuits, 7, 129. doi: 10.3389/fncir.2013.00129

Lepicard, E. M., Joubert, C., Hagneau, I., Perez-Diaz, F., \& Chapouthier, G. (2000). Differences in anxiety-related behavior and response to diazepam in BALB/cByJ and C57BL/6J strains of mice. Pharmacology Biochemistry and Behavior, 67(4), 739-748. doi: 10.1016/s0091-3057(00)00419-6

Loh, E.-W., \& Ball, D. (2000). Role of the GABAA $\beta 2$, GABAA $\alpha 6$, GABAA $\alpha 1$ and GABAA $\gamma 2$ receptor subunit genes cluster in drug responses and the development of alcohol dependence. Neurochemistry International, 37(5-6), 413-423. doi: 10.1016/s0197-0186(00)00054-1

Low, K., Crestani, F., Keist, R., Benke, D., Brunig, I., Benson, J. A., . . Rudolph, U. (2000). Molecular and neuronal substrate for the selective attenuation of anxiety. Science, 290(5489), 131-134.

Markowitz, J. C., Lipsitz, J., \& Milrod, B. L. (2014). Critical review of outcome research on interpersonal psychotherapy for anxiety disorders. Depress Anxiety, 31(4), 316-325. doi: 10.1002/da.22238

Marks, I. f., \& Nesse, R. M. (1994). Fear and fitness: An evolutionary analysis of anxiety disorders. Ethology and Sociobiology, 15(5-6), 247-261. 
Marowsky, A., Rudolph, U., Fritschy, J. M., \& Arand, M. (2012). Tonic inhibition in principal cells of the amygdala: a central role for alpha3 subunit-containing GABAA receptors. $J$ Neurosci, 32(25), 8611-8619. doi: 10.1523/JNEUROSCI.4404-11.2012

Mathiasen, L. S., Mirza, N. R., \& Rodgers, R. J. (2008). Strain- and model-dependent effects of chlordiazepoxide, L-838,417 and zolpidem on anxiety-like behaviours in laboratory mice. Pharmacol Biochem Behav, 90(1), 19-36. doi:

10.1016/j.pbb.2008.01.014

Mathiasen, L. S., Rodgers, R. J., \& Mirza, N. R. (2007). Comparative effects of nonselective and subtype-selective gamma-aminobutyric acidA receptor positive modulators in the rat-conditioned emotional response test. Behav Pharmacol, 18(3), 191-203. doi: 10.1097/FBP.0b013e32814fcdd4

McEown, K., \& Treit, D. (2013). Alpha2 GABAA receptor sub-units in the ventral hippocampus and alpha5 GABAA receptor sub-units in the dorsal hippocampus mediate anxiety and fear memory. Neuroscience, 252, 169-177. doi: 10.1016/j.neuroscience.2013.08.012

McKernan, R. M., Rosahl, T. W., Reynolds, D. S., Sur, C., Wafford, K. A., Atack, J. R., . . Whiting, P. J. (2000). Sedative but not anxiolytic properties of benzodiazepines are mediated by the GABA(A) receptor alphal subtype. Nat Neurosci, 3(6), 587592. doi: $10.1038 / 75761$

McNamara, R. K., \& Skeleton, R. W. (1993). Effects of intracranial infusions of chlordiazepoxide on spatial learning in the Morris water maze. I. Neuroanatomical specificity. Behav Brain Res, 59(1-2), 175-191.

Menard, J., \& Treit, D. (1999). Effects of centrally administered anxiolytic compounds in animal models of anxiety. Neuroscience \& Biobehavioral Reviews, 23(4), 591613. doi: 10.1016/s0149-7634(98)00056-6

Milenkovic, I., Vasiljevic, M., Maurer, D., Hoger, H., Klausberger, T., \& Sieghart, W. (2013). The parvalbumin-positive interneurons in the mouse dentate gyrus express GABAA receptor subunits alpha1, beta2, and delta along their extrasynaptic cell membrane. Neuroscience, 254, 80-96. doi: 10.1016/j.neuroscience.2013.09.019

Mody, I., \& Maguire, J. (2011). The reciprocal regulation of stress hormones and GABA(A) receptors. Front Cell Neurosci, 6, 4. doi: 10.3389/fncel.2012.00004

Möhler, H., Crestani, F., \& Rudolph, U. (2001). GABAA-receptor subtypes: a new pharmacology. Current Opinion in Pharmacology, 1(1), 22-25. doi: 10.1016/s1471-4892(01)00008-x

Möller, C., Wiklund, L., Sommer, W., Thorsell, A., \& Heilig, M. (1997). Decreased experimental anxiety and voluntary ethanol consumption in rats following central but not basolateral amygdala lesions. Brain Res., 760(1-2), 94-101.

Moreira, C. M., Masson, S., Carvalho, M. C., \& Brandão, M. L. (2007). Exploratory behaviour of rats in the elevated plus-maze is differentially sensitive to inactivation of the basolateral and central amygdaloid nuclei. Brain Res Bull., 71(5), 466-474.

Morris, H. V., Dawson, G. R., Reynolds, D. S., Atack, J. R., \& Stephens, D. N. (2006). Both alpha2 and alpha3 GABAA receptor subtypes mediate the anxiolytic properties of benzodiazepine site ligands in the conditioned emotional response 
paradigm. Eur J Neurosci, 23(9), 2495-2504. doi: 10.1111/j.1460-

9568.2006.04775.x

Nagaya, N., Acca, G. M., \& Maren, S. (2015). Allopregnanolone in the bed nucleus of the stria terminalis modulates contextual fear in rats. Front Behav Neurosci, 9, 205. doi: 10.3389/fnbeh.2015.00205

Navarro, J. F., Burón, E., \& Martín-López, M. (2002). Anxiogenic-like activity of L655,708 , a selective ligand for the benzodiazepine site of GABAA receptors which contain the alpha-5 subunit, in the elevated plus-maze test. Progress in Neuro-Psychopharmacology and Biological Psychiatry, 26(7-8), 1389-1392. doi: 10.1016/s0278-5846(02)00305-6

Nett, S. T., Jorge-Rivera, J. C., Myers, M., Clark, A. S., \& Henderson, L. P. (1999). Properties and sex-specific differences of GABAA receptors in neurons expressing gammal subunit mRNA in the preoptic area of the rat. J Neurophysiol, 81(1), 192-203.

Newman, E. L., Smith, K. S., Takahashi, A., Chu, A., Hwa, L. S., Chen, Y., . . Miczek, K. A. (2015). alpha2-containing GABA(A) receptors: a requirement for midazolam-escalated aggression and social approach in mice. Psychopharmacology (Berl), 232(23), 4359-4369. doi: 10.1007/s00213-0154069-9

Njung'e, K., \& Handley, S. L. (1991). Evaluation of marble-burying behavior as a model of anxiety. Pharmacol Biochem Behav., 38(1), 63-67.

Ohman, A., \& Mineka, S. (2001). Fears, phobias, and preparedness: toward an evolved module of fear and fear learning. Psychol Rev, 108(3), 483-522.

Olsen, R. W. (2015). Allosteric ligands and their binding sites define gammaaminobutyric acid (GABA) type A receptor subtypes. Adv Pharmacol, 73, 167202. doi: 10.1016/bs.apha.2014.11.005

Olsen, R. W., \& Sieghart, W. (2009). GABA A receptors: subtypes provide diversity of function and pharmacology. Neuropharmacology, 56(1), 141-148. doi: 10.1016/j.neuropharm.2008.07.045

Pape, H. C. (2005). GABAergic neurons: gate masters of the amygdala, mastered by dopamine. Neuron, 48(6), 877-879. doi: 10.1016/j.neuron.2005.12.002

Paxinos, G., \& Franklin, K. (2001). The Mouse Brain in Stereotaxic Coordinates (second edition ed.). San Diego, CA: Academic Press.

Pellow, S., \& File, S. E. (1986). Anxiolytic and anxiogenic drug effects on exploratory activity in an elevated plus-maze: a novel test of anxiety in the rat. Pharmacol Biochem Behav, 24(3), 525-529.

Penzo, M. A., Robert, V., Tucciarone, J., De Bundel, D., Wang, M., Van Aelst, L., . . Li, B. (2015). The paraventricular thalamus controls a central amygdala fear circuit. Nature, 519(7544), 455-459. doi: 10.1038/nature13978

Perez de la Mora, M., Gallegos-Cari, A., Crespo-Ramirez, M., Marcellino, D., Hansson, A. C., \& Fuxe, K. (2012). Distribution of dopamine D(2)-like receptors in the rat amygdala and their role in the modulation of unconditioned fear and anxiety. Neuroscience, 201, 252-266. doi: 10.1016/j.neuroscience.2011.10.045

Perusini, J., \& Fanselow, M. (2015). Neurobehavioral perspectives on the distinction between fear and anxiety. Learn. Mem., 22(9), 417-425. doi:

10.1101/lm.039180.115 
Pesold, C., \& Treit, D. (1995). The central and basolateral amygdala differentially mediate the anxiolytic effects of benzodiazepines. Brain Res, 671(2), 213-221.

Petroski, R. E., Pomeroy, J. E., Das, R., Bowman, H., Yang, W., Chen, A. P., \& Foster, A. C. (2006). Indiplon is a high-affinity positive allosteric modulator with selectivity for alpha1 subunit-containing GABAA receptors. J Pharmacol Exp Ther, 317(1), 369-377. doi: 10.1124/jpet.105.096701

Pettersson, R., Naslund, J., Nilsson, S., Eriksson, E., \& Hagsater, S. M. (2015). Acute escitalopram but not contextual conditioning exerts a stronger "anxiogenic" effect in rats with high baseline "anxiety" in the acoustic startle paradigm.

Psychopharmacology (Berl), 232(8), 1461-1469. doi: 10.1007/s00213-014-3783-z

Pirker, S., Schwarzer, C., Wieselthaler, A., Sieghart, W., \& Sperk, G. (2000). GABAA receptors: immunocytochemical distribution of 13 subunits in the adult rat brain. Neuroscience, 101(4), 815-850. doi: 10.1016/s0306-4522(00)00442-5

Prager, E. M., Bergstrom, H. C., Wynn, G. H., \& Braga, M. F. (2015). The basolateral amygdala gamma-aminobutyric acidergic system in health and disease. $J$ Neurosci Res. doi: 10.1002/jnr.23690

Preibisch, S., Saalfeld, S., \& Tomancak, P. (2009). Globally optimal stitching of tiled 3D microscopic image acquisitions. Bioinformatics, 25(11), 1463-1465. doi: 10.1093/bioinformatics/btp 184

Price, J. S. (2003). Evolutionary aspects of anxiety disorders. Dialogues Clin Neurosci, 5(3), 223-236.

Reinhold, J. A., \& Rickels, K. (2015). Pharmacological treatment for generalized anxiety disorder in adults: an update. Expert Opin Pharmacother, 16(11), 1669-1681. doi: 10.1517/14656566.2015.1059424

Reynolds, D. S., McKernan, R. M., \& Dawson, G. R. (2001). Anxiolytic-like action of diazepam: which GABAA receptor subtype is involved? Trends in Pharmacological Sciences, 22(8), 402. doi: 10.1016/s0165-6147(00)01773-9

Roberts, E. (1974). $\gamma$-aminobutyric acid and nervous system function-A perspective. Biochemical Pharmacology, 23(19), 2637-2649. doi: 10.1016/00062952(74)90033-1

Roberts, E., \& Frankel, S. (1950). gamma-Aminobutyric acid in brain: its formation from glutamic acid. J Biol Chem., 187(1), 55-63.

Romeo, R. D., Mueller, A., Sisti, H. M., Ogawa, S., McEwen, B. S., \& Brake, W. G. (2003). Anxiety and fear behaviors in adult male and female C57BL/6 mice are modulated by maternal separation. Hormones and Behavior, 43(5), 561-567. doi: 10.1016/s0018-506x(03)00063-1

Rowlett, J. K., \& Lelas, S. (2007). Comparison of zolpidem and midazolam selfadministration under progressive-ratio schedules: consumer demand and labor supply analyses. Exp Clin Psychopharmacol, 15(4), 328-337. doi: 10.1037/10641297.15.4.328

Rudolph, U., Crestani, F., Benke, D., Brunig, I., Benson, J. A., Fritschy, J. M., . . . Mohler, H. (1999). Benzodiazepine actions mediated by specific gammaaminobutyric acid(A) receptor subtypes. Nature, 401(6755), 796-800. doi: $10.1038 / 44579$ 
Rudolph, U., \& Knoflach, F. (2011). Beyond classical benzodiazepines: novel therapeutic potential of GABAA receptor subtypes. Nat Rev Drug Discov, 10(9), 685-697. doi: $10.1038 / \mathrm{nrd} 3502$

Rudolph, U., \& Mohler, H. (2004). Analysis of GABAA receptor function and dissection of the pharmacology of benzodiazepines and general anesthetics through mouse genetics. Annu Rev Pharmacol Toxicol, 44, 475-498. doi: 10.1146/annurev.pharmtox.44.101802.121429

Sah, P., Faber, E. S., Lopez De Armentia, M., \& Power, J. (2003). The amygdaloid complex: anatomy and physiology. Physiol Rev, 83(3), 803-834. doi: 10.1152/physrev.00002.2003

Sajdyk, T. J., Vandergriff, M. G., \& Gehlert, D. R. (1999). Amygdalar neuropeptide Y Y1 receptors mediate the anxiolytic-like actions of neuropeptide $\mathrm{Y}$ in the social interaction test. Eur J Pharmacol, 368(2-3), 143-147.

Sakanaka, M., Shibasaki, T., \& Lederis, K. (1986). Distribution and efferent projections of corticotropin-releasing factor-like immunoreactivity in the rat amygdaloid complex. Brain Res, 382(2), 213-238.

Sanders, S. K., \& Shekhar, A. (1995). Regulation of anxiety by GABAA receptors in the rat amygdala. Pharmacol Biochem Behav, 52(4), 701-706.

Savic, M. M., Obradovic, D. I., Ugresic, N. D., Cook, J. M., Yin, W., \& Bokonjic, D. R. (2004). Bidirectional effects of benzodiazepine binding site ligands in the elevated plus-maze: differential antagonism by flumazenil and beta-CCt. Pharmacol Biochem Behav, 79(2), 279-290. doi: 10.1016/j.pbb.2004.07.013

Schindelin, J., Arganda-Carreras, I., Frise, E., Kaynig, V., Longair, M., Pietzsch, T., . . . Cardona, A. (2012). Fiji: an open-source platform for biological-image analysis. Nat Methods, 9(7), 676-682. doi: 10.1038/nmeth.2019

Schneider, C. A., Rasband, W. S., \& Eliceiri, K. W. (2012). NIH Image to ImageJ: 25 years of image analysis. Nat Methods, 9(7), 671-675.

Scott-Stevens, P., Atack, J. R., Sohal, B., \& Worboys, P. (2005). Rodent pharmacokinetics and receptor occupancy of the GABAA receptor subtype selective benzodiazepine site ligand L-838417. Biopharm Drug Dispos, 26(1), 13 20. doi: 10.1002/bdd.423

Shen, H., Gong, Q. H., Aoki, C., Yuan, M., Ruderman, Y., Dattilo, M., . . Smith, S. S. (2007). Reversal of neurosteroid effects at alpha4beta2delta GABAA receptors triggers anxiety at puberty. Nat Neurosci, 10(4), 469-477. doi: 10.1038/nn1868

Shen, H., Mohammad, A., Ramroop, J., \& Smith, S. S. (2013). A stress steroid triggers anxiety via increased expression of alpha4betadelta GABAA receptors in methamphetamine dependence. Neuroscience, 254, 452-475. doi: 10.1016/j.neuroscience.2013.08.033

Sigel, E. (2002). Mapping of the Benzodiazepine Recognition Site on GABA-A Receptors. Current Topics in Medicinal Chemistry, 2(8), 833-839. doi: $10.2174 / 1568026023393444$

Sigel, E., \& Steinmann, M. E. (2012). Structure, function, and modulation of GABA(A) receptors. J Biol Chem, 287(48), 40224-40231. doi: 10.1074/jbc.R112.386664

Smith, K. S., Engin, E., Meloni, E. G., \& Rudolph, U. (2012). Benzodiazepine-induced anxiolysis and reduction of conditioned fear are mediated by distinct GABAA 
receptor subtypes in mice. Neuropharmacology, 63(2), 250-258. doi:

10.1016/j.neuropharm.2012.03.001

Smith, S. S. (2013). The influence of stress at puberty on mood and learning: role of the alpha4betadelta GABAA receptor. Neuroscience, 249, 192-213. doi:

10.1016/j.neuroscience.2012.09.065

Smith, S. S., Gong, Q. H., Hsu, F. C., Markowitz, R. S., ffrench-Mullen, J. M., \& Li, X. (1998). GABA(A) receptor alpha4 subunit suppression prevents withdrawal properties of an endogenous steroid. Nature, 392(6679), 926-930. doi: $10.1038 / 31948$

Smith, S. S., Shen, H., Gong, Q. H., \& Zhou, X. (2007). Neurosteroid regulation of GABA(A) receptors: Focus on the alpha4 and delta subunits. Pharmacol Ther, 116(1), 58-76. doi: 10.1016/j.pharmthera.2007.03.008

Smith, T. A. (2001). Type A gamma-aminobutyric acid (GABAA) receptor subunits and benzodiazepine binding: significance to clinical syndromes and their treatment. $\mathrm{Br}$ J Biomed Sci., 58(2), 111-121.

Spampanato, J., Polepalli, J., \& Sah, P. (2011 ). Interneurons in the basolateral amygdala. Neuropharmacology., 60(5), 765-773.

Spampanato, J., Sullivan, R. K., Perumal, M. B., \& Sah, P. (2016). Development and physiology of GABAergic feedback excitation in parvalbumin expressing interneurons of the mouse basolateral amygdala. Physiol Rep, 4(1). doi: 10.14814/phy2.12664

Spencer, S. J., Buller, K. M., \& Day, T. A. (2005). Medial prefrontal cortex control of the paraventricular hypothalamic nucleus response to psychological stress: possible role of the bed nucleus of the stria terminalis. J Comp Neurol, 481(4), 363-376. doi: 10.1002/cne.20376

Stackman, R. W., \& Walsh, T. J. (1995). Anatomical specificity and time-dependence of chlordiazepoxide-induced spatial memory impairments. Behav Neurosci, 109(3), 436-445.

Stevens, J. C., \& Pollack, M. H. (2005). Benzodiazepines in clinical practice: consideration of their long-term use and alternative agents. J Clin Psychiatry., 66 Suppl 2, 21-27.

Suinn, R. M. (1969). The relationship between fears and anxiety: a further study. Behav Res Ther., 7(3), 317-318.

Sullivan, G. M., Apergis, J., Bush, D. E., Johnson, L. R., Hou, M., \& Ledoux, J. E. (2004). Lesions in the bed nucleus of the stria terminalis disrupt corticosterone and freezing responses elicited by a contextual but not by a specific cueconditioned fear stimulus. Neuroscience, 128(1), 7-14. doi: 10.1016/j.neuroscience.2004.06.015

Sur, C., Farrar, S. J., Kerby, J., Whiting, P. J., Atack, J. R., \& McKernan, R. M. (1999). Preferential coassembly of alpha4 and delta subunits of the gamma-aminobutyric acidA receptor in rat thalamus. Mol Pharmacol, 56(1), 110-115.

Swanson, L. W., \& Petrovich, G. D. (1998). What is the amygdala? Trends Neurosci, 21(8), 323-331. doi: 10.1016/s0166-2236(98)01265-x

Taliani, S., Cosimelli, B., Da Settimo, F., Marini, A. M., La Motta, C., Simorini, F., .. . Martini, C. (2009). Identification of anxiolytic/nonsedative agents among indol-3ylglyoxylamides acting as functionally selective agonists at the gamma- 
aminobutyric acid-A (GABAA) alpha2 benzodiazepine receptor. $J$ Med Chem, 52(12), 3723-3734. doi: 10.1021/jm9001154

Tan, K. R., Brown, M., Labouebe, G., Yvon, C., Creton, C., Fritschy, J. M., . . . Luscher, C. (2010). Neural bases for addictive properties of benzodiazepines. Nature, 463(7282), 769-774. doi: 10.1038/nature08758

Tan, K. R., Rudolph, U., \& Luscher, C. (2011). Hooked on benzodiazepines: GABAA receptor subtypes and addiction. Trends Neurosci, 34(4), 188-197. doi: 10.1016/j.tins.2011.01.004

Toufexis, D. (2007). Region- and sex-specific modulation of anxiety behaviours in the rat. J Neuroendocrinol, 19(6), 461-473. doi: 10.1111/j.1365-2826.2007.01552.x

Tovote, P., Fadok, J. P., \& Lüthi, A. (2015). Neuronal circuits for fear and anxiety. Nat Rev Neurosci., 16(6), 317-331.

Tye, K. M., Prakash, R., Kim, S. Y., Fenno, L. E., Grosenick, L., Zarabi, H., . . . Deisseroth, K. (2011). Amygdala circuitry mediating reversible and bidirectional control of anxiety. Nature, 471(7338), 358-362. doi: 10.1038/nature09820

Urakawa, S., Takamoto, K., Hori, E., Sakai, N., Ono, T., \& Nishijo, H. (2013). Rearing in enriched environment increases parvalbumin-positive small neurons in the amygdala and decreases anxiety-like behavior of male rats. BMC Neurosci, 14, 13. doi: 10.1186/1471-2202-14-13

Ventura-Silva, A. P., Melo, A., Ferreira, A. C., Carvalho, M. M., Campos, F. L., Sousa, N., \& Pego, J. M. (2013). Excitotoxic lesions in the central nucleus of the amygdala attenuate stress-induced anxiety behavior. Front Behav Neurosci, 7, 32. doi: $10.3389 /$ fnbeh.2013.00032

Vinkers, C. H., van Oorschot, R., Korte, S. M., Olivier, B., \& Groenink, L. (2010). 5HT1A receptor blockade reverses GABA(A) receptor alpha3 subunit-mediated anxiolytic effects on stress-induced hyperthermia. Psychopharmacology (Berl), 211(2), 123-130. doi: 10.1007/s00213-010-1895-7

Violle, N., Balandras, F., Le Roux, Y., Desor, D., \& Schroeder, H. (2009). Variations in illumination, closed wall transparency and/or extramaze space influence both baseline anxiety and response to diazepam in the rat elevated plus-maze. Behav Brain Res, 203(1), 35-42. doi: 10.1016/j.bbr.2009.04.015

Viswanatha, G. L., Shylaja, H., Sandeep Rao, K. S., Santhosh Kumar, V. R., \& Jagadeesh, M. (2012). Hesperidin ameliorates immobilization-stress-induced behavioral and biochemical alterations and mitochondrial dysfunction in mice by modulating nitrergic pathway. ISRN Pharmacol, 2012, 479570. doi: $10.5402 / 2012 / 479570$

Vollenweider, I., Smith, K. S., Keist, R., \& Rudolph, U. (2011). Antidepressant-like properties of alpha2-containing GABA(A) receptors. Behav Brain Res, 217(1), 77-80. doi: 10.1016/j.bbr.2010.10.009

Waddell, J., Dunnett, C., \& Falls, W. A. (2004). C57BL/6J and DBA/2J mice differ in extinction and renewal of extinguished conditioned fear. Behav Brain Res, 154(2), 567-576. doi: 10.1016/j.bbr.2004.03.025

Wafford, K. A., Thompson, S. A., Thomas, D., Sikela, J., Wilcox, A. S., \& Whiting, P. J. (1996). Functional characterization of human gamma-aminobutyric acidA receptors containing the alpha 4 subunit. Mol Pharmacol, 50(3), 670-678. 
Walf, A. A., \& Frye, C. A. (2007). The use of the elevated plus maze as an assay of anxiety-related behavior in rodents. Nat Protoc, 2(2), 322-328. doi: 10.1038/nprot.2007.44

Walker, D. L., Toufexis, D. J., \& Davis, M. (2003). Role of the bed nucleus of the stria terminalis versus the amygdala in fear, stress, and anxiety. Eur J Pharmacol, 463(1-3), 199-216.

Wang, Y., Zhao, S., Liu, X., \& Fu, Q. (2014). Effects of the medial or basolateral amygdala upon social anxiety and social recognition in mice. Turk J Med Sci., 44(3), 353-359.

Whiting, P. J. (2003). GABA-A receptor subtypes in the brain: a paradigm for CNS drug discovery? Drug Discovery Today, 8(10), 445-450. doi: 10.1016/s13596446(03)02703-X

Wieland, H. A., Lüddens, H., \& Seeburg, P. H. (1992). A single histidine in GABAA receptors is essential for benzodiazepine agonist binding. J Biol Chem., 267(3), 1426-1429.

Willner, P. (1984). The validity of animal models of depression. Psychopharmacology (Berl). 83(1), 1-16.

Wilson, M. A., \& Junor, L. (2008). The role of amygdalar mu-opioid receptors in anxiety-related responses in two rat models. Neuropsychopharmacology, 33(12), 2957-2968. doi: 10.1038/sj.npp.1301675

Wolff, S. B., Gründemann, J., Tovote, P., Krabbe, S., Jacobson, G. A., Müller, C., . . . Lüthi, A. (2014). Amygdala interneuron subtypes control fear learning through disinhibition. Nature, 509(7501), 453-458.

Yee, B. K., Keist, R., von Boehmer, L., Studer, R., Benke, D., Hagenbuch, N., . . . Rudolph, U. (2005). A schizophrenia-related sensorimotor deficit links alpha 3containing GABAA receptors to a dopamine hyperfunction. Proc Natl Acad Sci U $S$ A, 102(47), 17154-17159. doi: 10.1073/pnas.0508752102

Zanin, K. A., Patti, C. L., Sanday, L., Fernandes-Santos, L., Oliveira, L. C., Poyares, D., . .. Frussa-Filho, R. (2013). Effects of zolpidem on sedation, anxiety, and memory in the plus-maze discriminative avoidance task. Psychopharmacology (Berl), 226(3), 459-474. doi: 10.1007/s00213-012-2756-3

Zanoveli, J. M., Carvalho, M. C., Cunha, J. M., \& Brandao, M. L. (2009). Extracellular serotonin level in the basolateral nucleus of the amygdala and dorsal periaqueductal gray under unconditioned and conditioned fear states: an in vivo microdialysis study. Brain Res, 1294, 106-115. doi:

10.1016/j.brainres.2009.07.074

Zethof, T. J., Van der Heyden, J. A., Tolboom, J. T., \& Olivier, B. (1995). Stress-induced hyperthermia as a putative anxiety model. Eur J Pharmacol., 294(1), 125-135.

Zurek, A. A., Bridgwater, E. M., \& Orser, B. A. (2012). Inhibition of alpha5 gammaAminobutyric acid type A receptors restores recognition memory after general anesthesia. Anesth Analg, 114(4), 845-855. doi: 10.1213/ANE.0b013e31824720da 


\section{VITA}

Yudong Gao, born in 1987, received his Bachelor's degree in Biomedical Engineering from the Zhejiang University in 2009. Upon approval of this Dissertation, he will receive his Doctor of Philosophy degree in Biomedical Sciences from the University of Tennessee Health Science Center in 2016.

\section{List of Publications}

Gao, Y., \& Heldt, S. A. (2016). Enrichment of GABAA receptor $\alpha$-subunits on the axonal initial segment shows regional differences. Front. Cell. Neurosci. 10:39. doi:

10.3389/fncel.2016.00039

Gao, Y., \& Heldt, S. A. (2015). Lack of neuronal nitric oxide synthase results in attention deficit hyperactivity disorder-like behaviors in mice. Behavioral Neuroscience, 129(1):50-61. doi: 10.1037/bne0000031.

Wang, M., Li, Z. \& Gao, Y. (2008). Electrochemical analysis of pesticides by nano zirconia modified film electrode. Sensor Letters, 6(6), 966-969. doi: 10.1166/s1.2008.541

\section{Selected Conference Presentations}

Gao, Y., \& Heldt, S. A. (2015). Differential contribution of amygdala GABAA receptors in benzodiazepine-induced anxiolysis. Program No. 635.22. 2015 Neuroscience Meeting Planner. Chicago, IL: Society for Neuroscience, 2015.

Gao, Y., \& Heldt, S. A. (2014). Selective agonism of $\alpha 3$, but not $\alpha 1$ subunit-containing GABAA receptors in the amygdala induces anxiolytic-like effects as measured by elevated plus maze in mice. 2014 International Behavioral Neuroscience Society (IBNS) Annual Meeting, Las Vegas, USA. 